University of Louisville

ThinkIR: The University of Louisville's Institutional Repository

\title{
The regulatory function of social referencing in preschoolers with Down syndrome or Williams syndrome.
}

Angela E. John

University of Louisville

Follow this and additional works at: https://ir.library.louisville.edu/etd

\section{Recommended Citation}

John, Angela E., "The regulatory function of social referencing in preschoolers with Down syndrome or Williams syndrome." (2011). Electronic Theses and Dissertations. Paper 694.

https://doi.org/10.18297/etd/694

This Doctoral Dissertation is brought to you for free and open access by ThinkIR: The University of Louisville's Institutional Repository. It has been accepted for inclusion in Electronic Theses and Dissertations by an authorized administrator of ThinkIR: The University of Louisville's Institutional Repository. This title appears here courtesy of the author, who has retained all other copyrights. For more information, please contact thinkir@louisville.edu. 
THE REGULATORY FUNCTION OF SOCIAL REFERENCING IN

PRESCHOOLERS WITH DOWN SYNDROME OR WILLIAMS SYNDROME

\author{
By
}

\author{
Angela E. John \\ B.A., University of Colorado at Denver, 2003 \\ M.A., University of Louisville, 2006

\begin{abstract}
A Dissertation
Submitted to the Faculty of the

Graduate School of the University of Louisville

In Partial Fulfillment of the Requirements

For the Degree of
\end{abstract}

\author{
Doctor of Philosophy \\ Department of Psychological and Brain Sciences \\ University of Louisville \\ Louisville, KY
}

May 2011 
Copyright 2011 by Angela E. John

All rights reserved 



\title{
THE REGULATORY FUNCTION OF SOCIAL REFERENCING IN
}

\section{PRESCHOOLERS WITH DOWN SYNDROME OR WILLIAMS SYNDROME}

\author{
By \\ Angela E. John \\ B.A., University of Colorado at Denver, 2003 \\ M.A., University of Louisville, 2006 \\ A Dissertation Approved on
}

May 2011

by the following Dissertation Committee:

Carolyn B. Mervis, Ph.D.

Dissertation Director

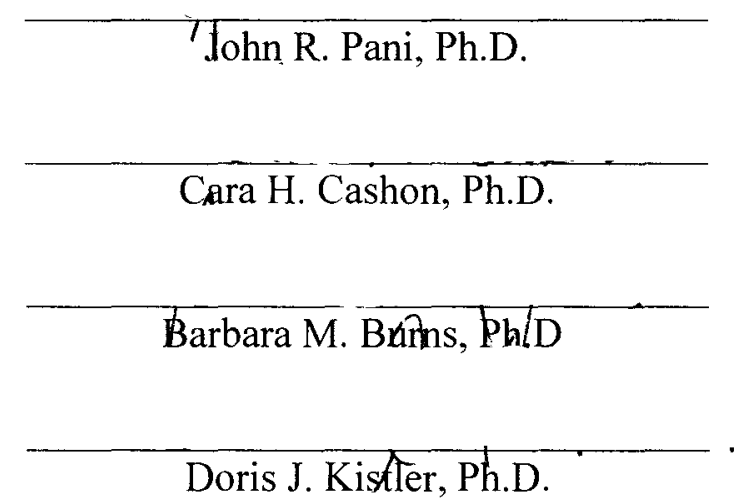




\section{DEDICATION}

This dissertation is dedicated to the amazing children, and their families, I have had both the pleasure and privilege of getting to know through the course of my training.

Thank you for letting me be a part of your lives and teaching me how to allow myself to laugh, to enjoy the moment, and to be inspired. 


\section{ACKNOWLEDGEMENTS}

I wish to express my gratitude to the people who made this dissertation project possible:

- Dr. Carolyn B. Mervis, my advisor and mentor, who was there for me every day of my graduate career, providing mentorship, encouragement, and unsurpassed support. I could not have done any of this without your guidance and support. Thank you for always believing in my ideas and me and helping me look beyond life's challenges to see the light at the end of the tunnel.

- Dr. John Pani, Dr. Doris Kistler, Dr. Cara Cashon, and Dr. Barbara Burns, the members of my dissertation committee, for their time, support, and contribution.

- The federal agency that supported this research: National Institute of Child Health and Human Development grant \#R37 HD29957.

- The families of the children with Down syndrome and the families of the children with Williams syndrome, who devoted their time to participate in this project.

- Dr. Sally Rogers, Dr. Susan Hepburn, and Dr. Deborah Fidler, who helped me realize how much I love working with children with intellectual disabilities, taught me the value of conducting research, and provided guidance in my work, studies, and life.

- All of the members of the Neurodevelopmental Sciences Lab for their help with data collection, support, and willingness to contribute, and especially to Lauren Dobson, for being a great friend, for all of the hours of her time she devoted to 
make this project possible, and for making this experience more enjoyable.

Without all of you, this project would not have been possible.

- My classmates, friends, and academic siblings, for the many words of wisdom and support offered during the process of my graduate career.

- Finally, and most importantly, my family: my brother, Reggie John, for being there for me every step of the way and encouraging me to not take everything so seriously and my parents, Sam John and Anna John, for giving me everything they possibly could to help me succeed in life and for always being there for me. 


\begin{abstract}
THE REGULATORY FUNCTION OF SOCIAL REFERENCING IN

PRESCHOOLERS WITH DOWN SYNDROME OR WILLIAMS SYNDROME
\end{abstract}

\author{
Angela E. John
}

April 11, 2011

The present project examined the regulatory function of social referencing in two neurodevelopmental disorders that have been well defined genetically and are characterized by differing patterns of socio-cognitive development: Down syndrome (DS) and Williams syndrome (WS). In addition, since the social referencing process requires children to coordinate three fundamental abilities (initiation of joint attention, gaze following, emotional responsivity), the present project also included three follow-up studies which examined these abilities separately.

Participants were 21 children with DS $(M$ age $=4.97$ years; $S D=.74)$ and 21 children with WS ( $M$ age $=4.92$ years; $S D=.76)$ closely matched on age and gender. The results of the Social Referencing task indicated that the majority of children in both diagnostic groups formed positive opinions about the ambiguous stimulus when the adult communicated a joyful nonverbal message but had difficulty using the adult's expression of fear to regulate their behavior in response to the ambiguous stimulus. Children with DS were more likely than were children with WS to shift gaze between the adult and the ambiguous stimulus. However, the children with DS frequently formed a positive opinion of the fearful stimulus and were more likely than were the children with WS to touch the 
stimulus. When the adult reacted fearfully to the ambiguous stimulus, the longest look directed to her by children with WS was significantly longer than the longest look directed by children with DS. In addition, children with WS were less likely to form an opinion of the fearful stimulus and more likely than children with DS to resort to superficially imitating the adult's display as opposed to using the adult's opinion of the stimulus to form their own.

The results of the follow-up studies demonstrated that children with DS were more likely than were children with WS to initiate joint attention with the adult and to respond to joint attention in triadic situations. In addition, in a situation with a reduced attentional demand on the child than that used in the Social Referencing task, results indicated that the majority of children in both groups formed a positive opinion of the stimulus when the adult communicated a joyful message about it. However, when the adult communicated a fearful message, only one child in each group formed a negative opinion of the stimulus.

In summary, the results indicate that there are both similarities and differences in the problems encountered by children with DS and children with WS in the social referencing process. Both groups had difficulty interpreting the communicative significance of fearful reactions. However, children with DS were more successful than children with WS both at coordinating attention in triadic interactions and at identifying the source of the adult's interest. Furthermore, despite demonstrating poorer overall intellectual ability and more limited verbal ability, children with DS evidenced better executive functioning than did children with WS. This difference in executive functioning may contribute to some of the advantages shown by children with DS. 


\section{TABLE OF CONTENTS}

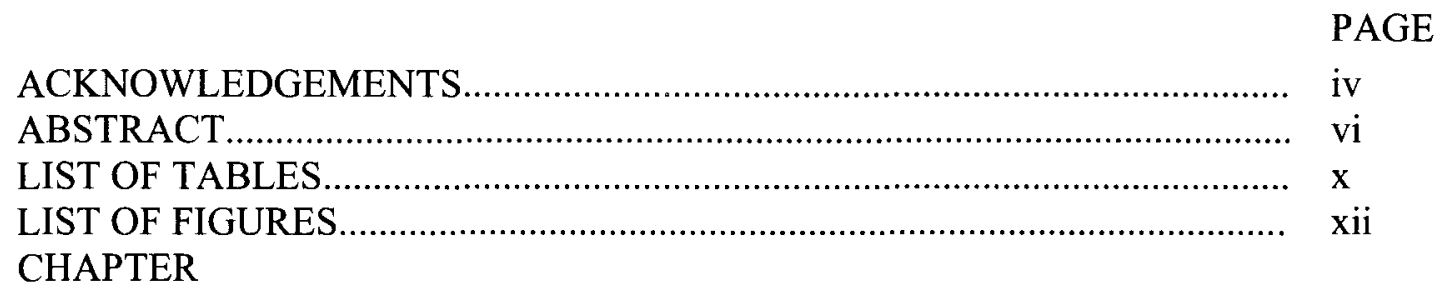

I. GENERAL INTRODUCTION ................................................... $\quad 1$

Social Referencing by Typically Developing Children................ 3

Social Referencing by Children with Developmental Delay........ 17

The Behavioral Phenotypes..................................................... 26

The Present Study................................................................ 43

II. DEVELOPMENTAL ASSESSMENT_.......................................... 47

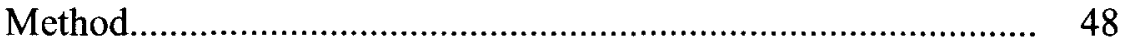

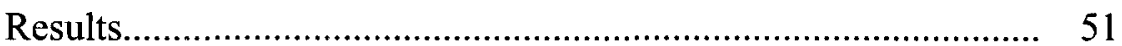

Discussion..................................................................... 53

III. REGULATORY FUNCTION OF SOCIAL REFERENCING......... 56

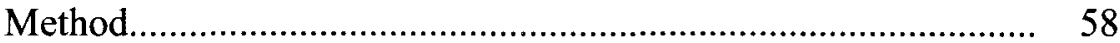

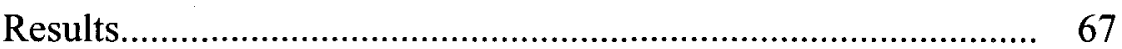

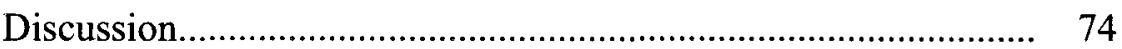




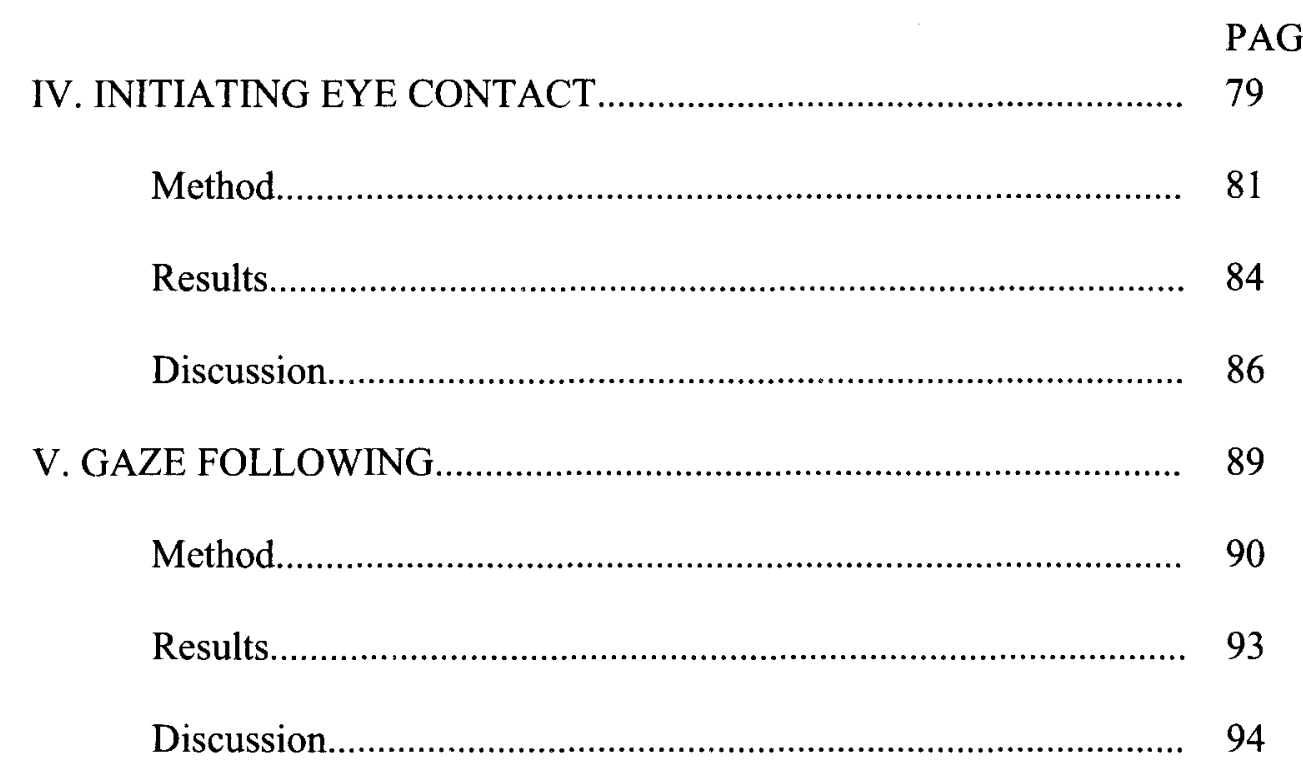

VI. UTILIZING EMOTIONAL REACTIONS................................ 96

Method....................................................................... 97

Results..................................................................... 102

Discussion.................................................................. 106

VII. GENERAL DISCUSSION.................................................... 109

Regulatory Function of Social Referencing........................... 110

Initiating Eye Contact.......................................................... 114

Gaze Following ........................................................ 115

Utilizing Emotional Reactions.......................................... 117

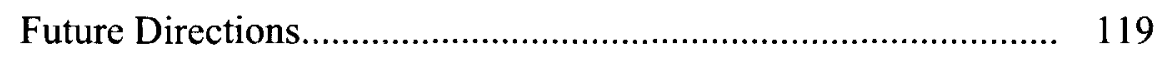

Conclusions................................................................. 123

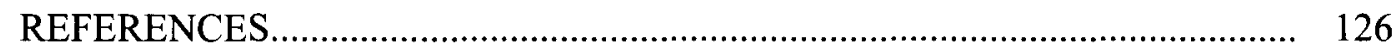

CURRICULUM VITAE.................................................................... 140 


\section{LIST OF TABLES}

TABLE

PAGE

1. Summary of Empirical Research on Social Referencing by Typically

Developing Children.

2. Descriptive Statistics for Performance on DAS-II and BRIEF-Preschool......

3. Descriptive Statistics for Performance on Gazing Behavior Variables as a Function of Condition and Diagnostic Group.

4. Number of Children who 'Acknowledged and Mapped' in the Joy Condition as a Function of Diagnostic Group.

5. Number of Children who 'Acknowledged and Mapped' in the Fear Condition as a Function of Diagnostic Group.

6. Number of Children who 'Imitated' the Experimenter's Behavioral

Response in the Joy Condition as a Function of Diagnostic Group.

7. Number of Children who 'Imitated' the Experimenter's Behavioral Response in the Fear Condition as a Function of Diagnostic Group.........

8. Number of Children who Touched the Stimulus in the Joy Condition as a Function of Diagnostic Group.

9. Number of Children who Touched the Stimulus in the Fear Condition as a Function of Diagnostic Group. 
TABLE

10. Number of Children who 'Formed an Opinion' of the Stimulus in the Joy Condition as a Function of Diagnostic Group

11. Number of Children who 'Formed an Opinion' of the Stimulus in the Fear Condition as a Function of Diagnostic Group.

12. Descriptive Statistics for Proportion of Trials on which Children Looked at the Experimenter's Face within Four Seconds of Trial Onset in the Goal Ambiguity Task.

13. Descriptive Statistics for 'Following' as a Function of Diagnostic Group in the Gaze Following Task.

14. Number of Children who 'Acknowledged and Mapped' the Experimenter's Emotion in the Joy Condition as a Function of Diagnostic Group.

15. Number of Children who 'Acknowledged and Mapped' the Experimenter's Emotion in the Fear Condition as a Function of Diagnostic Group.

16. Number of Children who Reached for the Box in the Joy Condition as a Function of Diagnostic Group

17. Number of Children who Reached for the Box in the Fear Condition as a Function of Diagnostic Group

18. Number of Children who 'Formed an Opinion' in the Joy Condition as a Function of Diagnostic Group.

19. Number of Children who 'Formed an Opinion' in the Fear Condition as a Function of Diagnostic Group. 


\section{LIST OF FIGURES}

$\begin{array}{lll}\text { Figure } & \text { PAGE }\end{array}$

1. Diagram of the project experimental tasks..................................................... 45

2. Diagram of Social Referencing task room setup......................................... 60 


\section{CHAPTER I}

\section{GENERAL INTRODUCTION}

One of the key challenges influencing children's ability to cope with life demands involves understanding and navigating the surrounding world of people. Over the course of development, children learn that actions produced by people differ from actions produced by objects. That is, children learn to make sense of a person's actions in terms of his or her underlying mental states (e.g., how a person thinks, perceives, infers, feels). The ability to interpret a person's actions in terms of his or her underlying mental state involves a complex interweaving of cognitive, affective, and personality factors. The ability to predict, explain, and manipulate people's actions is important for psychological growth and effective functioning within the environment as it facilitates children's learning about the world around them and about themselves (Hala, 1997).

Consider the situation in which a young child encounters a novel object. The child has no information regarding this new object; as such he or she turns to his or her mother and sees that she is smiling while shifting her attention between the child and the object. The child is able to interpret these behaviors as an indication that it is safe to approach and explore the object. This socially guided method of learning, referred to as the social referencing process, is one of the most important ways children are socialized into their environment (Feinman, 1982). Specifically, the social referencing process refers to an interactive social situation in which one person uses another person's interpretation of a 
situation to form his or her own understanding of that situation (Campos \& Stenberg, 1981; Feinman, 1982; Klinnert, Campos, Sorce, Emde, \& Svejda, 1983; Moore \& Corkum, 1994). The study of the social referencing process allows cognition and learning to be examined in the context of a social and interactive environment and provides researchers with a tool for examining how children use other people to learn about the world around them (Feinman, 1982). While there is some research indicating that the onset of the social referencing process is delayed in children with developmental delays (Dissanayake \& Crossley, 1996; Sigman, Kasari, Kwon, \& Yirmiya, 1992; Warreyn, Roeyers, \& De Groote, 2005), few of these studies used a standard social referencing paradigm or focused on specific neurodevelopmental disorders, especially genetic syndromes.

Advances made in the area of scientific technology and methodological procedures have led to the discovery of a large number of underlying chromosomal or genetic anomalies resulting in intellectual disability (e.g., Down syndrome, fragile X syndrome, Williams syndrome). Furthermore, researchers now know that many of these syndromes, as a result of differing genotypes, are associated with specific patterns of behavioral characteristics, referred to as behavioral phenotypes (Hodapp \& Dykens, 2001). Despite these advances, very little is known about the differential impact of these behavioral phenotypes on children's socio-cognitive development and about how sociocognitive development affects later outcome. A syndrome-specific approach to the examination of the social referencing process offers the opportunity to begin to consider the influence of specific syndromes on abilities fundamental to the development of social 
cognition, providing information on genetic or other mechanisms associated with sociocognitive abilities.

The purpose of this project is to provide the first set of studies directly focused on the regulatory function of social referencing in two neurodevelopmental disorders that have been well defined genetically and are characterized by differing patterns of sociocognitive development: Down syndrome (DS) and Williams syndrome (WS). In the remainder of the introduction I review four sets of literature that provide background for this project: the social referencing process in typically-developing (TD) children, the social referencing process in children with developmental delay (DD), an overview of the behavioral phenotypes associated with DS and WS, and finally characteristics of the DS and WS socio-communicative phenotypes relevant to the abilities that are fundamental to the social referencing process (initiating joint attention, gaze following, and emotional responsiveness/emotion recognition).

\section{Social Referencing by Typically Developing Children}

Understanding how infants make sense of the world around them has long held the interest of researchers. However, it was only in the late 1970s that young children's cognition and learning was considered within the context of the surrounding social environment (Feinman, 1992a). The climate of this new zeitgeist sparked interest in determining if children are influenced by the people around them as they learn about their environment. One topic of specific interest involved determining if infants use others' interpretations of situations when formulating their own interpretations; that is, if infants are able to access the regulatory function of social referencing (Feinman, 1982, 1991; Feinman, Roberts, Hsieh, Sawyer, \& Swanson, 1992). Since the early 1980s, a number of 
studies have been conducted focused on answering this question. While there has been considerable variation in the methodological approaches used to examine the regulatory function of social referencing, four elemental components are consistently addressed: the child (the person being influenced), the referee (the person providing the message), the referent (the topic of the message), and the message itself (the manipulation used to influence the child; Feinman et al., 1992). Manipulating each of these components has allowed a clearer understanding of the circumstances in which children will use another person's interpretation of a situation to guide their own behavior. In the next few sections, I present the overall findings of the studies examining the regulatory function of social referencing by TD children (see Table 1 for review) as a function of each of these elements to demonstrate what is known about their role in the social referencing process. Before presenting these findings, I explain the organization of Table 1 to aid in interpretation.

In Table 1, I present specific information from the studies that have been conducted to examine the regulatory function of social referencing by TD children. For each study I include information, if available, regarding: who the children within the study were [the chronological age (CA) of the participants and the sample size; column 2], whether or not the experimental manipulation required the child to initiate a look to the referee in order for the message to be communicated (column 3), who the referee was (column 4), what the referent was (column 5), what type of emotional reaction was communicated in the message, whether a between-subjects or within-subjects design was used (column 6), and what the results of the study were (column 7). In addition, 
information regarding the findings relating to four specific variables is presented in the Results (column 7):

1. Ref: the likelihood that the child referenced the referee

2. Prox A: the child's proximity to the adult (referee)

3. Prox R: the child's proximity to the referent

4. Affect: the likelihood that the child displayed positive affect.

$\mathrm{I}$ also indicate the significant differences reported between message conditions $[\mathrm{Joy}=\mathrm{J}$, Neutral $=\mathrm{N}$, Fear $=\mathrm{F}$, Inattentive (referee's face not visible) $=\mathrm{I}]$ or participant groups for these four specific variables. For example, if a study found that the participants were significantly more likely to reference the adult (referee) in the Joy condition as compared to the Fear condition, that finding would be reported as follows in the Results column:

'Ref: $\mathrm{J}>\mathrm{N}$. ' 


\begin{tabular}{|c|c|c|c|c|c|c|}
\hline \multicolumn{7}{|c|}{ Summary of Empirical Research on Social Referencing by Typically Developing Children } \\
\hline Study & $\begin{array}{c}\text { CA } \\
\text { (mos) } \\
\text { and } n\end{array}$ & $\begin{array}{l}\text { Message/Emotional } \\
\text { display provided only if } \\
\text { child established eye } \\
\text { contact? }\end{array}$ & Referee & Referent & $\begin{array}{c}\text { Message/ } \\
\text { Emotional } \\
\text { Display } \\
\text { (within or } \\
\text { between } \\
\text { subject design) }\end{array}$ & Results \\
\hline $\begin{array}{l}\text { Feinman \& Lewis } \\
\text { (1984) }\end{array}$ & $\begin{array}{c}10 \\
n=87\end{array}$ & No & Mother & Stranger & $\begin{array}{c}\text { Joy } \\
\text { Neutral } \\
\text { (between) }\end{array}$ & $\begin{array}{l}\text { Ref: } \text { no info } \\
\text { Prox A: no info } \\
\text { Prox } \mathbf{R}: \mathbf{J}<\mathrm{N}^{\mathrm{a}} \\
\text { Affect: } \mathbf{J}>\mathrm{N}^{\mathbf{a}}\end{array}$ \\
\hline $\begin{array}{l}\text { Dickstein et al. } \\
\text { (1984) }\end{array}$ & $\begin{array}{c}19 \\
n=43\end{array}$ & No & Mother & Stranger & $\begin{array}{l}\text { Neutral } \\
\text { Joy } \\
\text { (within) }\end{array}$ & $\begin{array}{l}\text { Ref: } \mathrm{N}>\mathrm{J} \\
\text { Prox A: } \mathrm{N}<\mathrm{J} \\
\text { Prox R: no info } \\
\text { Affect: no info }\end{array}$ \\
\hline $\begin{array}{l}\text { Gunnar \& Stone } \\
\text { (1984) }\end{array}$ & $\begin{array}{l}12-13 \\
n=40\end{array}$ & No & Mother & $\begin{array}{c}\text { Novel } \\
\text { Toy }\end{array}$ & $\begin{array}{c}\text { Joy } \\
\text { Neutral } \\
\text { (within) }\end{array}$ & $\begin{array}{l}\text { Ref: } \text { no info } \\
\text { Prox A: no info } \\
\text { Prox R: no info } \\
\text { Affect: } \mathrm{J}>\mathrm{N}^{\mathrm{b}}\end{array}$ \\
\hline Sorce et al. (1985) & $\begin{array}{c}12 \\
n=40\end{array}$ & Yes & Mother & $\begin{array}{l}\text { Visual } \\
\text { Cliff }\end{array}$ & $\begin{array}{c}\text { Joy } \\
\text { Fear } \\
\text { (between) }\end{array}$ & $\begin{array}{l}\text { Crossed: } \mathrm{J}>\mathrm{F} \\
\text { Ref: } \text { no info } \\
\text { Prox A: no info } \\
\text { Prox R: } \mathrm{J}<\mathrm{F} \\
\text { Affect: } \mathrm{J}>\mathrm{F}^{\mathrm{c}}\end{array}$ \\
\hline $\begin{array}{l}\text { Zarbatany \& Lamb } \\
(1985)^{d}\end{array}$ & $\begin{array}{l}13-15 \\
n=36\end{array}$ & No & $\begin{array}{l}\text { Mother vs. } \\
\text { Stranger }\end{array}$ & $\begin{array}{c}\text { Toy } \\
\text { Spider }\end{array}$ & $\begin{array}{c}\text { Joy } \\
\text { Fear } \\
\text { (between) }\end{array}$ & $\begin{array}{l}\text { Ref: } \mathrm{F}>\mathrm{J} \\
\text { Prox A: no info } \\
\text { Prox R: } \mathrm{J}=\mathrm{F} \\
\text { Affect: no info }\end{array}$ \\
\hline Klinnert et al. (1986) & $\begin{array}{l}12-18 \\
n=72\end{array}$ & Yes & $\begin{array}{l}\text { Familiar } \\
\text { Adult }\end{array}$ & $\begin{array}{l}\text { Novel } \\
\text { Toys }\end{array}$ & $\begin{array}{c}\text { Joy } \\
\text { Fear } \\
\text { (between) }\end{array}$ & $\begin{array}{l}\text { Ref: } 83 \% \text { referenced } \\
\text { Prox A: } F<J \\
\text { Prox } R: J<F \\
\text { Affect: } J>F\end{array}$ \\
\hline
\end{tabular}




\begin{tabular}{|c|c|c|c|c|c|c|}
\hline \multicolumn{7}{|c|}{$\begin{array}{l}\text { Table } 1 \text { (continued) } \\
\text { Summary of Empirical Research on Social Referencing by Typically Developing Children }\end{array}$} \\
\hline Study & $\begin{array}{l}\text { CA } \\
(\operatorname{mos}) \\
\text { and } n\end{array}$ & $\begin{array}{l}\text { Message/Emotional } \\
\text { display provided only if } \\
\text { child established eye } \\
\text { contact? }\end{array}$ & Referee & Referent & $\begin{array}{c}\text { Message/ } \\
\text { Emotional } \\
\text { Display } \\
\text { (within or } \\
\text { between } \\
\text { subject design) }\end{array}$ & Results \\
\hline Hornik et al. $(1987)^{\mathrm{e}}$ & $\begin{array}{c}12 \\
n=48\end{array}$ & No & Mother & $\begin{array}{l}2 \text { semi- } \\
\text { familiar } \\
\text { toys; } 1 \\
\text { novel toy }\end{array}$ & $\begin{array}{l}\text { Joy } \\
\text { Neutral } \\
\text { Disgust } \\
\text { (between) }\end{array}$ & $\begin{array}{l}\text { Ref: no info } \\
\text { Prox A: Disgust }<\mathrm{J} \\
\text { Prox R: }(\mathrm{J}=\mathrm{N})<\text { Disgust } \\
\text { Affect: }(\mathrm{J}=\mathrm{N})>\text { Disgust }\end{array}$ \\
\hline $\begin{array}{l}\text { Hornik \& Gunnar } \\
(1988)^{\mathrm{f}}\end{array}$ & $\begin{array}{c}12 \\
n=16 \\
18 \\
n=32\end{array}$ & Yes & Mother & $\begin{array}{l}\text { Caged } \\
\text { rabbit }\end{array}$ & $\begin{array}{c}\text { Joy } \\
\text { (within) }\end{array}$ & $\begin{array}{l}\text { Ref: wary children }>\text { bold } \\
\text { children } \\
\text { Prox A: no info } \\
\text { Prox R: both groups increased } \\
\text { proximity when mom came } \\
\text { over. } \\
\text { Affect: wary children < bold } \\
\text { children }\end{array}$ \\
\hline $\begin{array}{l}\text { Walden \& Ogan } \\
\text { (1988) }\end{array}$ & $\begin{array}{c}6-9 \\
n=11 \\
10-13 \\
n=15 \\
14-20 \\
n=14\end{array}$ & Yes & Parent & $\begin{array}{l}\text { Novel } \\
\text { Stimuli }\end{array}$ & $\begin{array}{l}\text { Joy } \\
\text { Fear } \\
\text { (within) }\end{array}$ & $\begin{array}{l}\text { Ref: } 6-9 \text { mos: } \mathrm{J}>\mathrm{F} \\
10-13 \text { mos: } \mathrm{J}=\mathrm{F} \\
14-22 \text { mos: } \mathrm{J}<\mathrm{F} \\
\text { Prox A: } \text { no info } \\
\text { Prox R: } 6-9 \text { mos: } \mathrm{J}=\mathrm{F} \\
\quad 10-13 \text { mos: } \mathrm{J}<\mathrm{F} \\
14-22 \text { mos: } \mathrm{J}=\mathrm{F}^{\mathrm{g}} \\
\text { Affect: } \text { no info }\end{array}$ \\
\hline
\end{tabular}




\begin{tabular}{|c|c|c|c|c|c|c|}
\hline \multicolumn{7}{|c|}{$\begin{array}{l}\text { Table } 1 \text { (continued) } \\
\text { Summary of Empirical Research on Social Referencing by Typically Developing Children }\end{array}$} \\
\hline Study & $\begin{array}{l}\text { CA } \\
\text { (mos) } \\
\text { and } n\end{array}$ & $\begin{array}{l}\text { Message/Emotional } \\
\text { display provided only if } \\
\text { child established eye } \\
\text { contact? }\end{array}$ & Referee & Referent & $\begin{array}{c}\text { Message/ } \\
\text { Emotional } \\
\text { Display } \\
\text { (within or } \\
\text { between } \\
\text { subject design) }\end{array}$ & Results \\
\hline $\begin{array}{l}\text { Walden \& Baxter } \\
\text { (1989) }\end{array}$ & $\begin{array}{l}6-40 \\
n=48\end{array}$ & Yes & Parent & $\begin{array}{l}\text { Novel } \\
\text { Stimuli }\end{array}$ & $\begin{array}{c}\text { Joy } \\
\text { Fear } \\
\text { (between) }\end{array}$ & $\begin{array}{l}\text { Ref: } 6-12 \text { mos: } \mathrm{J}>\mathrm{F} \\
13-23 \text { mos: } \mathrm{J}<\mathrm{F} \\
24-40 \text { mos: } \mathrm{J}=\mathrm{F}^{\mathrm{h}} \\
\text { Prox A: } \text { no info } \\
\text { Prox R: } \mathrm{J}<\mathrm{F} \\
\text { Affect: } 6-12 \text { mos: } \mathrm{J}=\mathrm{F} \\
13-23 \text { mos: } \mathrm{J}=\mathrm{F} \\
24-40 \text { mos: } \mathrm{J}>\mathrm{F}\end{array}$ \\
\hline $\begin{array}{l}\text { Hirshberg \& Svejda } \\
\text { (1990) }\end{array}$ & $\begin{array}{c}12 \\
n=74\end{array}$ & No & $\begin{array}{l}\text { Mother } \\
\text { Father }\end{array}$ & $\begin{array}{l}\text { Novel } \\
\text { Stimuli }\end{array}$ & $\begin{array}{c}\text { Joy } \\
\text { Fear } \\
\text { Both } \\
\text { (between) }\end{array}$ & $\begin{array}{l}\text { Ref: } J<F \\
\text { Prox A: } J<F \\
\text { Prox R: } J<F \\
\text { Affect: } J>F\end{array}$ \\
\hline $\begin{array}{l}\text { Camras \& Sachs } \\
\text { (1991) }\end{array}$ & $\begin{array}{c}10-19 \\
n=36\end{array}$ & No & $\begin{array}{l}\text { Familiar } \\
\text { adult }\end{array}$ & $\begin{array}{l}\text { Novel } \\
\text { Stimuli }\end{array}$ & $\begin{array}{c}\text { Joy } \\
\text { Fear } \\
\text { (within) }\end{array}$ & $\begin{array}{l}\text { Ref: } \mathrm{J}=\mathrm{F} \\
\text { Prox A: } \text { no info } \\
\text { Prox R: } \mathrm{J}<\mathrm{F} \\
\text { Affect: } \text { no info } \\
\end{array}$ \\
\hline Rosen et al. (1992) & $\begin{array}{c}12 \\
n=37\end{array}$ & Yes & Mother & $\begin{array}{l}\text { Novel } \\
\text { Stimuli }\end{array}$ & $\begin{array}{l}\text { Joy } \\
\text { Fear } \\
\text { (within) }\end{array}$ & $\begin{array}{r}\text { Ref: } J=F \\
\text { Prox A: Girls: } F<J \\
\text { Boys: } J=F \\
\text { Prox R: Girls: } J<F \\
\text { Boys: } J=F \\
\text { Affect: Girls: } J>F \\
\text { Boys: } J>F\end{array}$ \\
\hline
\end{tabular}




\begin{tabular}{|c|c|c|c|c|c|c|}
\hline \multicolumn{7}{|c|}{$\begin{array}{l}\text { Table } 1 \text { (continued) } \\
\text { Summary of Empirical Research on Social Referencing by Typically Developing Children }\end{array}$} \\
\hline Study & $\begin{array}{l}\text { CA } \\
\text { (mos) } \\
\text { and } n\end{array}$ & $\begin{array}{l}\text { Message/Emotional } \\
\text { display provided only if } \\
\text { child established eye } \\
\text { contact? }\end{array}$ & Referee & Referent & $\begin{array}{c}\text { Message/ } \\
\text { Emotional } \\
\text { Display } \\
\text { (within or } \\
\text { between } \\
\text { subject design) }\end{array}$ & Results \\
\hline Mumme et al. (1996) & $\begin{array}{c}12-13 \\
n=90\end{array}$ & No & Mother & $\begin{array}{l}\text { Novel } \\
\text { Stimuli }\end{array}$ & $\begin{array}{c}\text { Vocal: } \\
\text { Joy } \\
\text { Neutral } \\
\text { Fear } \\
\text { Facial: } \\
\text { Joy } \\
\text { Neutral } \\
\text { Fear } \\
\text { (between) }\end{array}$ & $\begin{array}{l}\text { Vocal - } \\
\text { Ref: } N=J ; N<F \\
\text { Prox A: } N=J ; N=F \\
\text { Prox R: } N=J ; N<F \\
\text { Affect: } N=J ; N<F \\
\text { Facial - } \\
\text { Ref: } \\
\text { Girls: }(N=J)<F \text {; } \\
\text { Boys: } N=J=F \\
\text { Prox A: } \text { no info } \\
\text { Prox R: } \\
\text { Girls: }(N=J)<F \\
\text { Boys: } N=J=F \\
\text { Affect: } N=J=F \\
\end{array}$ \\
\hline Stenberg (2003) & $\begin{array}{c}12 \\
n=96\end{array}$ & No & Mother & $\begin{array}{l}\text { Novel } \\
\text { Stimuli }\end{array}$ & $\begin{array}{c}\text { Joy } \\
\text { Inattentive } \\
\text { Fear } \\
\text { (between) }\end{array}$ & $\begin{array}{l}\text { Ref: } \mathrm{J}=\mathrm{I} ; \mathrm{I}<\mathrm{F} \\
\text { Prox A: J }>\mathrm{I} ; \mathrm{I}>\mathrm{I} \\
\text { Prox R: } \mathrm{J}<\mathrm{I} ; \mathrm{F}<\mathrm{I} \\
\text { Affect: } \mathrm{J}=\mathrm{I} ; \mathrm{F}=\mathrm{I}\end{array}$ \\
\hline $\begin{array}{l}\text { Vaish \& Striano } \\
(2004)\end{array}$ & $\begin{array}{l}11-12 \\
n=45\end{array}$ & No & Mother & $\begin{array}{l}\text { Visual } \\
\text { Cliff }\end{array}$ & $\begin{array}{c}\text { Positive } \\
\text { (Face, Face }+ \\
\text { Voice, Voice) } \\
\text { (between) }\end{array}$ & $\begin{array}{c}\text { Ref: } \mathrm{Fa}=\mathrm{Vo} \\
\mathrm{Fa}=\mathrm{Fa}+\mathrm{Vo} \\
\mathrm{Fa}+\mathrm{Vo}>\mathrm{Vo} \\
\text { Crossing Time: } \\
\quad \mathrm{F}+\mathrm{V}=\mathrm{V})<\mathrm{F} \\
\text { Prox A: } \text { no info } \\
\text { Prox R: } \text { no info } \\
\text { Affect: } \text { no info } \\
\end{array}$ \\
\hline
\end{tabular}




\section{The Child}

As indicated in Table 1 (column 2), studies of the social referencing process in TD children have considered the behavior of children as young as 6 months of age and as old as 40 months of age. Most researchers have focused on children between 9 and 14 months of age. Results of these studies have indicated that, beginning at around 12 months of age, children will change their proximity to both the referent and the referee (the adult), their affective responses, and their referencing or looking behavior in response to another person's appraisal of the situation (e.g., Dickstein et al., 1984; Feinman \& Lewis, 1984; Klinnert et al., 1986; Walden \& Ogan, 1988).

\section{The Referee}

When researchers first became interested in examining the regulatory function of social referencing, it was hypothesized that infants would be selectively more receptive to some referees in comparison to others. However, there was some disagreement as to what factors influenced an infant's receptivity. While some researchers theorized that infants would be more receptive to messages given by referees perceived to be credible, knowledgeable, or powerful (e.g., Bandura, 1969; Feinman, 1982), others took a more restrictive position, theorizing that social referencing was a process that occurred specifically between infants and their mothers and therefore arguing for a strong relation between attachment and referencing (e.g., Campos \& Stenberg, 1981). By examining the results of the studies described in Table 1 as a function of the referee (column 4), we see that while there is some evidence that infants are more receptive to their mother's messages in comparison to strangers' (e.g., Feiring, Lewis, \& Starr, 1984; Zarbatany \& Lamb, 1985), several investigations have found that when infants encountered a novel 
object/event with their mothers present (and appearing either non-communicative or puzzled) and received an emotional message regarding the referent from an unfamiliar experimenter, infants used the experimenter's message to regulate their own behavior toward the object. Children were more likely to approach the referent in the Joy condition and were more likely to avoid the referent in the Fear condition (e.g., Feinman et al., 1992; Klinnert et al., 1986; Walden \& Kim, 2005). Taken together, it seems that while infants may be selectively more receptive to guidance from a caregiver, other people perceived to be knowledgeable about the surrounding environment are able to regulate infants' behavior if the mother is non-communicative, puzzled, or not available (Feinman et al., 1992).

\section{The Referent}

Considerable variation is observed in the choice of referent across studies examining social referencing (Table 1, column 5). Referents used have included strangers (de Rosnay et al., 2006; Dickstein et al., 1984; Feinman \& Lewis, 1983), novel objects (Camras \& Sachs, 1991; Hirshberg \& Svejda, 1990; Klinnert et al., 1986; Mumme et al., 1996; Rosen, 1988; Stenberg, 2003; Walden \& Baxter, 1989; Walden \& Kim, 2005;

Walden \& Ogan, 1988), semi-familiar objects (Hornik et al., 1987), visual cliffs (Sorce et al., 1985; Vaish \& Striano, 2004), toy spiders (Zarbatany \& Lamb, 1985), and live animals (Hornik \& Gunnar, 1988). An examination of the results of these studies as a function of referent indicates that the ambiguity of the referent seems to be a vital factor in children's use of another person's appraisal of the situation. Children seem far more likely to use another person's appraisal to guide their own behavior in ambiguous situations (e.g., Camras \& Sachs, 1991; de Rosnay et al., 2006; Hirshberg \& Svejda, 
1990; Klinnert et al., 1986). When children are presented with a referent with which they have some experience, or opinions on, they seem more resistant to another person's appraisal of the situation when it differs from their own (e.g., de Rosnay et al., 2006; Feinman, 1992b; Mumme et al., 1996; Rosen et al., 1992; Walden \& Baxter, 1989; Walden \& Ogan, 1988; Zarbatany \& Lamb, 1985). For example, as reported by Hornik and Gunner (1988), if a child is shown a live rabbit and is immediately fearful of the rabbit, the child's opinion of the rabbit does not seem to be changed by the experimenter's display of joy.

\section{The Message}

Finally, the most important element in studies examining the social referencing process is arguably the message itself (Table 1, column 6). Most commonly, researchers have used experimental designs that evaluate the impact of referencing messages by contrasting the impact of positive and negative messages (Boccia \& Campos, 1989; Klinnert et al., 1986; Sorce et al., 1985). Some researchers have also examined the differential impact of neutral messages in comparison to positive or negative messages (e.g., Feinman \& Lewis, 1984; Gunnar \& Stone, 1984; Klinnert et al., 1986). While positive messages have consistently been provided through expressions of joy, the negative message conditions used in studies examining social referencing have included demonstrations of fear (e.g., Klinnert et al., 1986; Sorce et al., 1985; Walden \& Ogan, 1988), disgust (Hornik \& Gunnar, 1988), and anxiety (de Rosnay et al., 2006). The results of these studies consistently document that when provided with a positive message, children are more likely to venture farther away from the adult, approach the novel/ambiguous object, and demonstrate more positive affect. In contrast, when 
provided with a negative message children tend to stay closer to the adult, stay farther away from the object, and display more negative affect themselves (e.g., Camras \& Sachs, 1991; Hirshberg \& Svejda, 1990; Klinnert et al., 1986; Mumme et al., 1996; Sorce et al., 1985; Walden \& Baxter, 1989; Walden \& Kim, 2005; Walden \& Ogan, 1988).

While results of these studies provide consistent evidence that infants change their behavior within a situation depending on whether another person's interpretation of the situation is positive or negative, it is important to evaluate the manner in which the message was provided to obtain a thorough understanding of the social referencing process. For example, did the infant have to request information from the adult regarding the novel/ambiguous object or was the message provided automatically (Table 1 column 3; yes indicates that the child had to make eye contact with the referee to receive the message, no indicates that the message was provided automatically)? Examining this design manipulation across studies, once again there is evidence supporting the hypothesis that children change their behavior toward a novel/ambiguous object depending upon the reactions of those around them both in studies where a message was provided automatically (e.g., Camras \& Sachs, 1991; de Rosnay et al., 2006; Hirshberg \& Svejda, 1990; Hornik et al., 1987) and in studies requiring the child to look to the adult to obtain the message (e.g., Klinnert et al., 1986; Sorce et al., 1985; Walden \& Baxter, 1989; Walden \& Kim, 2005; Walden \& Ogan, 1988). This evidence suggests that TD children are not only responsive to messages, but also that they spontaneously seek information regarding these novel/ambiguous stimuli and events.

Finally, it is important to consider the channel(s) through which the message was provided. That is, was the message provided through a single channel (e.g., facial affect 
only, vocal affect only) or through multiple channels? While most of the early studies used single-channel messages, primarily facial affect, more recently the use of multiplechannel messages including facial affect, vocal affect, and behavior has been more common. As discussed by Emde (1992), a multi-channel message is more indicative of the types of messages that children are likely to encounter in the real world and may be more likely to influence children's behavior (e.g., Vaish \& Striano, 2004). This is an important manipulation to consider as it changes the ways in which children are able to obtain the information provided. For example, a single-channel approach using facial affect requires that the child look at the adult's face to receive the message. Using a multiple-channel approach, in situations in which the message is provided automatically the vocal affective information may cue the child to look to the adult. While TD children consistently looked to the adult in all of the studies discussed above, it is important to consider the implications of channel selection when interpreting data regarding the regulatory function of social referencing, especially when working with children with developmental disabilities, who often display abnormalities in their use of eye gaze.

\section{Summary and Discussion}

Overall, the results of this line of research demonstrate the influence of other people on how children make sense of their environment. There is consistent evidence that beginning around 12 months of age children are more likely to approach ambiguous stimuli/events after receiving positive messages from those around them in comparison to after receiving neutral or negative messages. It is important to note that successful performance in a standard social referencing paradigm requires the child to demonstrate and coordinate three fundamental abilities. First, the child must coordinate his or her 
attention between objects and the adult in a social context. That is, the child must initiate joint attention. The ability to initiate joint attention is important to the social referencing process, as the child must shift his or her attention from the referent to the referee in order to gain access to the message (referee's reaction.) Secondly, once the child notices the adult's reaction, the child must be able to identify the focus of the adult's attention. In order to do so, the child must be able to follow the adult's gaze to determine the referent of interest. Finally, in order for the child to regulate his or her own behavior in response to the experimenter's reaction, the child must demonstrate the ability to comprehend the significance of the adult's emotionally valenced message and use this information as a source of information.

It is vital to consider these fundamental abilities (initiation of joint attention, gaze following, and emotional responsivity/emotion recognition) when studying the social referencing process by children who have syndromes associated with developmental delay, such as DS or WS, as impairment in one or more of these fundamental abilities could in turn affect performance on a social referencing task. As described in the remaining sections of this chapter, different syndromes are associated with differing behavioral phenotypes. While it is important to determine if children use the people around them to learn about stimuli within their environments, it is also important to consider which, if any, of the fundamental abilities is impaired or delayed, as this will likely influence the children's behavioral responses during the social referencing process.

\section{Social Referencing by Children with Developmental Delay}

To date there have been only a few studies reported that examine the social referencing process in children with DD. Walden, Kneips, and Baxter (1991) examined 
the behavioral responses of children with DD aged 15 - 54 months and mental age (MA)matched TD children (age range: $6-27$ months) when presented with two ambiguous toys paired with either a positive verbal response (i.e., "Oh look at that! What a nice toy! Nice Toy!") or a negative verbal response (i.e., "Oh, look at that! What a scary toy! Ooooh scary toy!"). Results indicated that the MA-matched TD children were significantly more likely to touch the toy and touched the toy sooner in the positive verbal response condition in comparison to the negative verbal response condition. In contrast, the likelihood of touching the toy and the latency to the child's touch did not differ significantly between the positive verbal response condition and the negative verbal response conditions for the children with DD.

Other studies have looked at the social referencing process in children with particular developmental disorders. For example, social referencing deficits have often been argued to be extremely characteristic of the autism spectrum phenotype (e.g., Bacon, Fein, Morris, Waterhouse, \& Allen, 1998; Robins, Fein, Barton, \& Green, 2001; Sigman, Arbelle, \& Dissanayake, 1995). However, findings from studies examining the social referencing process in children with autism spectrum disorders (ASDs) have been inconsistent. These inconsistencies are likely due to differences between studies in both the operational definitions of social referencing and the methodological approach used.

As part of a larger study conducted to examine the responses of children with autism to the distress of others, Bacon and colleagues (1998) examined children's behavioral response to an unfamiliar stimulus, in this case an "animal-like honkingbraying sound emitted from a speaker in the room (p. 133)". All groups were matched for $\mathrm{CA}$; in addition, pairs of groups of children with disabilities were matched for nonverbal 
ratio IQ (nonverbal MA/CA*100) computed based on the Pattern Analysis and Copying subscales of the Stanford-Binet 4th edition (Thorndike, Hagen, \& Sattler, 1986). The four groups were: a group of high functioning children with autism (NVIQ $>80, n=32$, mean $C A=55.84$ months) matched to a group of children with developmental language disorder (DLD; $n=42$, mean $C A=55.85$ ) for CA and nonverbal ratio IQ, a group of lower functioning children with autism (NVIQ $<80 ; n=51$, mean $C A=62.04$ ) matched to a group of children with $\mathrm{DD}(n=39$; mean $C A=55.85)$ on $\mathrm{CA}$ and nonverbal ratio IQ score, and a group of TD children $(n=29$; mean $C A=55.72)$ matched to the groups of children with disabilities for CA. The authors found that children in the autism groups looked significantly less than the TD children to the adult in response to the animal-like sound and argued that this finding demonstrated impairment in social referencing. This was the only behavioral feature on which both autism groups demonstrated comparable performance. Bacon and colleagues hypothesized that the observed deficit potentially relates to the core social deficit that characterizes individuals with autism, regardless of ability level.

More recently, Wetherby, Watt, Morgan, and Shumway (2007) examined social communication profiles of 2-year-old children with ASD $(n=50)$, children with DD $(n=$ 23), and TD children $(n=50)$ on the Communication and Symbolic Behavior Scales First normed edition - Behavior Sample (CSBS; Wetherby \& Prizant, 1993), a play based task designed to press for various communicative abilities. Participants in all groups were matched on CA, parental education, and maternal age. The ASD and DD groups were further matched on nonverbal (NV) developmental quotient calculated by averaging the age-equivalent scores from the Fine Motor and Visual Reception scales from the Mullen 
Scales of Early Learning (MSEL; Mullen, 1995). It is important to note that, within this study, children assigned to the ASD group had either a diagnosis of Autistic Disorder or Pervasive Developmental Disorder - Not Otherwise Specified (PDD-NOS), a milder condition on the autism spectrum. No information was available regarding the number of children in each of these diagnostic groups. The results indicated that the children with ASD had considerable difficulty with gaze shifting and sharing positive affect when compared to both children with DD and TD children. These findings were interpreted to reflect difficulty with social referencing as TD children actively gaze shift between people and objects to check if their caregiver is attending to their focus of interest (Bakeman \& Adamson, 1984) and are able to coordinate gaze and affect sharing.

The definition of social referencing used in these two studies focused solely on children's ability to look to their communicative partner when encountering uncertain/ambiguous situations. In both research and clinical practice, it is widely accepted that children with autism demonstrate a significant impairment in the use of eye gaze to regulate social interactions (e.g., American Psychological Association, 1996; Charman et al., 1998; World Health Organization, 1996). Therefore, if only eye gaze shifting is coded to demonstrate social referencing, children with autism will indeed demonstrate deficits in social referencing. However, using this methodological approach tells us little about the actual regulatory function of social referencing. While the studies above indicate that children with ASDs demonstrate atypical behavior, or atypical eye gaze when seeking information, we still have no information on whether children with ASDs are using other modalities to seek information, can interpret affective expressions, or will use others to guide their approach to their environment. The methodological 
designs used in the studies described below allow us to obtain more information regarding these aspects of social referencing and seem to provide some preliminary evidence that despite their limited use of eye contact, children with ASDs might not demonstrate impairments in the other abilities involved in the social referencing process (e.g., Campos \& Stenberg, 1981; Feinman, 1982; Klinnert et al., 1983; Moore \& Corkum, 1994).

Sigman and colleagues (1992) examined the attention, facial affect, and behavioral responses of children with autism ( $n=30$; mean $C A=42.40$ months), children with DD (matched on MA and CA; $n=30$; mean $C A=41.67$ months) and TD children (matched on MA; $n=30$; mean $C A=19.83$ months) in response to the presentation of a novel object paired with expressions of fear (demonstrated through affect, gesture, and non-word verbalization) modeled by both the child's mother and a researcher. Though the children with autism looked at the adults significantly less than the control groups did and their approach behavior indicated that they were less hesitant than were children with DD, the approach behavior of the children with autism was not significantly different from that of the TD children. The authors also reported that when the adult demonstrated expressions of pleasure, once again children with autism looked at the adult less often than did both children with DD and TD children. No information was reported regarding children's responses toward the object in this condition. Sigman and colleagues interpreted their finding to indicate a social referencing deficit, based on the atypical looking behavior exhibited by the children with autism, but they did acknowledge that the children with autism seemed influenced by demonstrations of fear even though they were less likely to look at the adults. 
Dissanayake and Crossley (1996) used a modified social referencing task to investigate attachment in children with autism. The child's response to a stranger entering a room in which the child was playing with his or her mother was recorded and compared to the child's behavior prior to the stranger's entrance. Participants included 16 children with autism (mean $C A=51.10$ months), $16 \mathrm{CA}$-matched $\mathrm{TD}$ children (mean $C A=51.10$ months), and 16 children with DS matched as a group to the 8 verbal children with autism on receptive language ability (mean $C A=55.10$ months). The authors found that when observed in free play with their mothers, the children with autism looked, smiled, and showed objects to their mother less frequently than did the control groups, demonstrating impairments in their interaction skills. Nevertheless, when the stranger entered the room, children in all three groups changed their behavior as they spent significantly more time in close proximity to their mother and spent significantly more time looking at and facing their mother in comparison to the stranger. The results of these studies, at the very least, raise the possibility that children with autism are referring to or evaluating the behavior of others in uncertain/ambiguous situations despite their atypical use of eye gaze. However, none of the studies reviewed thus far used a methodological approach that would allow us to evaluate the social referencing process in autism using a paradigm consistent with those used to study social referencing by TD children. To evaluate social referencing behaviors comprehensively one would need to examine whether the behaviors of children with autism differ in situations in which an adult provides positive or negative affective expressions directed toward ambiguous stimuli.

To date, only one study has examined the behavior of children with autism in response to both positive and negative affective expressions. Warreyn, Roeyers, and 
DeGroote (2005) examined the early social communicative behaviors of children from 3 to 6 years of age with $\operatorname{ASD}(n=20$; mean $C A=58.70$ months $)$ and children with language or developmental delay of unknown etiology $(\mathrm{LD} / \mathrm{DD} ; n=20$; mean $C A=$ 62.25 months) who were individually matched on CA, IQ, and gender. Once again, the results raise the possibility that behavior by children with autism may be impacted by the affective expressions of others. In their task, an ambiguous object entered the room from under a black screen and mothers were asked to express an emotional reaction (happiness or fear) both verbally and nonverbally in response to the object. A between-subjects design was used such that half of the children in each group were assigned to the fear condition and half of the children were assigned to the happy condition.

The children with ASD in the happy condition made more eye contact with their mothers than did the children with ASD in the fear condition. Furthermore, although a statistically significant difference was not obtained, more children with ASD in the happy condition approached the object and more children with ASD in the fear condition avoided the object. The children in the LD/DD group were found to be less avoidant of the ambiguous object than were the children with ASD in both conditions. However, when examining the behavioral responses of the LD/DD group across the two conditions, no statistical differences were found. On this basis, the authors hypothesized that the children in the LD/DD group were too old for the task and "saw through" the mother's expressions of fear. It is important to note that since Warreyn and colleagues used a between-subjects design there were only 10 children per group in each condition. This limited sample size clearly affected the likelihood of obtaining statistically significant 
effects. It is also possible that including both children with autism and children with PDD-NOS in one group reduced the likelihood of finding significant effects.

To date, there are no studies comprehensively examining the regulatory function of social referencing in children with DS or WS. However, two studies have been reported that used a social referencing paradigm to examine particular aspects of the DS behavioral phenotype. Kasari, Freeman, Mundy, and Sigman (1995) examined attention regulation by children with DS in two different situations designed to press for triadic interactions: (1) the Early Social Communication Scales (Mundy \& Hogan, 1996), a semi-structured play based assessment designed to evaluate early socio-communicative abilities in an unambiguous context, and (2) a social referencing procedure used to evaluate triadic attention in an ambiguous context. Results indicated that even though the children with DS ( $n=58$; mean $C A=24.60$ months; $S D=8.85)$ did not differ from the TD children matched on verbal MA $(n=23$; mean $C A=14.22$ months; $S D=4.40)$ on rates of joint attention during the ESCS, children with DS were less likely to demonstrate joint attention during the social referencing task regardless of the emotional display (joy or fear). Further analyses indicated that children with DS spent approximately the same amount of time looking at the stimulus and looking at the adult whereas the TD children spent considerably more time attending to the stimulus than to the adult. Kasari and colleagues interpret their findings to suggest that children with DS were less able to appraise the situation in the social referencing procedure, theorizing that they may have failed to make the connection between the intended emotional message and the stimulus.

Using a similar design, Kneips, Walden, and Baxter (1994) also found that children with DS ( $n=11$; CA range: $15-41$ months) spent more time looking at the 
adult's face in comparison to MA-matched TD children $(n=11$; CA range: $10-23$ months). Furthermore, the authors found that toddlers with DS were more likely than were MA-matched TD children to demonstrate positive affect in response to adults' negative emotional displays.

So what do the findings of these studies tell us about social referencing in children with syndromes associated with intellectual disability (ID)? The limited evidence available suggests that it is likely that children with syndromes associated with ID are delayed in their acquisition and/or coordination of the abilities required to succeed in a social referencing paradigm. However, far more research directly focused on examining social referencing abilities in children with syndromes associated with ID is necessary. In addition, an examination of the underlying abilities required for successful performance on a social referencing paradigm is important. The results of research studies on social referencing in children with ASDs demonstrate that the phenotype is associated with specific impairments in use of gaze. As such, children with ASDs demonstrate abnormalities in the use of eye gaze during the social referencing tasks. However, more research is needed to determine if impairments are evident in other areas, as there was some evidence to suggest that even though children with ASDs have difficulty using eye gaze in social interactions they still might be using the adult's response to guide their behavior toward the ambiguous object.

A better understanding of how specific aspects of a particular behavioral phenotype impact children's ability to use other people to learn about objects and events in their environment is likely to result when social referencing abilities are examined as a function of developmental disorder. The results of studies examining performance on 
social referencing tasks by children with DS suggest that they also have difficulty using the people around them to learn about their surrounding environments. To more fully evaluate this hypothesis and to begin to understand what challenges are encountered by children with DS and children with WS during the social referencing process, it is vital that a comprehensive examination of social referencing be conducted including assessment of the fundamental abilities used during the social referencing process.

\section{The Behavioral Phenotypes}

\section{Overview}

Down syndrome. DS, with a prevalence of 1 in 733 live births (Centers for Disease Control and Prevention, 2006), is the most common genetic cause of ID. DS results from the presence of an extra copy of the long arm of chromosome 21 . Most individuals with DS $(\sim 95 \%)$ have three full copies of chromosome 21 (trisomy 21$)$. The remaining $5 \%$ have either a translocation $(3-4 \%)$, in which part of a third copy of chromosome 21 attaches to another chromosome, or are mosaic $(1-2 \%)$; these individuals have some cells with three copies of chromosome 21 and others with two copies (Mutton, Alberman, \& Hook, 1996). While the prognosis for individuals with mosaic DS is not always better than for those with the other forms of DS (Carr, 2002), on average people with mosaic DS have higher IQs than those with trisomy 21 or translocation DS (Fishler \& Koch, 1991).

DS is associated with a particular pattern of dysmorphic facial characteristics, congenital heart defects, short stature, hypotonia, and immune system and endocrine system abnormalities (Korenberg et al., 1994). Young children with DS have DD and the majority of older children and adults with DS have mild to moderate ID. In addition, 
individuals with DS demonstrate a particular pattern of cognitive and linguistic strengths and weaknesses. The cognitive phenotype of individuals with DS typically involves relative strengths in nonverbal communication, motor skills, visual memory, visual motor integration, and visual imitation paired with relative weaknesses in auditory and verbal abilities (Fidler, 2005; Jarrold, Baddeley, \& Hewes, 2005; Klein \& Mervis, 1999; Miller \& Leddy, 1999). When performance within the language domain is examined more specifically, receptive language skills are typically stronger than expressive language skills, and vocabulary skills are typically stronger than grammatical skills and verbal working memory skills (e.g., Chapman, 1999, 2003; Fidler, 2005; Miller \& Leddy, 1999).

Despite significant expressive language difficulties, individuals with DS demonstrate a relative strength in socio-communicative abilities that may be used to compensate for limitations in other areas (Kasari \& Freeman, 2002; Pitcairn \& Wishart, 1994). Individuals with DS are frequently described as having charming personalities (Gibbs \& Thorpe, 1983; Rodgers, 1987; Wishart \& Johnston, 1990), as being affectionate and loveable, and as getting along well with others (Carr, 1995). Young children with DS also have been found to smile more than do children with DD of mixed etiology matched on CA (Fidler, Barrett, \& Most, 2005; Kasari, Mundy, Yirmiya, \& Sigman, 1990; Knieps et al., 1994). Individuals with DS also demonstrate a relative strength in forming relationships with others. Freeman and Kasari (2002) found that the majority of children with DS in their sample (mean $C A=8.37$ years) had relationships with peers that met criteria for true friendships (reciprocal nomination in the friendship dyad, convergence between parental and child nomination, and at least 6 months stability of the friendship). 
Despite these positive depictions regarding the social ability of children with DS, some difficulties in social functioning have been noted as well. Fidler, Barrett, and Most (2005) found that adolescents and young adults with DS smiled less, showed less attention seeking behavior and evidenced increased anxiety/depression relative to younger individuals with DS. Similarly, toddlers and older children with DS are often described as demonstrating sudden changes in mood, being stubborn, or withdrawing from situations when frustrated (e.g., Jahromi, Gulsrud, \& Kasari, 2008; Pueschel, Bernier, \& Pezzullo, 1991). Furthermore, researchers have theorized that traits such as stubbornness and strong-willed behavior resulting in task refusal may be contributing to inconsistent performance on tasks examining motivation and persistence (Carr, 1995; Fidler, 2005). Difficulties recognizing facial expressions have also been documented in individuals with DS (Porter, 2008; Porter, Coltheart, \& Langdon, 2007).

Williams syndrome. WS is a less common neurodevelopmental disorder resulting from a hemideletion of $\sim 25$ genes on chromosome 7q11.23 (Ewart et al., 1993; Morris, 2006). The prevalence of WS is estimated to be 1 in 7500 live births (Strømme, Bjørnstad, \& Ramstad, 2002). Most individuals with WS ( $95 \%)$ have the same set of genes deleted (“classic deletion”).

WS is characterized by mild to moderate ID or learning difficulties, dysmorphic facial features, heart disease (especially supravalvar aortic stenosis), connective tissue abnormalities, and failure to thrive or growth deficiency (Morris, 2006). Considerable heterogeneity is observed in the cognitive and linguistic abilities demonstrated by individuals with WS. WS is associated with a specific cognitive profile characterized by relative strengths in verbal short-term memory and the concrete vocabulary component of 
language accompanied by a severe weakness in visuospatial construction (Jarrold, Baddeley, \& Hewes, 1998; Mervis \& Klein-Tasman, 2000; Mervis \& Morris, 2007; Mervis et al., 2000; Udwin \& Yule, 1991). Within language, the greatest strength is in concrete vocabulary and the greatest weakness is in relational vocabulary (Mervis \& Becerra, 2007; Mervis \& John, 2008, 2010, in press).

Individuals with WS are often described as demonstrating an excessive interest in others and a distinct lack of inhibition with regard to approaching others in social contexts (Jones et al., 2000). As a group, children with WS are often described as being gregarious and overly friendly (Gosch \& Pankau, 1997), highly sociable (Dilts, Morris, \& Leonard, 1990), charming (Fryns, Borghgraef, Volcke, \& van den Berge, 1991), and never going unnoticed in a group (Dykens \& Rosner, 1999). Despite these seemingly positive characteristics, children with WS demonstrate significant difficulty with peer relationships (Davies, Udwin, \& Howlin, 1998; Sullivan, Winner, \& Tager-Flusberg, 2003), high levels of tension and sensitivity (Klein-Tasman \& Mervis, 2003), and impairments in pragmatic abilities (for review see Mervis \& Becerra, 2007; Mervis \& John, 2010; Tager-Flusberg \& Plesa Skwerer, 2006). In adulthood, most individuals with WS demonstrate difficulty with social interactions, including establishing and maintaining relationships. In addition, they have high levels of anxiety and are socially isolated (Cherniske et al., 2004; Davies et al., 1998; Dykens \& Rosner, 1999; Howlin \& Udwin, 2006; Stinton, Elison, \& Howlin, 2010; Udwin \& Yule, 1991).

While progress has been made with regard to understanding the behavioral phenotypes associated with both DS and WS; much remains to be understood. To date, there are no published studies specifically designed to examine the regulatory function of 
social referencing in individuals with either DS or WS. However, there have been some studies of the component abilities (initiating joint attention, gaze following, and emotion recognition) theorized to impact successful social referencing performance. In the remainder of this chapter, I briefly review this literature with regard to TD children, children with DS, and children with WS, and then provide an overview of the studies included in my dissertation.

\section{Initiating Joint Attention}

The emergence and development of the ability to coordinate one's attention between a social partner and objects or events of mutual interest, known as joint attention, has been argued to evidence the child's recognition of people as intentional agents (Thompson, 2006) and mark a turning point in children's communicative competence (Bakeman \& Adamson, 1984; Carpenter, Nagell, \& Tomasello, 1998; Thompson, 2006). Some researchers have argued that this integration of objects/events into social interactions facilitates social learning (Baldwin, 1995; Mundy \& Neal, 2001), reflecting a sensitivity to the reward of sharing with others (Mundy, 1995; Trevarthen \& Aitken, 2001) and serving as a precursor for the later development of understanding others' intentions, feelings, and thoughts (e.g., Bretherton, 1991; Tomasello, 1995).

Initiated joint attention behaviors can be divided into two categories: (1) imperative joint attention (IJA) acts in which the child's behavior serves an instrumental function (e.g., to request) and (2) declarative joint attention (DJA) acts in which the behavior is intended to share awareness or enjoyment of an object or event (Charman et al., 1998; Mundy, Sigman, \& Kasari, 1993). TD infants begin to participate in episodes of joint attention with adults between 8 and 10 months of age (Saxon, Frick, \& Colombo, 
1997; Trevarthen \& Hubley, 1978), and between 12 and 15 months of age joint attention becomes a consistent part of infant-adult interactions (Bakeman \& Adamson, 1984). From 9 to 12 months of age TD children produce more DJA acts than IJA acts, but between 12 and 18 months of age TD children consistently produce more IJA acts than DJA acts (Mundy et al., 2007).

Down syndrome. Although social interaction skills are considered a relative strength for children with DS, difficulties in the area of joint attention have been documented. Toddlers with DS tend to maintain eye contact with other people much longer than do MA-matched and receptive language matched TD children (Berger \& Cunningham, 1981, 1983; Kasari et al., 1990; Lewy \& Dawson, 1992). Kasari and colleagues (1990) found that children with DS ( $n=30$; mean $C A=22.9$ months $)$ were more likely to look at the experimenter's face, less likely to look at toys in view but out of reach, and more likely to look away from an interaction in comparison to MA-matched TD children ( $n=30$; mean $C A=15.2$ months). Similarly, Lewy and Dawson (1992) found that children with DS ( $n=20$; mean $C A=37.00$ months) spent significantly more time engaged solely with the adult as well as significantly more time in coordinated joint attention (defined as actively involved with both the person and the toy alternating periods of gaze between the object and the adult) than did either children with autism ( $n=$ $20 ;$ mean $C A=50.00$ months) or TD children matched for receptive language age ( $n=$ 20; mean $C A=17.80$ months). These findings, indicating that children with DS spend increased time attending to the people around them, have been theorized to indicate a deficiency in exploring and assessing the environment and provide evidence for an early preference for social interaction/stimuli. 
The results of studies directly focused on examining the initiation of joint attention by children with DS indicate a similar pattern of preference for or increased attention to social interactions. For example, Mundy and colleagues (1988) examined social interaction skills in a sample of 30 children with DS divided into two groups: lowMA ( $n=15 ;$ mean $C A=22.9$ months, mean $M A=15.6$ months $)$ and high-MA $(n=15$; mean $C A=43$ months, mean $M A=27.7$ months). The social interaction skills of the two groups of children with DS were compared to those of two MA-matched groups of TD children (low-MA group: $n=15$; mean $C A=15.2$ months, mean $M A=16.4$ months; High-MA group: $n=15$, mean $C A=22.6$ months, mean $M A=28.1$ months). The results of this study indicated that both groups of children with DS demonstrated more social interaction behaviors (e.g., initiating turn-taking, throwing toys while smiling at the researcher) than did the TD children but were less likely than the TD children to make requests. A closer examination of requesting behaviors indicated that this difficulty for the children with DS was limited to requesting objects or assistance with objects (triadic requests); children with DS were not less likely to request a physical interaction game (dyadic request). Similarly, Fidler and colleagues (2005) found that children with DS ( $n=$ 16; mean $C A=34.25$ months) were less likely to demonstrate IJA acts in comparison to MA-matched TD children ( $n=19$; mean $C A=18.42$ months $)$ and MA- and CA-matched children with mixed or nonspecific etiology $\mathrm{DD}(n=18 ;$ mean $C A=33.94$ months). No significant differences between the three groups were observed for DJA acts or for social requests.

Williams syndrome. To date there are only a few studies examining joint attention in children with WS. The emergence of joint attention in WS is delayed relative to both 
CA and language ability (Mervis \& Bertrand, 1993, 1997; Mervis et al., 2003). Children with WS also have been shown to be significantly less likely to engage in joint attention acts than MA-matched TD children or children with DS individually matched on CA, developmental quotient (DQ), and expressive vocabulary size (Laing et al., 2002; Rowe, Peregrine, \& Mervis, 2005).

Laing et al. (2002) examined the early communicative behaviors of 13 toddlers with WS (mean $C A=31$ months) in comparison to 13 MA-matched TD children (mean $C A=13$ months). Using the ESCS (Mundy \& Hogan, 1996), Laing and colleagues found that children with WS were significantly less likely to initiate IJA acts and less likely to incorporate a pointing gesture into either IJA or DJA acts. Laing et al. also noted that the analysis examining whether children with WS initiated DJA acts less often than controls approached significance $(p=.07)$. However, the children with WS were significantly more likely than were the TD children to produce dyadic social interaction behaviors.

Two other studies (Klein-Tasman, Mervis, Lord, \& Phillips, 2007; Lincoln, Searcy, Jones, \& Lord, 2007) report specific information regarding the proportion of children with WS of similar age ( $30-63$ months vs. $27-58$ months) who demonstrate joint attention using the Autism Diagnostic Observation Schedule-Generic (ADOS-G; Lord, Rutter, DiLavore, \& Risi, 1999), a semi-structured, play based interaction designed to assess difficulties characteristic of children with ASDs in the areas of communication, reciprocal social interaction, creativity and imagination, and the presence of restricted and repetitive behaviors. Both Klein-Tasman et al. (2007) and Lincoln et al. (2007) reported that approximately half ( $45 \%$ and $50 \%$ respectively) of their participants did not clearly integrate eye contact to reference an object that was out of reach with their 
communicative partner and more than half $(79 \%$ and $65 \%)$ of the participants did not integrate eye contact or vocalization with acts of showing objects. Lincoln et al. (2007) also compared the performance on the ADOS-G of children with WS to CA- and ratio IQ-matched children with autism. It is important to note that ratio IQ scores (MA/CAx100) were calculated based on performance on the Bayley Scales of Infant Development (Bayley, 1969) for the WS group and were calculated based on performance on the MSEL (Mullen, 1995) for the autism group. Results of this comparison indicated that even though more than half of the children with WS demonstrated difficulties with joint attention and showing, the WS group still performed significantly better than the autism group, as all of the children with autism demonstrated these types of difficulties. Klein-Tasman, Phillips, Lord, Mervis, and Gallo (2009) replicated this finding, also using the ADOS-G, demonstrating that children with WS ( $n=$ 28; mean $C A=41.68$ months, mean $M S E L E L C=56.29$ ) evidenced significantly better joint attention skills than did children with autism $(n=28$, mean $C A=41.00$, mean $M S E L$ $E L C=55.78)$ who were matched on gender, $C A$, and overall intellectual ability when controlling for receptive language ability and when controlling for expressive language ability.

Comparison of Down syndrome and Williams syndrome. Only one study directly compared the joint attention abilities of children with DS to children with WS. Using the CSBS (Wetherby \& Prizant, 2002), Rowe, Peregrine, and Mervis (2005) found somewhat different profiles when comparing 10 toddlers with WS (mean $C A=26.6$ months) to 10 toddlers with DS matched on CA, DQ, and expressive vocabulary size. The authors reported that children with WS were significantly less likely to initiate DJA acts or shift 
gaze than were children with DS. The two groups did not differ on frequency of IJA acts produced. Given that the DS phenotype is theorized to be associated with a specific deficit in IJA acts, the results of this study suggest that children with WS demonstrate impairments in joint attention with difficulties observed for both IJA and DJA acts.

Taken together, the results of the studies described above indicate that both children with DS and children with WS demonstrate impairments in joint attention ability. Within triadic interactions, children with DS demonstrate more difficulty with regard to regulating another person's behavior for instrumental purposes (IJA acts) than they do with regard to either directing and focusing another person's attention on an object or event (DJA acts) or requesting within dyadic interactions. In comparison, children with WS demonstrate difficulty with both DJA and IJA acts within triadic interactions relative to both MA-matched TD children and CA- and MA-matched children with DS. Similar to children with DS, they demonstrate a relative strength in the ability to request in dyadic interactions.

\section{Gaze Following}

The ability to follow another person's gaze is an important milestone in early development as it is a governing factor in both social and communicative interactions between a young child and an adult (Adamson, 1995; D'Entremont, Hains, \& Muir, 1997). So what drives a person to turn to look in the same direction as another person? Most basically, it is theorized to be the desire to see what the other person is looking at, or the desire to share in another person's perspective (Moore, 1999). Although this is likely what compels adults to follow gaze, this may not be the case throughout development. 
While some theorists have suggested that the ability of young children to follow another person's gaze indicates the understanding of intentionality (e.g., Baron-Cohen, 1995; Bretherton, 1991), other researchers have strongly cautioned against this interpretation, pointing out that children must be sensitive to changes in eye direction specifically in order to demonstrate an understanding of joint visual attention (Moore, 1999). Whereas prior to 10 months TD children will turn their heads in response to another person's change in head direction, it is only around 10 months of age that TD children will selectively follow changes in eye gaze specifically (e.g., Brooks \& Meltzoff, 2002; Corkum \& Moore, 1995).

Down syndrome. Only a few studies have examined gaze following by children with DS. Leekam, Baron-Cohen, Perrett, Milders, and Brown (1997) examined gaze monitoring and visual perspective taking in three groups matched on receptive language age equivalent: children with autism ( $n=12$; mean $C A=11.67$ years; range: $5.58-$ $17.42)$, children with $\mathrm{DD}(n=11$; mean $C A=7.58$ years; range: $4.5-12.25$ years $)$, and TD children $(n=12$, mean $C A=5.67$ years; range: $5.5-5.92)$. Results indicated that, when it came to following the adult's gaze shifts, the DS group performed similarly to the TD group and significantly better than the autism group. Sigman and Ruskin (1999) similarly reported that children with DS (CA range: $2-8$ years) were significantly more likely than MA-matched children with autism (CA range: $3-11$ years) to follow another person's gaze. The performance of children with DS did not differ significantly from that of other children with DD (CA range: 2 - 6 years) or MA-matched TD children (mean $C A=19.49$ months). While these results demonstrate that children with DS can follow 
another person's gaze shift, participants in these studies were considerably older than the age at which TD children consistently follow gaze.

Williams syndrome. Two studies (Klein-Tasman et al., 2007; Lincoln et al., 2007) reported specific information regarding the proportion of children with WS of similar age (30-62 months vs. $27-58$ months) who followed a gazing or pointing gesture paired with a verbalization during the ADOS-G. Klein-Tasman et al. (2007) found that approximately $34 \%$ of the children in their sample were unable to use an examiner's communicative gaze shift paired with the verbalization "Look" to locate a target from a distance. Half of these children ( $17 \%$ of the total sample) were still unable to locate the intended target even when a communicative pointing gesture was added. Lincoln et al. (2007) reported that $20 \%$ of their sample had difficulty following a communicative eyegaze gesture accompanied by the verbalization "Look;" no information was provided regarding the percentage of children demonstrating difficulty using the examiner's eye gaze paired with a pointing gesture. In addition, Lincoln et al. (2007) found that children with WS evidenced significantly better scores on the responding to joint attention item of the ADOS-G than did children with autism. This finding was also supported by KleinTasman et al. (2009), who found that children with WS evidenced significantly better scores than did gender-, CA-, and DQ-matched children with autism both when controlling for receptive language ability and when controlling for expressive language ability.

Laing et al. (2002) found that children with WS ( $n=13$; mean $C A=31$ months; CA range: $17-55$ ) followed the adult's pointing gestures (whether proximal or distal) less often than the MA-matched TD group ( $n=13$; mean $C A=13$ months; $30.8 \%$ vs. 
$41.06 \%$ of the time respectively). However, this difference did not reach conventional significance levels $(p=.07$ vs. $p<.05)$, perhaps due to the small sample sizes. The authors also reported data for a second study using 11 of the MA-matched pairs (mean $C A: \mathrm{WS}=29.6$ months vs. $\mathrm{TD}=13.1$ months) examining the ability to follow an adult's point to distal objects. Results indicated that the children with WS followed the adult's pointing gesture less often than the TD children did $(p=.05)$.

Comparison of Down syndrome and Williams syndrome. To date only two studies have directly compared the performance of children with DS and children with WS on a gaze following task. Using a semi-structured play based assessment designed to press for early communicative behaviors, Rowe et al. (2005) compared the performance of 10 pairs of children (one child with WS, one child with DS) matched on CA (range: 18 -26 months; $p=.56), \mathrm{DQ}(p=.76)$, and expressive vocabulary size $(p=.36)$. Results indicated that the toddlers with DS successfully followed a distal pointing gesture significantly more often than did the toddlers with WS $(p=.008)$. John and Mervis (2010) examined the comprehension of the communicative intent behind pointing and gazing gestures by children with DS ( $n=25$; mean $C A=4.34$ years; range: $3.02-5.40$ years) and children with WS ( $n=33$; mean $C A=4.14$ years; range: $3.00-5.33$ years). Results indicated that despite significantly lower MSEL DQs and MSEL receptive and expressive language raw scores, children with DS were significantly better at comprehending communicative intent. Both groups were better at comprehending communicative intent indicated by a pointing gesture paired with eye gaze than by eye gaze alone. 
Taken together, the results of the studies described above indicate that both children with DS and children with WS demonstrate delay in the ability to follow another person's gaze. There is some evidence suggesting that children with WS have more difficulty following gaze than do children with DS but more research is necessary to evaluate this possibility fully.

\section{Emotion Recognition}

Emotional development is an area of study for which systematic investigation began only recently. The lack of prior research is likely due to both the methodological complexity of studying emotional development and the belief that emotions were secondary responses to more important underlying processes (e.g., Saarni, Campos, Camras, \& Witherington, 2006). Facial expressions of emotion are generally viewed as behavioral responses indicative of underlying mental states (Sorce et al., 1985). However, emotional expressions are more than an index of underlying states; they also have an interpersonal function, regulating the behavior of other individuals. It is this interpersonal regulatory function of emotion that makes affective expression an important component of the communicative process (Holodynski \& Friedlmeier, 2005). Cross-cultural studies examining TD adult facial expressions have shown that the facial expressions indicating certain emotions (i.e., joy, fear, anger, sadness, surprise, and disgust) are virtually identical across cultures (Ekman, Sorenson, \& Friesen, 1969; Izard, 1971).

Even at a young age, TD children are very attentive to others' emotions. Around 6 months of age TD infants respond differentially to their mothers' happy and sad expressions (Cohn, Campbell, Matias, \& Hopkins, 1990; Termine \& Izard, 1988) and around 12 months of age infants use emotional information communicated by another 
person to help appraise an ambiguous situation (e.g., Feinman, 1992b; Sorce et al., 1985).

This ability to regulate one's own behavior in response to another person's emotional display requires that children both be responsive to the emotional display and comprehend its significance.

Down syndrome. To date, there are only a few studies of emotion recognition by children with DS. Kasari, Freeman, and Hughes (2001) studied emotion recognition in 4to 6-year-olds with DS using three different studies. Study 1 included children with DS (n $=20 ;$ mean $C A=76.7$ months $),$ MA-matched TD children $(n=20 ;$ mean $C A=39.65$ months), and CA-matched TD children ( $n=20$; mean $C A=77.90$ months). Overall, children with DS performed significantly worse than the CA-matched TD children on both the emotion labeling and the emotion recognition tasks. The children in all three groups were more accurate at recognizing, identifying, and labeling happy expressions than they were at recognizing, identifying, and labeling fear expressions.

In Study 2, Kasari and colleagues (2001) examined the emotion recognition ability of children with DS ( $n=36$, mean $C A=97.6$ months), MA-matched children with DD of mixed etiology ( $n=27$; mean $C A=104.1$ months $)$, and MA-matched TD children ( $n=33$; mean $C A=43.6$ months). Results from this study demonstrated that the MAmatched TD children were significantly better at labeling 'fear' than were the children with DS and the children with DD. In addition, children with DS were significantly worse at identifying fear within a story scenario than were the children with DD and the TD children. Finally, the authors found that when children incorrectly identified the emotion 'fear,' the responses of children with DS were significantly more likely to be that of 
positively valenced emotions than were the responses of children with DD and the TD children.

Williams, Wishart, Pitcairn, and Willis (2005) found that children with DS ( $n=$ 34; mean $C A=13.33$ years) performed similarly to MA-matched children with nonspecific ID ( $n=53$; mean $C A=11.83$ years) but significantly worse than MAmatched TD children ( $n=39$; mean $C A=4.08$ years $)$ on an emotion-matching task. The children with DS demonstrated significantly poorer performance on matching expressions of fear than did the MA-matched TD group. The error patterns for the DS group were more variable than for the other two groups, for whom errors were more consistent (e.g., surprise for fear).

Williams syndrome. Individuals with WS also evidence difficulty matching and labeling emotional expressions. Tager-Flusberg and Sullivan (2000) found that children with WS ( $n=22$; mean $C A=7$ years 2 months) performed similarly to children with Prader-Willi syndrome ( $n=15$; mean $C A=6$ years 11 months) and children with nonspecific ID ( $n=11$; mean $C A=7$ years 7 months) on a task involving matching facial expressions (scared, happy, angry, and sad). All three groups were significantly better at recognizing scared and happy expressions than at recognizing angry and sad expressions (a pattern also observed in TD children and children with autism; Gross \& Ballif, 1991; Hobson, Ouston, \& Lee, 1988).

Gagliardi et al. (2003) conducted a similar study using a wider age range for individuals with WS ( $n=26$; mean $C A=14.35$ years; range: $5.6-32.3$ ). Comparison groups were MA-matched TD children $(n=26$; mean $C A=5.5$ years; range: $4.3-11.3)$ and CA-matched TD individuals ( $n=26$; mean $C A=14.49$ years; range: $5.8-29.7$ ). All 
participants completed an animated facial expression comprehension test. The WS group performed significantly worse than the CA-matched TD group but similarly to the MAmatched TD group on both happy and fear (as well as on anger, disgust, sad). Individuals in all three groups were significantly better at recognizing happy expressions in comparison to all other emotions. Finally, Plesa-Skwerer et al. (2006) administered the Diagnostic Analysis of Nonverbal Accuracy Scale $-2^{\text {nd }}$ edition (DANVA-2; Nowicki \& Duke, 1994), a standardized measure of emotion recognition, to adolescents and adults with WS ( $n=47$; mean $C A=19.49$ years; range: $12.1-32.4)$. The WS group performed similarly to IQ-matched participants with learning/intellectual disability ( $n=49$; mean $C A=17.88$ years; range: $13.5-23.1$ ) but significantly worse than CA-matched TD participants $(n=58$; mean $C A=18.19$ years; range: $12.1-31.8)$ when controlling for performance on the Benton Test of Facial Recognition (Benton, Hamsher, Varney, \& Spreen, 1983) at identifying emotions in faces (WS: $75.83 \%$ correct, TD: $85.34 \%$ correct) and emotions in voices (WS: $60.84 \%$ correct, TD: $76.21 \%$ correct). The WS group (facial; $66.13 \%$ correct, vocal: $42.19 \%$ correct) was also significantly less accurate at identifying both facial and vocal expressions of fear than were the CA-matched TD participants (facial: $84.19 \%$ correct, vocal: 73.56 ). All three groups were significantly better at recognizing happy expressions than at recognizing fear expressions.

Comparison of Down syndrome and Williams syndrome. Porter (2008) directly compared the ability of individuals with DS and individuals with WS to recognize emotions as measured by the DANVA-2. Results indicated that, when controlling for MA, individuals with WS $[n=9$ ( 8 with a genetically confirmed diagnosis); CA range: $6.0-43.67$ years] and individuals with DS ( $n=20 ;$ CA range: $6.75-40.75$ years) 
demonstrated comparable performance with regard to recognizing expressions of fear. High mean proportions of errors for expressions of fear were observed for both groups, even when high intensity stimuli were used (High Intensity Stimuli: WS $=.56$, DS $=.56$; Low Intensity Stimuli: WS $=.66, \mathrm{DS}=.75$ ).

Results of these studies suggest that individuals with DS and individuals with WS have more difficulty recognizing fearful expressions than do their same age TD peers. Overall, however, very little is known about emotion recognition in individuals with DS or WS, especially in young children with these syndromes. In addition, the majority of studies examining emotion recognition used either adolescents/adults or included participants ranging from young children to adults in the same group making the results difficult to interpret. More information is necessary to evaluate emotion recognition ability and, in particular, to determine if young children with DS or WS recognize the communicative significance of emotional expressions.

\section{The Present Study}

An evaluation of social referencing skills in children with DS and children with WS will assist in developing a better understanding of the difficulties encountered by children with these neurodevelopmental disorders in social interactions. In addition, this type of study will allow us to have a better understanding of how these socio-cognitive and socio-communicative behavioral phenotypes influence children's ability to both interact with and use people as a source of information about the world around them. The purpose of this dissertation is two-fold: (1) To provide the first study directly focused on examining the ability of children with DS and children with WS to use another person as a source of information in ambiguous situations using a standard social referencing 
paradigm, and (2) To examine three abilities fundamental to the social referencing process (initiation of joint attention, gaze following, and emotional responsiveness/recognition) to help provide clarifying information as to the potential areas of difficulty encountered within the social referencing process.

To address these goals, I used data collected from four experimental tasks to begin to characterize the social referencing abilities of children with DS and children with WS (see Figure 1). In the first task, I used a standard social referencing paradigm task to assess the regulatory function of social referencing in children with DS and children with WS (Chapter III). As performance on the Social Referencing task requires a child to coordinate multiple abilities, if the child does not utilize another person as a source of information about this ambiguous stimulus it may be difficult to specify if and where the children are encountering difficulties. To obtain clarifying information as to where difficulties may be encountered, three additional tasks examining the fundamental abilities needed for social referencing were included in the present project. 
Figure 1: Diagram of the Project Experimental Tasks

CHAPTER III: Regulatory Function of Social Referencing: When encountering an ambiguous object, does the child use another person's appraisal of the object to guide his/her own behavior?

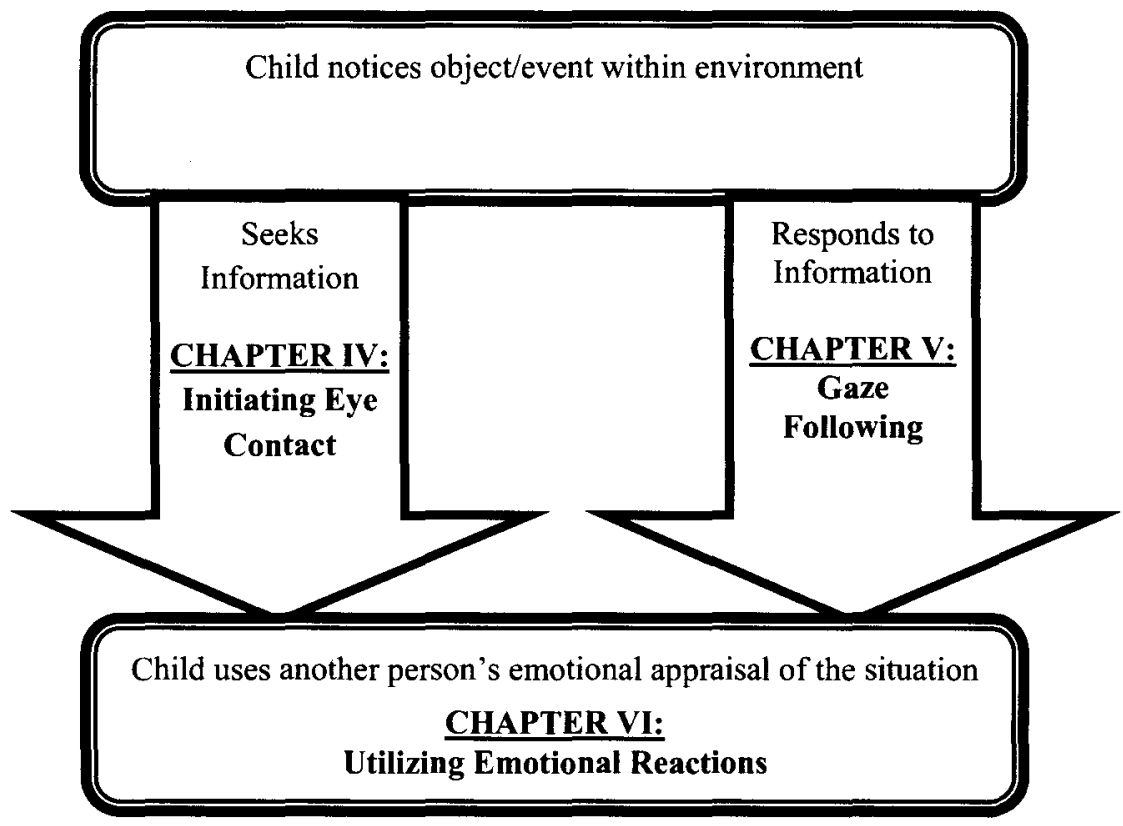

There are three fundamental abilities that a child uses during the social referencing process. First, the child must initiate joint attention between the object and the adult (Chapter IV). Secondly, once the child notices the adult's reaction, the child must be able to identify the focus of the adult's attention. This requires that the child be able to follow the adult's gaze to identify the referent (Chapter V). Finally, in order for the child to regulate his or her own behavior in response to the adult's reaction, the child must demonstrate the ability to comprehend the significance of the adult's emotionally valenced reaction in order to use this information to guide his or her own behavior (Chapter VI). 
Due to the prevalence rates of these neurodevelopmental disorders, a within subjects design was used to address my research questions. As the social referencing task evaluates cognition and learning in the context of a social and interactive environment, it was vital that the tasks used to assess the component abilities also be presented in a naturalistic interaction. As such, the trials/conditions from the tasks assessing component abilities (Chapters IV - VI) were interspersed such that they could be administered to the children in the context of two structured play interactions at a table. As the social referencing task (Chapter III) was administered on the floor, it was always administered either before or after the table play-interaction to limit the number of times children needed to be transitioned between playing at a table and playing on the floor.

In the remaining chapters, I present the research questions, methods, results, and discussions for the developmental assessment (Chapter II), social referencing task (Chapter III), and the tasks assessing the proposed abilities vital to the process of using another person's appraisal of a situation to guide one's own behavior (Chapters IV - VI). Finally, I conclude with a general discussion of what the findings tell us as a whole and some possible lines of future research (Chapter VII). 


\section{CHAPTER II \\ DEVELOPMENTAL ASSESSMENT}

As discussed in Chapter I, underlying chromosomal or genetic anomalies have been associated with many ID syndromes (e.g., Down syndrome, fragile X syndrome, Williams syndrome) and specific behavioral phenotypes resulting from these differing genotypes have also been associated with many of these syndromes (e.g., Hodapp \& Dykens, 2001). In addition to being associated with reduced overall intellectual ability and specific cognitive profiles, these syndromes involve a complex array of personality and motivational characteristics that profoundly affect both interactions with others and successful navigation of the surrounding environment (Zigler, 1971). In the present chapter, I compare the performance of children with DS and children with WS on two standardized assessments, one measuring overall intellectual ability and one assessing executive functioning, to provide basic descriptive information about the participants. The following research questions were evaluated in the present chapter:

(1) Do children with DS and children with WS differ with regard to overall intellectual ability?

Previous research has demonstrated that when matched for CA, children with DS earn significantly lower raw scores than children with WS on standardized assessments of overall intellectual ability (e.g., John \& 
Mervis, 2010; Klein \& Mervis, 1999; Rowe, 2007). Based on this literature I predicted:

Prediction: Children with WS will demonstrate higher General Conceptual Ability (GCA; similar to IQ) standard scores on the Differential Ability Scales-II (DAS-II) than will CA-matched children with DS.

(2) Are there differences in the verbal, nonverbal reasoning, and spatial abilities of CA-matched children with DS and children with WS?

Previous research has demonstrated that children with DS earn significantly lower raw scores on tests of language ability than do CAmatched children with WS (e.g., John \& Mervis, 2010; Klein \& Mervis, 1999; Rowe, 2007). Based on this literature I predicted:

Prediction: Children with WS will demonstrate higher DAS-II Verbal cluster standard scores than will CA-matched children with DS.

(3) Do children with DS and children with WS differ with regard to overall executive functioning ability?

(4) Are there differences in the inhibitory self-control, flexibility, and emergent metacognitive abilities of children with DS and children with WS?

\section{Method}

\section{Participant Eligibility}

Children were eligible to participate in the present study if they were between 42 and 71 months of age and had a genetically confirmed diagnosis of DS (trisomy 21) or WS (classic deletion). Exclusionary criteria included: 1) presence of another genetic or 
neurodevelopmental disorder (e.g., ASD) in addition to the diagnosis of DS or WS or 2) presence of organic brain damage.

\section{Participants}

The two groups of children who participated in the present project were recruited through a study of language and cognitive development of children with neurodevelopmental disorders conducted by Dr. Carolyn B. Mervis at the University of Louisville. The DS group included 21 children (13 boys, 8 girls) aged $3.51-5.88$ years $(M=4.97 ; S D=.74)$. The racial/ethnic background of the children in the DS group was: $90 \%$ Caucasian and 10\% mixed (more than one race/ethnicity).

The WS group included 21 children (13 boys, 8 girls) aged $3.52-5.94$ years $(M=$ $4.92 ; S D=.76)$ selected to match the DS group on CA $(p=.79)$ and gender from a larger pool of children with WS who participated in the project $(n=36)$. Of this larger pool of children with WS, four children were excluded due to incomplete data on the Social Referencing Task presented in Chapter III (one child due to uncorrected hearing loss, two children due to a phobia of loud noises, and one child who demonstrated an immediate reaction of intense fear to the robot). From the remaining 32 children, the final WS group was selected by choosing the child closest in age to each child with DS and, if possible, who was of the same gender. The racial/ethnic constitution of the children in the final WS group was: 67\% Caucasian, 5\% African-American, 9\% Asian, and 19\% mixed.

\section{Standardized Assessments}

Differential Ability Scales - II Early Years (DAS-II; Elliott, 2007). The DASII Early Years provides an assessment of general intellectual functioning for children aged $2 \frac{1}{2}-8$ years and was designed to provide specific information about an individual's 
strengths and weaknesses across a wide range of intellectual activities. To provide a description of the participants' intellectual abilities, I considered the DAS-II Early Years GCA $(M=100 ; S D=15)$ and the cluster standard scores (SSs) measuring Verbal, Nonverbal Reasoning, and Spatial abilities $(M=100 ; S D=15)$.

\section{Behavior Rating Inventory of Executive Functioning-Preschool (BRIEF-}

Preschool; Gioia, Espy, \& Isquith, 2003). The BRIEF-Preschool is a 63-item questionnaire for parents of children aged $2-5$ years regarding executive functioning behaviors in both home and school environments. Parents use a 3-point scale (never, sometimes, often) to indicate how often each item has been a problem in the past six months. The mean $T$ score for children in the general population is 50 , with a standard deviation of 10. On this measure, lower T scores indicate better executive functioning. To provide a description of the participants' executive functioning abilities, I considered the BRIEF-Preschool Global Executive Composite (GEC, $M=50 ; S D=10$ ) and the three index T scores measuring Inhibitory Self-Control, Flexibility, and Emergent Metacognition $(M=50 ; S D=10)$.

\section{Procedure}

Children completed a battery of cognitive and language assessments including an assessment of intellectual abilities (DAS-II). Parents completed several questionnaires including the BRIEF-Preschool. These measures were administered according to the test authors' instructions and were almost always completed within a few days of each other. 


\section{Data Analysis}

This study focused on comparing the intellectual and executive functioning abilities of children with DS and children with WS. Data from the DAS-II and BRIEFPreschool met the necessary statistical assumptions for use of parametric analyses.

\section{Results}

Descriptive statistics for the DAS-II GCA and cluster SSs and the BRIEFPreschool GEC and index T scores are presented in Table 2. Analyses were computed to compare the intellectual abilities of children with DS and children with WS. It was predicted that children with WS would demonstrate higher DAS-II GCAs than would children with DS. To evaluate this prediction, a one-tailed $t$-test was conducted. Results indicated that, as predicted, the mean GCA for the WS group was significantly higher than the mean GCA for the DS group $(t[40]=1.76, p=.045$, Cohen's $d=-.54$, one-tailed test). Follow-up $t$-tests were conducted on the DAS-II cluster SSs to determine the locus of the significant effect (two-tailed $\alpha_{\mathrm{fw}}=.017$; one-tailed $\alpha_{\mathrm{fw}}=.034$ ). It was predicted that children with WS would demonstrate higher DAS-II Verbal cluster SSs than would children with DS. To test this prediction, a one-tailed $t$-test was conducted. Results indicated that as predicted, the two diagnostic groups differed significantly as a function of DAS-II Verbal cluster SS $(t[40]=2.53, p=.008$, Cohen's $d=-.78$, one-tailed $)$, with children with WS earning higher SSs than did children with DS. Comparisons for DAS-II Nonverbal Reasoning cluster SS $(t[40]=1.90, p=.06$, Cohen's $d=-.59$, two-tailed) and DAS-II Spatial cluster SS $(t[40]=0.39, p=.70$, Cohen's $d=-.06$, two-tailed $)$ did not reach criterion for a significant difference between groups. 
Table 2

Descriptive Statistics for Performance on DAS-II and BRIEF-Preschool

\begin{tabular}{|c|c|c|c|c|c|c|}
\hline \multirow[b]{2}{*}{ Measure } & \multicolumn{3}{|c|}{ Down Syndrome } & \multicolumn{3}{|c|}{ Williams Syndrome } \\
\hline & $M$ & $S D$ & Range & $M$ & $S D$ & Range \\
\hline \multicolumn{7}{|l|}{ DAS-II (SSs) } \\
\hline Verbal cluster & 68.00 & 10.72 & $51-91$ & 76.90 & 12.05 & $51-95$ \\
\hline $\begin{array}{l}\text { Nonverbal Reasoning } \\
\text { cluster }\end{array}$ & 76.95 & 14.13 & $36-97$ & 84.38 & 10.97 & $63-107$ \\
\hline Spatial cluster & 51.19 & 11.72 & $34-70$ & 52.76 & 14.05 & $34-82$ \\
\hline GCA & 59.19 & 10.49 & $37-73$ & 65.05 & 11.03 & $44-81$ \\
\hline \multicolumn{7}{|l|}{ BRIEF-Preschool (Ts) } \\
\hline Inhibitory Self-Control & 53.76 & 12.19 & $34-88$ & 64.76 & 9.73 & $38-83$ \\
\hline Flexibility & $49.25^{+}$ & 8.48 & $36-71$ & 56.71 & 6.45 & $37-66$ \\
\hline Emergent & 65.67 & 13.28 & $38-92$ & 77.52 & 10.83 & $44-93$ \\
\hline \multicolumn{7}{|l|}{ Metacognition } \\
\hline Global Executive & 59.57 & 12.87 & $35-73$ & $71.85^{+}$ & 6.29 & $60-85$ \\
\hline Composite & & & & & & \\
\hline
\end{tabular}

${ }^{+} \mathrm{T}$ score for one child was excluded, as it was an extreme score (more than 3 box lengths from either the upper or the lower edge of the box plot)

To compare the overall executive functioning abilities of children with DS and children with WS, an independent samples $t$-test was computed. Results indicated that the mean Global Executive Composite T score for the children with DS was significantly lower, indicating better overall executive functioning abilities, than the mean for the 
children with WS $(t[38]=3.85, p<.001$, Cohen's $d=1.20)$. Follow-up $t$-tests were conducted on the BRIEF-Preschool index T scores to determine the locus of the significant effect (two-tailed $\alpha_{\mathrm{fw}}=.017$ ). Results indicated that as predicted, the two diagnostic groups differed significantly on all three indices: Inhibitory Self-Control $(t[40]$ $=3.23, p=.002$, Cohen's $d=1.00)$, Flexibility $(t[39]=3.18, p=.003$, Cohen's $d=0.99)$ and Emergent Metacognition $(t[40]=3.17, p=.003$, Cohen's $d=1.00)$, with the children with DS earning lower (better) T scores than the children with WS on all three indices.

\section{Discussion}

In the present chapter, four research questions were addressed. The first two concerned the performance of the two groups of children on the assessment of general intellectual ability. The results confirmed the predictions that children with WS would demonstrate better overall intellectual ability and higher verbal abilities than would children with DS; the mean GCA and mean Verbal cluster SS for the children with WS were significantly higher than the mean GCA and Verbal cluster SS for the children with DS. An examination of performance on the DAS-II Nonverbal Reasoning cluster SSs indicated a trend for children with WS to demonstrate better Nonverbal Reasoning SSs than did the children with DS. In contrast, the performance by children with DS and children with WS was comparable on the DAS-II Spatial cluster.

On average, the children with DS earned SSs in the mild developmental delay range for Verbal ability, the borderline to low average range for Nonverbal Reasoning ability, and the moderate developmental delay range for Spatial ability. For children with WS, standard scores on average were in the borderline to low average range for Verbal 
ability, the low average range for Nonverbal Reasoning ability, and the moderate developmental delay range for Spatial ability.

The present study is the first to examine intellectual abilities in preschoolers with DS using a standardized assessment that is both CA-appropriate and normed low enough such that the SSs from the measure are not confounded by floor effects. However, the findings relating to overall intellectual ability and verbal ability are consistent with prior findings in the literature from studies using raw scores from standardized assessments that are CA-appropriate. As indicated in the introduction to this chapter, results of such studies have demonstrated that preschool children with WS earn significantly higher overall intellectual ability SSs, receptive language raw scores, and expressive language raw scores when compared to CA-matched children with DS (Mervis \& John, 2010; Rowe, 2007). In addition, this same pattern of findings has been replicated when comparing CA-matched groups of school-age children with WS and school-age children with DS (Klein \& Mervis, 1999).

The third and fourth research questions were concerned with performance of the two groups on a parent-report measure of executive functioning ability. The results indicated that children with DS demonstrated better overall executive functioning ability than did children with WS. Follow up analyses showed that children with DS earned lower scores, indicating better performance, than the children with WS on indices of inhibitory self-control, flexibility, and emergent metacognition.

In the next chapter, I present data from a study I conducted comparing the responses of children with DS and children with WS on a social referencing task. More specifically, I sought to determine if between-group differences are present in the 
children's ability to use another person's appraisal of a situation as a guide for his or her own behavior (social referencing ability). Then, in Chapters IV, V, and VI, I compared the two groups of children on three abilities that are fundamental to this social referencing process. 


\section{CHAPTER III}

\section{THE REGULATORY FUNCTION OF SOCIAL REFERENCING}

As discussed in Chapter I, previous research on social referencing in populations with DD suggests that social referencing skills are atypical and may vary as a function of neurodevelopmental disorder (e.g., Dissanayake \& Crossley, 1996; Sigman, Walden, Kneips, \& Baxter, 1991; Warreyn, Roeyers, \& De Groote, 2005). To date, no data are available directly examining the regulatory function of social referencing in children with DS or children with WS. In the present chapter, I evaluate whether or not the behavioral responses of children with DS and children with WS differ on a standard social referencing task in which the experimenter reacts with joy or with fear to an ambiguous stimulus. The following research questions were evaluated separately based upon whether the adult was joyful or fearful:

(1) Do the two groups differ in terms of their rate of looks between the adult and the stimulus?

Previous research exists regarding the gazing behaviors of children with DS and children with WS. Rowe et al. (2005) demonstrated that toddlers with DS were more likely to shift attention between an adult and toys than were toddlers with WS. Based on this finding, I predicted: 
Prediction: Rate of looks between the experimenter and the ambiguous stimulus will be significantly higher for children with DS than for children with WS.

(2) Do the two groups differ in the length of the longest look they produced to the experimenter during her behavioral reaction to the ambiguous stimulus?

Mervis et al. (2003) examined length and intensity of looks by $8-43-$ month-old children with WS during a clinical genetics evaluation and found that these children were significantly more likely than CA-matched children with DD of mixed etiology to be rated as consistently looking at the clinical geneticist's face during the evaluation. In addition, children with WS were significantly more likely than children with DD of mixed etiology to be rated as intensely looking at the geneticist. Based on these findings, I predicted:

Prediction: The longest look produced by children with WS will be significantly longer than the longest look produced by children with DS.

(3) Do the two groups differ in the proportion of children who produced behaviors that indicate they both acknowledged the experimenter's behavioral response and mapped it to the ambiguous stimulus?

(4) Do the two groups differ in the proportion of children who superficially imitated the experimenter's response to the ambiguous stimulus?

Fidler, Hepburn, Most, and Philofsky (2007) conducted a study exploring rate of emotional responsivity of children with WS between 2 and 8 years of age relative to children with DD of mixed etiologies, $30 \%$ of whom had DS. Results indicated that children with WS were 3.4 times more likely to imitate 
the experimenter's facial displays and 5.2 times more likely to imitate their vocal displays than were children with DD of mixed etiologies. These findings remained true even when the children with DS were not included in the analyses, suggesting that the performance of children with DS was consistent with the mixed etiology group overall. Based on these findings, I predicted:

Prediction: The proportion of children who imitated the experimenter's reaction to the ambiguous stimulus will be significantly higher for children with WS than for children with DS.

(5) Do the two groups differ in the proportion of children who touched or attempted to touch the stimulus?

(6) Do the two groups differ in the proportion of children who produced behaviors that indicate they formed an opinion of the stimulus?

\section{Method}

\section{Participants}

Participants were 40 of the 42 children described in Chapter II. One girl with DS was excluded from the present study due to experimenter error. To keep the number of participants the same in each group, the data for the girl with WS closest in age to the excluded participant with DS were also excluded. The final sample included 20 children with DS (13 boys, 7 girls) aged $3.51-5.88$ years $(M=4.97 ; S D=0.76)$ and 20 children with WS (13 boys, 7 girls) aged $3.52-5.94$ years $(M=4.92 ; S D=0.78)$.

\section{Social Referencing Task}

The Social Referencing task (modeled after Campos \& Stenberg, 1981; Feinman, 1982; Klinnert et al., 1986; Tomasello, 2001) was designed to assess the child's ability to 
seek out and use information communicated through the behavioral reactions of the experimenter to guide his/her own evaluation of and behavior toward the ambiguous stimulus. Children were presented with an ambiguous stimulus paired with either a positive (joy) or negative (fear) behavioral reaction communicated by an experimenter. The experimenter's behavioral reaction included affective, vocal, and postural information. Each child's behavior was observed following two different experimenter behavioral responses (joy, fear).

Settings. The settings for this task were two familiar playrooms each observable via a one-way mirror. A child-height table was placed in one corner of each room. On top of the table was an ambiguous stimulus. Prior to the Social Referencing task, each child played with an adult in each of the playrooms to become familiar with the setting. During the actual Social Referencing trials, toys were placed on the floor of the room for the child and the experimenter to play with until the experimenter was able to get the child in the correct position for the trial to be started (see Figure 2 for diagram of room set up.) 


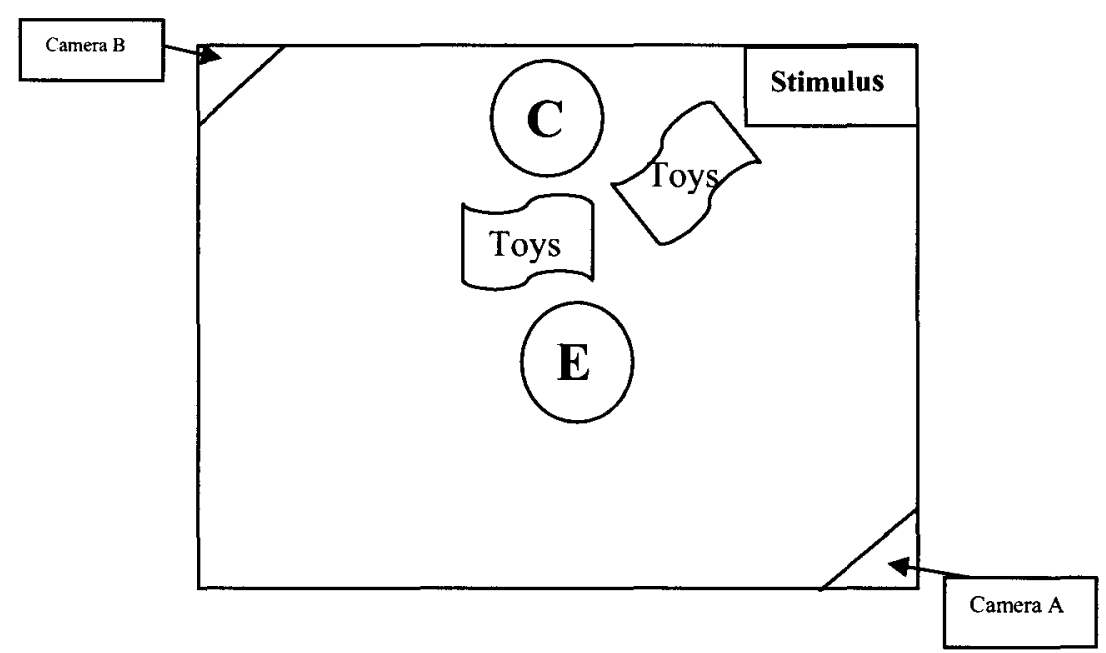

Figure 2. Diagram of Social Referencing task room setup. The experimenter (E) and the child $(\mathrm{C})$ played together with toys on the floor of the playroom until $\mathrm{E}$ could position $\mathrm{C}$ such that the stimulus on the child-height table was directly to the left of $\mathrm{C}$ and Camera $\mathrm{A}$ had a direct view of $\mathrm{C}$.

Stimuli. For each child, the experimental stimuli consisted of two remotecontrolled mechanical toy robots covered by a cloth. The robots varied in size, shape, movement pattern, and sound of the motor to maximize the perceptual cues that indicated that the objects moving under the cloth during the two trials were two different objects. An opaque cloth (one green, one gray) covered each of the remote-controlled robots. While it appeared that the cloth was draped over the object, the cloth was actually fixed to a base to ensure that the child would not be able to remove it. This method of presenting the stimuli was selected based on pilot testing the stimuli with children with WS and TD children in a similar age range. In the absence of a behavioral response from 
the adult, neither stimulus elicited a strong reaction from the children who participated in the pilot test.

Videotaped camera angles. The Social Referencing task was filmed as a picturein-picture video layout. The larger picture was focused on the child, the referent (stimulus), and the back of the experimenter. The smaller picture maintained a visual of the experimenter's face and torso.

Procedure. Each child participated in two trials, one with each stimulus. A different experimenter conducted each trial. For each child, one experimenter demonstrated the behavioral reaction of "joy" and the other demonstrated the behavioral reaction of "fear." For almost all children, the two trials took place on consecutive days. For the remaining children, the interval between trials was slightly longer. The experimenter and the child played together with the toys on the floor for approximately 2 minutes in a familiar playroom. This allowed the child time to become settled, to become disinterested in the toys on the floor, and to be positioned such that he or she would be able to see the ambiguous stimulus when it was activated.

Once the child was positioned correctly (see Figure 2), a second experimenter activated the robot from behind a one-way mirror. At this point, the robot, hidden under a cloth atop a child-height table, moved. After the robot was activated, the experimenter waited either $\sim 3$ seconds or until the child initiated eye contact (whichever came first) before beginning her specified behavioral reaction, allowing the child the opportunity to initiate eye contact with the experimenter. The experimenter's behavioral reaction, referred to as the Signal stage, lasted for $\sim 10$ seconds. During the Signal stage, the experimenter alternated gaze between the robot and the child. Following the Signal stage, 
the experimenter entered the Neutral stage, lasting $\sim 20$ seconds, during which the experimenter resumed looking at the toys on the floor to avoid giving the child further behavioral signals. During this Neutral stage, the experimenter refrained from interacting with the child unless the child became distressed or attempted to uncover the robot. If the child became distressed, the experimenter comforted the child and removed him or her from the playroom. If the child attempted to uncover the robot, the experimenter intervened to ensure the child was not successful in removing the cloth. The two Social Referencing trials were conducted in two different playrooms (both familiar to the child), on two different days, by two different experimenters, in an attempt to limit any carryover effect from the first trial. Order of room, experimenter, and behavioral response were counterbalanced within each diagnostic group.

Conditions. The experimenters demonstrated facial expressions based on descriptions provide by Izard (1971) and Ekman and Friesen (2003) for the respective emotions.

- Joy: "Corners of lips are drawn back and up. The mouth may or may not be parted with teeth exposed or not. A wrinkle (the naso-labial fold) runs down from the nose to the outer edge beyond the lip corners. The cheeks are raised. The lower eyelid shows wrinkles below it, and may be raised but not tense (Ekman \& Friesen, 2003, p. 112).” In addition, the experimenter vocalized "Ahhhh (joy) and giggling” and demonstrated a body posture indicating that she was relaxed and comfortable (e.g., clapping and leaning forward). 
- Fear: "The brows are raised and drawn together. The wrinkles in the forehead are in the center, not the entire forehead. The upper eyelid is raised, exposing sclera, and the lower eyelid is tensed and drawn up. The mouth is open and lips are either tensed slightly and drawn back or stretched and drawn back (Ekman \& Friesen, 2003, p. 63).” In addition, the experimenter vocalized "Gasp (fear)" and tensed her body drawing her arms to her chest and her knees closer together.

Coding. The Social Referencing trials were videotaped for coding purposes. The videotapes were coded to examine the experimenter's behavioral reactions, the child's gazing behavior, the child's approach to the robot, the child's imitation of the experimenter's behavioral reaction, and the child's behavioral reaction. To assess reliability, a second person independently coded six randomly selected tapes, three in each diagnostic group, which were stratified by age (one 3-year-old, one 4-year-old, and one 5-year-old).

Experimenter Behavioral Reaction. To confirm that the experimenter displayed the appropriate emotion, the experimenter's behavioral reaction during the 10 -second display was coded from the videotape by a coder blind to the conditions and hypotheses of the study using a 3-step system for coding facial expressions developed by Hiatt, Campos, and Emde (1979). The coding procedure occurred as follows:

1. Presence of Emotion: For each coding epoch, the coder indicated which of the six "primary" emotions (joy, surprise, anger, fear, disgust, and sadness) designated by Ekman and Friesen (1971) were present or displayed by the experimenter. Noting the presence 
of any of the six emotions allowed for the scoring of facial expression blends, either simultaneous or sequential, which the experimenter may have displayed while the child looked at her.

2. Predominance of Emotion: The rater made a forced choice indicating which of the emotions recorded to be present was predominant in the facial signal.

3. Intensity of Emotion: In the last step, a 5-point scale was used to judge the intensity of each emotion present in the experimenter's face. A score of 1 indicated that the emotion was barely detectable, while a score of 5 indicated that the rater could not imagine a face showing any greater intensity of the emotional expression being displayed naturally.

These data were evaluated to confirm that intensity of the experimenter's emotional display was similar across all participants. In addition to the target emotion, it was acceptable for the experimenter to demonstrate 'surprise' as long as the target emotion was reported to be the primary emotion. To be included in the study, the experimenter's predominant emotion (1) had to be the intended target emotion and (2) had to be coded as demonstrating an intensity rating of 4 or 5 . Percentage of agreement $(96.43 \%)$ and Cohen's kappa, $\kappa=.91$ indicated high reliability for which emotion(s) were present. High reliability was also observed (percentage of agreement $=100 \%, \kappa=1.00$ ) for primary emotion identified and for intensity of the predominant emotion. No trials were excluded due to errors in experimenter behavioral reaction. 
Gazing behavior. Children's gazing behavior was coded during the Ambiguous and Signal stages of the task using The Observer XT 10.0 (Noldus, 2010), a software program that allows for continuous coding of both state (records duration and frequency) and event (records frequency) behaviors. The videotapes were coded at 1/5 of the playback speed for when the child was looking at the Experimenter, the Stimulus, the Toys on the Floor, Away, or if the child's face was obstructed. A second coder, unaware of the hypotheses of the study, used this same procedure to assess reliability. Percentage of agreement $(99 \%)$ and Cohen's kappa, $\kappa=.99$, using a tolerance window of $500 \mathrm{ms,}$ indicated very high reliability for gazing behavior. Both the duration of the longest look to the experimenter and the rate of looks between the experimenter and stimulus per minute were calculated separately for each condition.

Acknowledgement and mapping of behavioral response. A composite variable was created to indicate whether or not children produced behaviors demonstrating that they both acknowledged the experimenter's behavioral response and mapped it to the stimulus. Children were coded as having mapped the experimenter's behavioral response to the stimulus if they either shifted their gaze at least once from the experimenter to the stimulus during the experimenter's behavioral display or produced verbalizations indicating that they understood the experimenter's behavior was about the stimulus.

In addition, children were coded as to whether or not they produced a behavior indicating that they acknowledged the emotion expressed by the experimenter. In the Joy condition, if the child smiled or produced a verbalization that referenced the experimenter's affective state (e.g., 'It is funny!'), he or she was coded as having acknowledged the experimenter's emotion. In the Fear condition, if the child became 
distressed, tried to comfort the experimenter, or tried to explain to the experimenter why the stimulus was not scary the child was coded as having acknowledged the experimenter's affective response. If the child received positive codes for both mapping the experimenter's emotion to the stimulus and acknowledging the emotion for a given condition (joy or fear), he or she was then coded as "yes" on the composite variable (acknowledge and map) for that condition. A second coder, not informed of the hypotheses of the study, used this same procedure to assess reliability. Percentage of agreement $(91.67 \%)$ and Cohen's kappa, $\kappa=.82$ indicated high reliability for the acknowledgement and mapping variable.

Imitation of behavioral response. Videotapes were also coded for superficial imitation of the experimenter's behavioral response. This variable represented situations in which the child demonstrated an affective/behavioral response because he or she was intentionally imitating the experimenter's behavioral response as opposed to actually experiencing the response him- or herself. Both the primary and secondary coders were blind to the hypotheses of the study. Percentage of agreement (91.67\%) and Cohen's kappa, $\kappa=.80$ indicated high reliability.

Touch stimulus. A dichotomous variable was created to indicate whether or not the child touched or attempted to touch the stimulus. Children were coded to have touched the stimulus if the experimenter stopped him or her before being able to touch it or if the child successfully touched it. A second coder, blind to the hypotheses of the study, used this same procedure to assess reliability. Percentage of agreement $(100.00 \%)$ and Cohen's kappa, $\kappa=1.0$ indicated very high reliability. 
Formation of opinion. The coder, using a dichotomous variable, recorded whether or not the child demonstrated behaviors that indicated that he or she formed an opinion regarding the stimulus. If the child formed an opinion, the coder also indicated whether the child's opinion was positive or negative. Both the primary and secondary coders were blind to the hypotheses of the study. Percentage of agreement $(91.67 \%)$ and Cohen's kappa, $\kappa=.83$ indicated high reliability.

\section{Data Analysis}

This study focused on comparing the behavioral reactions of children with DS and children with WS in two situations: (1) when the experimenter was joyful upon seeing an ambiguous stimulus, and (2) when the experimenter was fearful upon seeing an ambiguous stimulus. As the distributions for 'rate of looks between the experimenter and stimulus' and 'duration of longest look' violated the parametric assumptions of normality, Mann-Whitney $U$ tests were conducted. The remaining dependent variables included in the present chapter were dichotomous and did not violate the assumption of expected frequencies greater than 5 . As such, chi-square analyses were performed on the dichotomous variables.

\section{Results}

As order of condition was counterbalanced across children, analyses were computed to determine if order of condition affected children's performance on any of the variables included in this study. Analyses indicated no significant effect of order on any of the dependent variables (all ps $>.20$ ). Therefore, order was not included as a variable in any of the subsequent analyses. 


\section{Gazing Behavior}

Rate of Looking between Experimenter and Stimulus. Descriptive statistics for the gazing behavior variables as a function of condition are presented in Table 3 .

Table 3

Descriptive Statistics for Performance on Gazing Behavior Variables as a Function of Condition and Diagnostic Group

\begin{tabular}{|c|c|c|c|c|}
\hline \multirow[b]{2}{*}{ Measure } & \multicolumn{2}{|c|}{ Down Syndrome } & \multicolumn{2}{|c|}{ Williams Syndrome } \\
\hline & $M d n$ & Range & $M d n$ & Range \\
\hline \multicolumn{5}{|l|}{ Joy condition } \\
\hline Rate of Looks ${ }^{+}$ & 10.67 & $3.28-19.89$ & 6.72 & $0-18.86$ \\
\hline Duration of Longest & 2.25 & $0.58-6.62$ & 4.13 & $0.68-13.17$ \\
\hline \multicolumn{5}{|l|}{ Look (in sec.) } \\
\hline \multicolumn{5}{|l|}{ Fear condition } \\
\hline Rate of Looks ${ }^{+}$ & 9.98 & $3.14-18.00$ & 7.54 & $0-13.36$ \\
\hline Duration of Longest & 2.68 & $1.23-11.54$ & 4.33 & $0.91-8.67$ \\
\hline Look (in sec.) & & & & \\
\hline
\end{tabular}

${ }^{+}$Number of looks between Experimenter and Stimulus per minute

Mann-Whitney $U$ tests were conducted to compare the rate of looks between the experimenter and the stimulus for the children with DS in comparison to the children with WS in the Joy and Fear conditions $\left(\alpha_{\mathrm{fw}}=.025\right)$. As predicted, the distributions of rate of looks between the experimenter and the stimulus differed significantly for the two diagnostic groups with children with DS demonstrating higher rates of looking between the experimenter and the stimulus than did children with WS in both the Joy condition 
$(U=89.00, p=.002, r=-.48$, one-tailed test $)$ and the Fear condition $(U=121.00, p=$ $.02, r=-.34$, one-tailed test).

Duration of Longest Look. Mann-Whitney $U$ tests were also conducted to compare the duration of longest look to the experimenter between children with DS and children with WS in the Joy and Fear conditions $\left(\alpha_{\mathrm{fw}}=.025\right)$. In the Joy condition, the distributions of duration of longest look produced by the child did not reach criterion for a significant difference between diagnostic groups $(U=222.00, p=.11, r=.20$, onetailed test). However, as predicted, the distributions of duration of longest look differed significantly between the two diagnostic groups in the Fear condition, with the duration of the longest look being longer for children with WS than for children with DS $(U=$ $218.00, p=.01, r=.35$, one-tailed test).

\section{Acknowledgment and Mapping of Behavioral Reaction}

To examine the relation between diagnostic group and acknowledgement and mapping of the experimenter's behavioral display, two chi-square statistics were calculated $\left(\alpha_{\mathrm{fw}}=.025\right)$. The relation between these variables was significant in the Joy condition (see Table $4 ; \chi^{2}[1]=5.01, p=.025$ ). The odds ratio indicated that children with DS were 4.50 times more likely than were children with WS to acknowledge and map the experimenter's behavioral display in the Joy condition $\left(C I_{.95}=[1.17,17.37]\right)$. In contrast, the relation between diagnostic group and acknowledgement and mapping of the experimenter's behavioral display did not reach criterion for a significant association in the Fear condition (see Table $5 ; \chi^{2}[1]=2.51, p=.11$, odds ratio $=2.79, C I_{.95}=[0.77$, $10.04])$ 
Table 4

Number of Children who 'Acknowledged and Mapped' in the Joy Condition as a Function of Diagnostic Group

\begin{tabular}{lccc}
\hline & Down Syndrome & & \multicolumn{2}{c}{ Williams Syndrome } \\
\cline { 1 - 2 } Did Not Acknowledge/Map & 5 & 12 \\
Acknowledged/Mapped & 15 & 8 \\
\hline
\end{tabular}

Table 5

Number of Children who 'Acknowledged and Mapped' in the Fear Condition as a Function of Diagnostic Group

Down Syndrome Williams Syndrome

\begin{tabular}{lcc} 
Did Not Acknowledge/Map & 8 & 13 \\
Acknowledged/Mapped & 12 & 7 \\
\hline
\end{tabular}

\section{Imitation of Behavioral Reaction}

Finally, chi-square statistics were computed to examine the relation between diagnostic group and behavioral response $\left(\alpha_{\mathrm{fw}}=.025\right)$. This relation did not meet criterion for a significant association in the Joy condition (see Table $6 ; \chi^{2}[1]=2.06, p=.08$, odds ratio $=0.21, C_{.95}=[0.02,2.08]$, one-tailed test $)$. In the Fear condition, as predicted, the relation between these variables was significant (see Table $7 ; \chi^{2}[1]=4.80, p=.02$, onetailed test), with children with WS 6.01 times more likely than children with DS to imitate the experimenter's behavioral response $\left(C I_{.95}=[1.08,33.28]\right)$. 
Table 6

Number of Children who 'Imitated' the Experimenter's Behavioral Response in the Joy Condition as a Function of Diagnostic Group

\begin{tabular}{lccc}
\hline & Down Syndrome & & Williams Syndrome \\
\cline { 1 - 2 } Did Not Imitate & 19 & 16 \\
Imitated & 1 & 4 \\
\hline
\end{tabular}

Table 7

Number of Children who 'Imitated' the Experimenter's Behavioral Response in the Fear Condition as a Function of Diagnostic Group

\begin{tabular}{lccc}
\hline & Down Syndrome & & \multicolumn{2}{c}{ Williams Syndrome } \\
\cline { 1 - 2 } Did Not Imitate & 18 & 12 \\
Imitated & 2 & 8 \\
\hline
\end{tabular}

\section{Touch Stimulus}

Two chi-square statistics were performed to examine the relation between diagnostic group and touching the stimulus in the Joy condition and in the Fear condition $\left(\alpha_{\mathrm{fw}}=.025\right)$. The relation between these variables was not significant in the Joy condition (see Table $8 ; \chi^{2}[1]=3.96, p=.047$, odds ratio $\left.=4.0, C I_{.95}=[0.98,16.27]\right)$. However, this relation was significant in the Fear condition (see Table $9 ; \chi^{2}[1]=5.58, p=.02$ ). The odds ratio indicated that children with DS were 5.67 times more likely than were children with WS to touch the stimulus in the Fear condition $\left(C I_{.95}=[1.25,25.61]\right)$. 
Table 8

Number of Children who Touched the Stimulus in the Joy Condition as a Function of Diagnostic Group

\begin{tabular}{lccc}
\hline & Down Syndrome & & Williams Syndrome \\
\cline { 1 - 2 } Did Not Touch & 4 & 10 \\
Touched & 16 & 10 \\
\hline
\end{tabular}

Table 9

Number of Children who Touched the Stimulus in the Fear Condition as a Function of Diagnostic Group

\begin{tabular}{|c|c|c|}
\hline & Down Syndrome & Williams Syndrome \\
\hline Did Not Touch & 10 & 17 \\
\hline Touched & $10^{+}$ & 3 \\
\hline
\end{tabular}

${ }^{+}$One child approached the stimulus and threw it across the room

\section{Formation of an Opinion}

Two chi-square statistics were calculated to examine the relation between diagnostic group and whether or not the child formed an opinion $\left(\alpha_{\mathrm{fw}}=.025\right)$. The relation between these variables did not reach criterion for a significant association in the Joy condition (see Table $10 ; \chi^{2}[1]=1.13, p=.29$, odds ratio $=2.15, C I_{.95}=[0.52,9.00]$ ). Descriptive statistics addressing the emotional valence of the opinions that were formed indicated that most children with DS (15/16) and most children with WS (11/13) who were rated to have formed any opinion of the stimulus were rated to have formed a positive opinion.

In contrast, the relation between diagnostic group and formation of opinion was significant in the Fear condition (see Table $11 ; \chi^{2}[1]=6.47, p=.01$ ) with children with 
DS 5.57 times more likely than were children with WS to form an opinion of the stimulus $\left(C I_{.95}=[1.42,21.86]\right)$. Descriptive statistics addressing the emotional valence of the opinions that were formed indicated that despite the experimenter's fearful reaction, only a small proportion of the children who did form an opinion in the Fear condition $(5 / 13$ children with DS and $2 / 5$ children with WS) were rated as having formed a negative opinion of the stimulus. Thus, the majority of children who formed an opinion of the stimulus in the Fear condition were rated as having formed a positive opinion.

Descriptive information was also collected to provide more specific information regarding the responses of children who formed a positive opinion in the Fear condition (DS: $n=8$, WS: $n=3$ ). For children with DS, the results were as follows: four children saw the experimenter's fearful reaction and then approached the stimulus, one child watched the experimenter's fearful reaction for its entire duration and then approached the stimulus, one child watched the experimenter's fearful reaction for its entire duration and slyly approached the stimulus while checking to make sure the experimenter was not looking, one child decided the stimulus was an elephant and maintained this opinion even after seeing the fearful reaction, and one child communicated to the experimenter that she should not be afraid and approached the stimulus to show her it was okay. For children with WS, the results were as follows: two children saw the experimenter's fearful reaction and then approached the stimulus and one child watched the experimenter's fearful reaction for its entire duration and then approached the stimulus. 
Table 10

Number of Children who 'Formed an Opinion' of the Stimulus in the Joy Condition as a Function of Diagnostic Group

\begin{tabular}{lccc}
\hline & Down Syndrome & & Williams Syndrome \\
\cline { 1 - 3 } Did Not Form an Opinion & 4 & 7 \\
Formed an Opinion & 16 & 13 \\
\hline
\end{tabular}

Table 11

Number of Children who 'Formed an Opinion' of the Stimulus in the Fear Condition as a Function of Diagnostic Group

Down Syndrome Williams Syndrome

\begin{tabular}{lcc}
\hline Did Not Form an Opinion & 7 & 15 \\
Formed an Opinion & 13 & 5 \\
\hline
\end{tabular}

\section{Discussion}

In the present study, I addressed six research questions based upon whether the experimenter's reaction to the ambiguous stimulus was joyful or fearful. The first research question was concerned with the rate of looks between the experimenter and the stimulus for children with DS and children with WS in response to the experimenter's behavioral reactions. The results confirmed the prediction that the rate of looks between the experimenter and the ambiguous stimulus would be significantly higher for children with DS than for children with WS; the distribution of rate of looks for children with DS was significantly higher than the distribution of rate of looks for children with WS in both the Joy condition and the Fear condition. 
The second research question was concerned with the duration of longest look to the experimenter by children with DS and children with WS. The prediction that the longest look to the experimenter produced by children with WS would be significantly longer than the longest look to the experimenter produced by children with DS was confirmed in the Fear condition but not in the Joy condition; the distribution of duration of longest look produced by children with WS was significantly higher than the distribution of longest look for children with DS in the Fear condition but not in the Joy condition.

The third research question addressed the likelihood that the two groups of children would acknowledge the adult's reaction and map it to the stimulus. Results indicated a significant difference between the two groups of children in the Joy condition with children with DS $(75.0 \%)$ more likely than were than children with WS (40.0\%) to acknowledge the experimenter's reaction and map it to the stimulus. In the Fear condition, children with DS $(60.0 \%)$ were more likely than were children with WS $(35.0 \%)$ to acknowledge the experimenter's reaction and map it to the stimulus; however, this difference did not reach criterion for a significant difference between groups.

The fourth research question addressed the likelihood that the two groups of children would imitate the experimenter's reaction to the stimulus. The prediction that children with WS would be significantly more likely than children with DS to imitate was not confirmed in the Joy condition but was confirmed in the Fear condition. The relation between likelihood of imitating the experimenter's reaction and diagnostic group demonstrated a trend for children with WS $(20.0 \%)$ to be more likely than were children with DS (5.26\%) to imitate the experimenter's joyful reaction. This relation was 
significant in the Fear condition as children with WS $(40.0 \%)$ were more likely than were children with DS (11.11\%) to imitate the experimenter's reaction.

The fifth research question considered the likelihood that the two groups of children would approach the ambiguous stimulus. Results indicated that there was a marginally significant relation between touching the stimulus and diagnostic group in the Joy condition with $80 \%$ of children with DS and $50 \%$ of children with WS having touched or attempting to touch the stimulus $(p=.047)$. The relation between these variables was significant in the Fear condition with children with DS (50.0\%) more likely than were children with WS $(15.0 \%)$ to touch the stimulus.

The sixth research question addressed the likelihood that the two groups of children would form an opinion of the stimulus. While children with DS (80.0\%) were more likely than were children with WS (65.0\%) to form an opinion of the stimulus in the Joy condition, this difference did not reach criterion for a significant difference between groups. In addition, results indicated that the majority of both children with DS (93.75\%) and children with WS (84.52\%) who formed any opinion of the stimulus formed a positive opinion. In the Fear condition, the likelihood of forming an opinion also varied significantly as a function of diagnostic group with children with DS (60.0\%) more likely than were children with WS (35.0\%) to form any opinion. However, few of the children with DS (38.46\%) and children with WS (40.0\%) who formed any opinion of the stimulus formed a negative opinion. Closer examination of the behavioral responses of the children who formed a positive opinion of the fearful stimulus indicated that only one child, a child with DS, communicated to the experimenter that her fearful reaction was 
incorrect. Most of the children with DS (6/8) and children with WS (2/3) saw the experimenter's fearful reaction and got up to approach the stimulus.

Overall, the results of the present study demonstrate that the children with DS shifted their gaze between the experimenter and the stimulus more frequently than did the children with WS. However, the children with DS were still more likely to touch the stimulus when the experimenter was fearful than were the children with WS and frequently formed a positive opinion of the stimulus. Although the children with WS were less likely to approach the stimulus in the Fear condition than were the children with DS, they were more likely to produce "long looks" watching the experimenter's fearful reaction, more likely to imitate the fearful reaction, and less likely to form an opinion of the stimulus than were the children with DS. Similarly to the children with DS, when children with WS did form an opinion in the Fear condition, it was more likely to be positive than negative. Despite clearly seeing the experimenter's fearful reaction, the majority of children in both groups who formed an opinion approached the stimulus without communicating disagreement with the experimenter or demonstrating behaviors suggesting they saw through her fearful reaction.

As these results indicate, in response to the experimenter's expression of fear, few children in either diagnostic group demonstrated a reaction toward the stimulus indicative of comprehending the communicative significance of the experimenter's reaction and using this information to guide his or her own behavior. As performance on the Social Referencing task requires a child to coordinate multiple abilities, it is difficult to specify from this task alone what kinds of specific challenges children in the two groups are encountering in the social referencing process. To help provide insight into potential 
areas of difficulty, in the next three chapters (Chapters IV, V, and VI) I examine three abilities that are fundamental to the social referencing process. In Chapter IV, I present the results of a study comparing the ability of children with DS and children with WS to initiate looks to the experimenter in three situations in which the child's attention was first focused on an object. In such a situation, the child must shift his or her attention from the object to the experimenter in order to gain access to the experimenter's message. As such, initiating eye contact with an adult during interactions with objects is one of the fundamental abilities involved in the social referencing process. 


\section{CHAPTER IV}

\section{INITIATING EYE CONTACT}

During the first two years of life, children develop the ability to use social referencing as a regulatory function. In other words, children develop the ability to reference another person and use that person's appraisal of a situation when forming their own opinion, particularly in situations of ambiguity or uncertainty. Human beings are skillful at examining a situation based on another person's point of view, in that they are able to determine what other people are perceiving, intending, desiring, knowing, and believing (Tomasello, Carpenter, Call, Behne, \& Moll, 2005). One of the earliest mental states understood by TD children is "intention." This ability is often argued to be the foundation of "mind reading," or theory of mind ability (Tomasello et al., 2005), and to be evidence of the child's recognition of people as subjective intentional beings (Meltzoff, 1995; Thompson, 2006)

Children's conceptual understanding of people as subjective intentional agents develops over time. One of the earliest developmental stages of the understanding of intentions involves a child's ability to realize that people's actions have goals or have a purpose behind them (Tomasello et al., 2005). The results of previous research demonstrate that 18-month-old TD children understand that people have goals and intentions that inanimate objects do not have. Furthermore, TD 18-month-olds are able to distinguish between another person's intentional and accidental actions (Meltzoff, 1995). The foundational skills for understanding people as subjective agents are present in even 
younger children. For example, Phillips, Baron-Cohen, and Rutter (1992) demonstrated that when the goal of an adult's action is ambiguous, TD infants as young as 9 months of age looked to the adult's face. By looking to the adult's face in this scenario, the child is able to acquire more information about the intention of the adult's action.

In order to examine children's ability to initiate eye contact with an adult, an important underlying ability involved in social referencing, I investigated the looking behavior of preschoolers with DS or WS in three situations in which looking at the experimenter would require the child to shift his or her attention away from a toy of interest. The following research questions were evaluated:

(1) Do preschoolers with DS and preschoolers with WS differ in their likelihood of looking at the experimenter in response to a blocking, teasing, or giving gesture?

(2) Are there differences in the use of eye contact by children with DS and children with WS in response to the experimenter's gestures?

Results of previous studies have indicated that in triadic situations, children with WS evidence impairments in their use of eye gaze relative to both MA-matched TD children and CA- and MA-matched children with DS (e.g., Laing et al., 2002; Rowe et al., 2005). Based on these findings, I predicted:

Prediction: Children with DS will be more likely to look at the experimenter in response to her Giving gesture than will be children with WS. 


\section{Method}

\section{Participants}

Participants were the 42 children described in Chapter II. One boy with DS consistently cried in response to the Teasing condition. For this reason, his data, as well as those of the boy with WS closest in age to him, were excluded from the Teasing condition analyses.

\section{Goal Ambiguity Task}

The children were administered a task developed by Phillips et al. (1992). This task, which will be referred to as the Goal Ambiguity task, was designed to assess the child's use of gaze in response to gestures made by an adult that vary with regard to the ambiguity of the adult's intention.

Setting. The task trials were administered to the child during two structured play interactions at a table, each with a different experimenter and on a different day. The experimenter sat diagonally across the table from the child.

Videotaped Camera Angles. The Goal Ambiguity task was filmed using a split screen video layout with one video screen larger than the other. The larger picture was focused on the front of the child, the table, and the back of the experimenter. The smaller picture was focused on the front of the experimenter.

Procedure. The experimenter and child played at the table together with various developmentally appropriate toys, one toy at a time. The experimenter would pull out a toy and play with it to develop the child's interest in the toy. Once the child was interested, the experimenter encouraged the child to play with the toy by handing it (or starting to hand it) to the child. Two of the gestures (blocking and teasing) demonstrated 
by the experimenter were intended to create a situation that would encourage the child to look at the experimenter, as the intention behind the experimenter's gesture was ambiguous. The intention behind the experimenter's third gesture (give) was not ambiguous and therefore was not intended to draw the child's attention to the experimenter.

The three conditions were administered as follows:

- Blocking: In the context of a play activity, the experimenter encouraged the child to play with a developmentally appropriate toy. Once the child was interested in the toy, the experimenter handed the toy to the child. When the child was engaged with the toy both manually and visually, the experimenter covered the child's hands with her own hands, preventing the child from further activity. This gesture was held for 4 seconds while looking at the child with neutral affect or until the child initiated eye contact (whichever came first). The child's eye contact with the experimenter was noted during this 4-second period, as were any other responses (both verbal and nonverbal) he or she made. Each child was administered six Blocking trials ( 3 trials with one experimenter on Day 1 and 3 trials with the second experimenter on Day 2).

- Teasing: The experimenter encouraged the child to play with a developmentally appropriate toy within the context of a play activity. Once the child was interested in the toy, the experimenter offered the toy to the child. As the child reached for the toy, the experimenter quickly withdrew it and held the toy out of the child's reach for 4 seconds while 
looking at the child with neutral affect. After 4 seconds had elapsed or the child initiated eye contact (whichever came first), the child was given the toy. The child's eye contact with the experimenter was noted during this 4-second period, as were any other responses (both verbal and nonverbal) he or she made. Each child was administered six Teasing trials ( 3 trials with one experimenter on Day 1 and 3 trials with a second experimenter on Day 2).

- Giving: In the context of a play activity, the experimenter encouraged the child to play with a developmentally appropriate toy. Once the child was interested in the toy, the experimenter handed the toy to the child with neutral affect and the child was allowed to play with it. Each child was administered six Giving trials ( 3 trials with one experimenter on Day 1 and 3 trials with a second experimenter on Day 2).

Coding. A primary coder watched the videotapes and assessed whether or not the child made eye contact with the experimenter within 4 seconds of the experimenter's action. Children's eye contact with the experimenter was coded using The Observer XT 10.0 (Noldus, 2010). The latency between the start of the trial (see definitions below) and the onset of eye contact made by the child was calculated. The child was considered to have made eye contact with the experimenter if eye contact was made within 4 seconds of the start of the trial. A variable was then calculated indicating the proportion of trials during which the child made eye contact with the experimenter for each condition. The start of the trial was defined as follows: (1) Blocking condition: the point at which the experimenter placed her hands over the child's hands, (2) Teasing condition: the point at 
which the experimenter pulled the toy away from the child, (3) Giving condition: the point at which the child placed his or her hand on the toy. Percentage of agreement $(92.59 \%)$ and Cohen's kappa, $\kappa=.85$ indicated high reliability.

\section{Data Analysis}

This study focused on examining the likelihood of looks to the experimenter in response to three gestures. Data from this task violated the parametric assumption of normality. As such, Wilcoxon signed-rank test and Mann-Whitney U test statistics were computed.

\section{Results}

Due to administration errors, problems with videotape quality, or child refusal, data for 9 of 240 trials in the Blocking condition and 14 of 240 trials in the Teasing condition could not be scored. Accordingly, performance on the Goal Ambiguity task was measured by proportion of trials on which the child looked at the experimenter within 4 seconds of the start of the trial rather than number of trials the child looked at the experimenter. Descriptive statistics for proportion of trials on which children with DS or children with WS looked at the experimenter's face within 4 seconds of the onset of the trial for each condition are reported in Table 12. 
Table 12.

Descriptive Statistics for Proportion of Trials on which Children Looked at the Experimenter's Face within Four Seconds of Trial Onset in the Goal Ambiguity Task

\begin{tabular}{lccccc}
\hline & \multicolumn{2}{c}{ Down Syndrome } & & \multicolumn{2}{c}{ Williams Syndrome } \\
\cline { 2 - 3 } \cline { 5 - 6 } Measure & $M d n$ & Range & & $M d n$ & Range \\
\hline Ambiguous & & & & $0.00-1.00$ \\
Blocking & 0.80 & $0.17-1.00$ & & 0.83 & $0.00-1.00$ \\
Teasing & 0.67 & $0.17-1.00$ & & 0.83 & \\
Non-Ambiguous & & & & $0.00-0.67$ \\
Giving & 0.33 & $0.00-1.00$ & & 0.33 & 0.00 \\
\hline
\end{tabular}

\section{Within-Group Comparisons across Conditions}

Wilcoxon signed-rank test statistics were calculated to compare performance on the two ambiguous gesture conditions of the Goal Ambiguity task $\left(\alpha_{\mathrm{fw}}=.025\right)$. Separate analyses were computed for children with DS and children with WS. The differences in distributions of performance on the Blocking and Teasing conditions did not reach criterion for a statistical difference for either children with $\operatorname{DS}(T=92.50, p=.20, r=$ $.29)$ or children with WS $(T=63.00, p=.79, r=-.06)$.

To compare the looking behavior of children with DS and children with WS between each of the ambiguous gesture conditions (Blocking and Teasing) and the nonambiguous gesture condition (Giving), Wilcoxon signed-rank test statistics were calculated separately for each syndrome group $\left(\alpha_{\mathrm{fw}}=.013\right)$. Results comparing performance on the Blocking condition to performance on the Giving condition indicated that both children with DS $(T=15.00, p=.003, r=-.65)$ and children with WS $(T=7.00$, 
$p<.001, r=-.80)$ looked at the experimenter on a larger proportion of the trials in the Blocking condition than in the Giving condition. Similarly, results indicated that both children with DS $(T=3.00, p<.001, r=-.81)$ and children with WS $(T=5.00, p<.001$, $r=-.82)$ looked at the experimenter on a larger proportion of the trials in the Teasing condition than in the Giving condition.

\section{Between Group Comparisons across Conditions}

Mann-Whitney $U$ test statistics were computed to examine performance in the two ambiguous gesture conditions as a function of diagnostic group $\left(\alpha_{f w}=.025\right)$. The distributions for the proportion of trials on which the child made eye contact in the Blocking condition $(U=207.00, p=.73, r=-0.05)$ and the Teasing condition $(U=$ 200.50, $p=.99, r=0.002$ ) did not react criterion for a significant difference between groups. To consider the performance of the two diagnostic groups in the unambiguous gesture condition, a Mann-Whitney $U$ test was conducted with proportion of trials on which the child made eye contact with the experimenter in the Giving condition as the dependent variable. As predicted, the distributions for the proportion of trials on which the child made eye contact in the Giving condition differed significantly between the two diagnostic groups $(U=304.00, p=.02, r=-0.33$, one-tailed $)$, with children with DS looking at the experimenter on a larger proportion of the Giving trials than did children with WS.

\section{Discussion}

In the present study, two research questions were addressed. The first was concerned with the likelihood of looking at an adult in response to three types of gestures. The results indicated that both children with DS and children with WS were significantly more likely to look at the experimenter in response to her blocking and teasing gestures 
than in response to her giving gestures. These findings demonstrate that both groups of children were responsive to the design manipulation, as the blocking and teasing gestures were designed to create a situation in which the child would be expected to shift his or her attention from the object of interest to the experimenter.

This pattern of looking more frequently in response to ambiguous gestures than to non-ambiguous gestures was argued by Phillips and colleagues (1992) to be evidence that the purpose of the child's look is information-seeking, which indicates the child's attempt to "clarify" the adult's goal. In the study conducted by Phillips and colleagues (1992), both TD infants ( $n=18$; mean $C A=14.2$ months, range: $9-18$ months) and children with DD ( $n=18$; mean $C A=60.4$ months, range: $40-86$ months), six of whom had DS, demonstrated this same pattern of findings. In contrast, the participants with autism $(n=$ 18; mean $C A=53.3$ months, range: $36-70$ months), who were CA- and MA-matched to the children with DD, looked at the experimenter's hand or the toy rather than the experimenter's face.

Direct comparisons between the looking behavior of children with DS and children with WS confirmed the prediction that children with DS would be more likely than would children with WS to look at the experimenter when the intention behind her gesture was not ambiguous; the distribution of the likelihood of looking at the experimenter in the Giving condition for children with DS was significantly higher than was the corresponding distribution for children with WS. This finding is consistent with that of Rowe et al. (2005), who found that children with WS were significantly less likely to initiate DJA acts or shift gaze between an object and an adult than were CA-, DQ-, and expressive vocabulary size-matched children with DS. In the present study, comparisons 
of the distributions of the likelihood of looking at the experimenter in response to the experimenter's ambiguous gestures (Blocking and Teasing conditions) did not reach criterion for a significant difference between the two groups of children.

When one considers the social referencing process, after the child shifts his or her attention to the experimenter to obtain the message, the child must then be able to identify the focus of the experimenter's attention by following her gaze to determine the referent of interest. In the next chapter, I present the results of a study I conducted to evaluate children's ability to follow another person's gaze, the fundamental ability involved in linking the experimenter's reaction to an object when the child's attention is first drawn to the experimenter. 


\section{CHAPTER V}

\section{GAZE FOLLOWING}

As discussed in Chapter I, the ability to follow another person's gaze allows the child to determine what the adult's reaction is about (Brooks \& Meltzoff, 2002; Moses, Baldwin, Rosicky, \& Tidball, 2001; Repacholi, 1998). At about 10 months of age, TD children will selectively follow changes in another person's eye gaze (e.g., Brooks \& Meltzoff, 2002; Corkum \& Moore, 1995). In the present chapter, in order to examine the ability to follow another person's gaze, I investigated the likelihood that children with DS and children with WS would follow another person's head turn when her eyes were open vs. when her eyes were closed. The following research questions were evaluated:

(1) Are children with DS and children with WS more likely to look in the same direction as an adult's head turn when the adult's eyes are open in comparison to when her eyes are closed?

(2) Are there differences between children with DS and children with WS in the likelihood of looking in the same direction as an adult when her head turns and her eyes are open?

John and Mervis (2010) conducted a study exploring the ability of preschoolers with DS and preschoolers with WS to comprehend the communicative intent behind pointing and gaze-shifting gestures. Results indicated that despite significantly lower overall intellectual ability and language scores, significantly more children with DS (60.0\%) as compared to 
children with WS (26.7\%) followed a communicative gesture to find a hidden object at a rate significantly higher than chance. Based on this finding, I predicted:

Prediction: Children with DS will be more likely than will children with WS to look in the same direction as an adult when her head turns and her eyes are open.

\section{Method}

\section{Participants}

Participants were the 42 children described in Chapter II.

\section{Gaze Following Task}

The children were administered a Gaze Following task (modeled after Brooks \& Meltzoff, 2002; Carpenter, Nagell, \& Tomasello, 1998) which was designed to examine the child's ability to monitor looking/gazing behavior. More specifically, this task provides information as to whether following an adult's gaze reflects an understanding of the gazer's focus of attention.

Setting. The task trials were administered to the child during two structured play interactions at a table, each with a different experimenter and on a different day. The experimenter sat diagonally across the table from the child.

Videotaped Camera Angles. The Gaze Following task was filmed using a split screen video layout with one video screen larger than the other. The larger picture was focused on the front of the child, the table, and the back of the experimenter. The smaller picture was focused on the front of the experimenter. 
Procedure. The experimenter and child played at a table with a series of developmentally appropriate toys. Before the start of each head turn, the experimenter removed the toy the child had been playing with from his or her view. Next, the experimenter made eye contact with the child to ensure that each child began the trial in a controlled manner. After eye contact had been established, the experimenter turned her head (and eyes) toward a target to either her left or her right while demonstrating the appropriate cue in conjunction with a subtle vocalization ("Oh, hmm"). The experimenter demonstrated one of two cues:

- Eyes Open: The experimenter turned her head and eyes toward the object with eyes open and said "Oh, hmm." The experimenter fixated on the target for 5 seconds. After the 5 seconds had elapsed, the experimenter returned to midline, made eye contact with the child, and resumed the play interaction.

- Eyes Closed: The experimenter established eye contact with the child, closed her eyes, and turned her head toward the object and said "Oh, hmm." The experimenter maintained this position for 5 seconds. After the 5 seconds had elapsed, the experimenter returned to midline, opened her eyes, made eye contact with the child, and resumed the play interaction.

Coding. A primary coder coded all of the videotapes. The coder was only able to see the larger of the two video screens (the one focused on the front of the child) and therefore was blind with regard to the condition (open vs. closed eyes) and direction of the experimenter's head turn. The targets were not visible in the video. However, the coder was informed that targets were located on the walls to both the left and the right 
between the child and the experimenter. The coder then scored each trial for whether or not the child intentionally looked for a target. If the coder indicated that the child intentionally looked for a target, she was asked also to indicate if the child looked at the target on the left or the target on the right.

After all of the trials were coded, the coder then watched the tape a second time with both video screens visible to determine if the target the child looked at was the correct target, that is if it was the same target the experimenter turned her head toward. Of 252 trials, there were 7 trials in the Closed Eyes condition ( 4 trials by children with DS and 3 trials by children with WS) and 4 trials in the Open Eyes condition ( 3 trials by children with DS and 1 trial by a child with WS) on which the child turned his or her head in the opposite direction of the experimenter. A variable ("follow") was computed indicating the number of trials during which the child looked at the correct target within 5 seconds of the experimenter's head turn, separately for the Eyes Open condition and the Eyes Closed condition. To assess reliability a second person independently coded three randomly selected tapes stratified by participant age (one 3-year-old, one 4-year-old, and one 5-year-old.) for each diagnostic group. Percentage of agreement (97.8\%) and Cohen's kappa, $\kappa=.96$ indicated very high reliability.

\section{Data Analysis}

This study focused on examining the likelihood of following another person's head turn paired with either open eyes or closed eyes. Data from this task violated the parametric assumption of normality. As such, Wilcoxon signed-rank test and MannWhitney U test statistics were computed. 


\section{Results}

As order of condition and direction of adult's look were counterbalanced, analyses were computed to determine if order of Eyes Open or Eyes Closed trials and order of look to left or look to right affected children's following performance. Analyses indicated no significant effect of order $(p=.77)$ or direction of adult's look $(p=.81)$ on the dependent variable. Therefore, order was not included as a variable in any of the subsequent analyses.

Descriptive statistics for performance on the Eyes Open and Eyes Closed conditions are reported in Table 13. To examine following as a function of condition, Wilcoxon signed-rank tests were computed separately for children with DS and children with WS $\left(\alpha_{\mathrm{fw}}=.025\right)$. Results indicated that the distributions of following differed significantly as a function of condition for both children with DS $(T=2.0, p<.001, r=$ $.87)$ and children with WS $(T=4.00, p=.001, r=.75)$. For both diagnostic groups, children were significantly more likely to follow the experimenter's head turn in the Eyes Open condition in comparison to the Eyes Closed condition.

\section{Table13}

Descriptive Statistics for 'Following' as a Function of Diagnostic Group in the Gaze Following Task

\begin{tabular}{lccccc}
\hline & \multicolumn{2}{c}{ Down Syndrome } & & \multicolumn{2}{c}{ Williams Syndrome } \\
\cline { 2 - 3 } \cline { 5 - 6 } Measure & $M d n$ & Range & & $M d n$ & Range \\
\hline Eyes Open Follow & 5.00 & $1.00-6.00$ & & 4.00 & $0.00-6.00$ \\
Eyes Closed Follow & 1.00 & $0.00-4.00$ & & 0 & $0.00-3.00$ \\
\hline
\end{tabular}


Mann-Whitney U tests were computed to compare the following behavior of children with DS and children with WS in the Eyes Closed condition and in the Eyes Open condition $\left(\alpha_{\mathrm{fw}}=.025\right)$. The distributions of performance in the Eyes Closed condition between children with DS and children with WS did not reach criterion for a significant difference between diagnostic groups $(U=270.00, p=.16, r=.22)$. In contrast, as predicted, the distributions of performance in the Eyes Open condition differed significantly between the two diagnostic groups $(U=300.00, p=.025, r=.32$, one-tailed test) with children with DS more likely than children with WS to follow the experimenter's head turn in the Eyes Open condition.

\section{Discussion}

In the present chapter, two research questions were addressed concerning the likelihood of looking in the same direction as an adult's head turn when the adult's eyes were open and the likelihood of looking in the same direction as an adult's head turn when the adult's eyes were closed. The results indicated that for both diagnostic groups, children were significantly more likely to look in the same direction as an adult's head turn when her eyes were open than when her eyes were closed. This pattern of findings indicates that both preschoolers with DS and preschoolers with WS are sensitive to what another person's eyes are doing and interpret the person's looks as referential acts.

Comparisons of the likelihood of looking in the same direction as an adult's head turn between the two groups of children confirmed the prediction that children with DS would be significantly more likely than would children with WS to look in the same direction as an adult when her head turned and her eyes were open. That is, the occurrence of gaze following in the Eyes Open condition for children with DS was 
significantly higher than the occurrence of gaze following in the Eyes Open condition for children with WS. Gaze following rates did not differ significantly for the two groups in the Eyes Closed condition.

Although this is the first study directly focused on comparing the gaze following abilities of children with DS and children with WS, support for the finding of poorer response to joint attention for children with WS relative to children with DS is available within the existing literature examining the early socio-communicative abilities of children with these syndromes. Results of a study conducted by John and Mervis (2010) demonstrated that despite significantly lower overall intellectual ability and language scores, significantly more children with DS (60\%) than children with WS $(26.7 \%)$ followed a communicative gesture (gaze shifting or pointing paired with gaze shifting) to find a hidden object at a rate significantly higher than chance. In addition, Rowe and colleagues (2005) found that children with DS were significantly more likely to respond to joint attention (follow a pointing gesture) than were children with WS matched on CA, DQ, and expressive vocabulary size.

Thus far, I have presented data concerning two abilities that are fundamental to the social referencing process: the child's ability to shift his or her attention from an object to an adult (initiate eye contact) and the child's ability to shift his or her attention from an adult to an object in which the adult has taken an interest (gaze following.) In the next chapter, I examine the third ability fundamental to the social referencing process, the child's ability to comprehend the communicative significance of another person's emotionally valenced behavioral response. 


\section{CHAPTER VI}

\section{UTILIZING EMOTIONAL REACTIONS}

Affective expressions are an important part of the communicative process in that they can be used to regulate other people's behavior (Holodynski \& Friedlmeier, 2005). Even at a young age, TD children are very attentive to other people's emotions. Around 6 months of age TD infants respond differentially to their mothers' happy and sad expressions (Cohn et al., 1990; Termine \& Izard, 1988) and around 12 months of age TD infants use the emotional information communicated by another person to help appraise ambiguous situations (e.g., Feinman, 1992b; Sorce et al., 1985). In this chapter, I evaluate whether or not the behavioral responses of children with DS and children with WS differ on a task similar to the Social Referencing task (Chapter III) with one key difference, a reduction in the attentional demands on the child. The following research questions were evaluated separately based upon whether the experimenter demonstrated a joyful or fearful reaction toward a stimulus:

(1) Do the two groups differ in the proportion of children who acknowledged the experimenter's behavioral display and mapped it to the contents of the box?

(2) Do the two groups differ in the proportion of children who superficially imitated the experimenter's response to the content of the box?

Fidler et al. (2007) conducted a study exploring the rates of emotional responsivity of children with WS between 2 and 8 years of age relative to children with DD of mixed etiologies, $30 \%$ of who had DS. Their results 
indicated that children with WS were 3.4 times more likely to imitate experimenter's facial displays and 5.2 times more likely to imitate their vocal displays than were children with DD of mixed etiologies. These findings remained true even when the children with DS were not included in the analyses, suggesting that the performance of children with DS was consistent with the mixed etiology group overall. Based on these findings, I predicted:

Prediction: The proportion of children who imitated the experimenter's reaction to the ambiguous stimulus will be significantly higher for children with WS than for children with DS.

(3) Do the two groups differ in the proportion of children who attempted to touch the box?

(4) Do the two groups differ in the proportion of children who produced behaviors that indicated that they formed their own opinion of the contents of the box?

\section{Method}

\section{Participants}

Participants were 40 of the 42 children described in Chapter II. One girl with DS was excluded from the present study due to experimenter error. To keep the number of participants the same in each group, the girl with WS closest in age to the excluded child with DS was also excluded from the study. The final sample was the same as in the Floor Task (Chapter III).

The present study used a between-subjects design with approximately half of the children in the Joy condition and half of the children in the Fear condition. (See the 
Procedure section for an explanation of why a between-subjects design rather than a within-subjects design was used.) The sample of children in the Joy condition included 11 children with DS ( 8 boys, 3 girls) aged $3.77-5.87$ years $(M=4.88$ years, $S D=0.79)$ and 11 children with WS ( 6 boys, 5 girls) aged $3.52-5.81$ years $(M=4.80$ years, $S D=$ 0.83). The sample of children in the Fear condition included 9 children with DS ( 5 boys, 4 girls) aged $3.51-5.88$ years $(M=5.07$ years, $S D=0.75)$ and 9 children with WS $(7$ boys, 2 girls) aged $3.70-5.94$ years $(M=5.07$ years, $S D=0.73)$. The two diagnostic groups were well matched for CA in both the Joy condition $(p=.67)$ and the Fear condition $(p=.97)$.

\section{Surprise Box Task}

The Surprise Box task (modeled after Scambler, Hepburn, Rutherford, Wehner, \& Rogers, 2007) was designed both to evaluate children's responses to other people's emotional reactions (i.e., Joy and Fear) and to elicit emotional responses from children. While the Surprise Box task is similar to the Social Referencing task described in Chapter III, there are two key differences: (1) In the Surprise Box task the referent is in a box held by the experimenter, making it easier for the child to shift attention from the referee to the referent and (2) in the Surprise Box task the experimenter assumes the responsibility of ensuring she has the child's attention prior to demonstrating her behavioral reaction toward the contents of the box. This task was used to examine the child's ability to assess emotional information when attentional demands are reduced.

Setting. The task trials were administered to the child during two structured play interactions at a table, each with a different experimenter and on a different day. The experimenter sat diagonally across the table from the child. 
Videotaped Camera Angles. The Surprise Box task was filmed using a split screen video layout with one video screen larger than the other. The larger picture was focused on the front of the child, the table, and the back of the experimenter. The smaller picture was focused on the front of the experimenter.

Procedure. Each child participated in six trials, three on Day 1 and three on Day 2. Only the first of each participant's six trials was included in the analyses, resulting in a between-subjects design. The decision to include only the first trial was made based on experimenters' observations that the children clearly demonstrated carryover from the previously administered trials. The experimenters' observations were verified by statistical analyses that indicated significant order effects $(p=.02)$.

The box was paired with one of two behavioral reactions communicated by the experimenter (joy or fear). In the context of a play activity, the experimenter pulled out a small gift box and said, "I wonder what's in here." At no point during the trial was the child able to see the contents of the box. Once the experimenter had the child's attention, she opened the box and, while looking in the box, demonstrated the specified behavioral reaction for $\sim 10$ seconds, referred to as the Signal stage, alternating gaze between the contents of the box and the child. Once the Signal stage ended, indicated by a tap on the mirror by a researcher in the observation room, the experimenter entered the Neutral stage, lasting $\sim 20$ seconds, during which the experimenter displayed a neutral facial expression and looked down at something under the table for $\sim 20$ seconds to avoid giving the child any other cues. During this Neutral stage, the experimenter refrained from interacting with the child, unless the child became distressed or attempted to reach for the box. In situations where the child became distressed, the experimenter removed the box 
from the table, comforted the child, and distracted the child by playing with more toys. If the child attempted to reach for the box, the experimenter removed the box from the table and tried to distract the child by playing with more toys. The Surprise Box trial was conducted in a familiar playroom. Playroom location, experimenter, and behavioral reaction were alternated across participants in each diagnostic group.

Conditions. The experimenters demonstrated the facial expressions of joy and fear according to the descriptions provided by Izard (1971) and Ekman and Friesen (2003) for the respective emotions. These patterns were the same as described in Chapter III.

Coding. The Surprise Box trials were videotaped for coding purposes. The primary coder, blind to the hypotheses of the study, coded all of the videotapes. To assess reliability, a second person independently coded six randomly selected tapes, three in each diagnostic group, which were stratified by age (one 3-year-old, one 4-year-old, and one 5-year-old). The videotapes were coded to evaluate the experimenter's affective displays as well as to create the following dependent variables: 1) child's reach to the box, 2) child's imitation of the experimenter's behavioral reaction, and 3) child's formation of an opinion. In the four subsections below, I outline the procedures used to code the experimenter's affective display and the three dependent variables.

Experimenter Affective Display. To confirm that the experimenter displayed the appropriate emotion, the coding procedure that was used to code Experimenter Affective Display in Chapter III was used to code Experimenter Affective Display in the Surprise Box task. As in the Floor Task, the coder first indicated which of six emotions (Happiness, Surprise, Anger, Fear, Disgust, Sadness) were displayed by the experimenter. 
The coder was allowed to endorse the presence of multiple emotions. Next the coder indicated which of the emotions displayed was the experimenter's primary emotion. The experimenter's primary emotion had to be the intended primary emotion and be coded as demonstrating an intensity rating of 4 or 5 on a 5 -point scale in order for the trial to be included. Percentage of agreement $(96.15 \%)$ and Cohen's kappa, $\kappa=.92$, indicated high agreement on 'presence of emotion,' the variable indicating which of the six primary emotions were displayed by the experimenter. High reliability was also observed (percentage of agreement $=100 \%, \kappa=1.0)$ for primary emotion identified and for intensity of primary emotion (percentage of agreement $=100 \%, \kappa=1.0$ ). No trials were excluded due to errors in experimenter affect display.

Acknowledgement and mapping of behavioral response. The coding procedure that was used to code Acknowledgement and mapping of behavioral response in Chapter III was used to code this variable in the Surprise Box task. Percentage of agreement $(100.0 \%)$ and Cohen's kappa, $\kappa=1.0$ indicated high reliability for both the acknowledgement and mapping variables.

Imitation of behavioral response. The coding procedure that was used to code superficial imitation of the experimenter's behavioral response in Chapter III was used to code this variable in the Surprise Box task. Percentage of agreement (100.00\%) and Cohen's kappa, $\kappa=1.00$ indicated very high reliability.

Reach for box. A dichotomous variable was created to indicate whether or not the child attempted to touch the box. A child was coded to have attempted to touch the box if the child reached for it with an open hand. Percentage of agreement $(100.00 \%)$ and Cohen's kappa, $\kappa=1.00$ indicated very high reliability. 
Formation of opinion. The coding procedure that was used to code Formation of Opinion in Chapter III was used to code Formation of Opinion in the Surprise Box task. Percentage of agreement $(100.00 \%)$ and Cohen's kappa, $\kappa=1.00$ indicated very high reliability.

\section{Data Analysis}

This study focused on comparing the behavioral reactions of children with DS and children with WS in two situations: (1) when the experimenter looked into a box and was joyful upon seeing its contents, and (2) when the experimenter looked into a box and was fearful upon seeing its contents. A between subjects design was used with approximately half of the children in each diagnostic group in the Joy condition and the remainder in the Fear condition. As all of the dependent variables included in the present chapter were dichotomous and the assumption of expected frequencies greater than 5 necessary to perform a chi-square analysis was violated, Fisher-exact test statistics were computed.

\section{Results}

\section{Acknowledgment and Mapping of Behavioral Reaction}

Two Fisher-exact test statistics were computed to examine the relation between diagnostic group and the child's acknowledgment and mapping of the behavioral reaction $\left(\alpha_{\mathrm{fw}}=.025\right)$. The relation between these variables was not significant in either the Joy condition (see Table $14 ; \chi^{2}[1, \mathrm{~N}=22]=.21$, Fisher's exact $p=1.00$, odds ratio $=1.52$, $\left.C I_{.95}=[0.11,4.00]\right)$ or the Fear condition (see Table $15 ; \chi^{2}[1, \mathrm{~N}=18]=0.28$, Fisher's exact $p=1.00$, odds ratio $\left.=0.57, C I_{.95}=[0.07,4.64]\right)$. 
Table 14

Number of Children who 'Acknowledged and Mapped' the Experimenter's Emotion in the Joy Condition as a Function of Diagnostic Group

\begin{tabular}{lccc}
\hline & Down Syndrome & & \multicolumn{2}{c}{ Williams Syndrome } \\
\cline { 1 - 2 } Did Not Acknowledge/Map & 3 & 4 & 7 \\
\hline
\end{tabular}

Table 15

Number of Children who 'Acknowledged and Mapped' in the Fear Condition as a Function of Diagnostic Group

Down Syndrome Williams Syndrome

Did Not Acknowledge/Map

7

6

Acknowledged/Mapped

2

3

\section{Imitation of Behavioral Reaction}

None of the children imitated the experimenter's behavioral reaction.

\section{Reach for Box}

Two Fisher-exact test statistics were performed to examine the relation between diagnostic group and whether or not the child reached for the box $\left(\alpha_{\mathrm{fw}}=.025\right)$. The relation between these variables was not significant in either the Joy condition (see Table $16 ; \chi^{2}[1, \mathrm{~N}=22]=1.05$, Fisher's exact $p=1.00$, odds ratio cannot be computed as 1 cell has a frequency of 0 ) or the Fear condition (see Table $17 ; \chi^{2}[1, \mathrm{~N}=18]=1.05$, Fisher's exact $p=1.00$, odds ratio $\left.=1.00, C I_{.95}=[0.19,5.36]\right)$. 
Table 16

Number of Children who Reached for the Box in the Joy Condition as a Function of Diagnostic Group

\begin{tabular}{lccc}
\hline & Down Syndrome & & Williams Syndrome \\
\cline { 1 - 2 } Did Not Reach & 1 & 0 \\
Reached & 10 & 11 \\
\hline
\end{tabular}

Table 17

Number of Children who Reached for the Box in the Fear Condition as a Function of Diagnostic Group

Down Syndrome Williams Syndrome

Did Not Touch

3

3

Touched

6

6

\section{Formation of an Opinion}

Two Fisher-exact test statistics were calculated to examine the relation between diagnostic group and formation of an opinion. The relation between these variables did not reach criterion for a significant association in the Joy condition (see Table $18 ; \chi^{2}[1, \mathrm{~N}$ $=22]=2.22$, Fisher's exact $p=.48$, odds ratio cannot be computed as 1 cell has a frequency of 0 ). All of the children with DS and all of the children with WS who were rated as having formed an opinion were rated to have formed a positive opinion of the contents of the box. The relation between these variables also did not reach criterion for a significant association for the Fear condition (see Table $19 ; \chi^{2}[1, \mathrm{~N}=18]=0.23$, Fisher's exact $p=1.00$, odds ratio $\left.=1.60, C I_{.95}=[0.24,10.81]\right)$. Of the children who were rated as having formed an opinion of the contents of the box, only one child with DS (of 6) and 
one child with WS (of 5) was rated as having formed a negative opinion. Thus, most of the children who formed an opinion of the stimulus in the Fear condition were rated as having formed a positive opinion.

Descriptive information was also collected to provide more specific information regarding the responses of children who formed a positive opinion in the Fear condition (DS: $n=5$, WS: $n=4$ ). For children with DS, the results were as follows: three children saw the experimenter's fearful reaction and then reached for the box, one child watched the experimenter's fearful reaction for its entire duration and then reached for the box, and one child decided the stimulus was an owl and maintained this opinion even after seeing the fearful reaction. For children with WS, two children saw the experimenter's fearful reaction and then reached for the box, one child communicated to the experimenter that she should not be afraid and intensely laughed at the experimenter, and one child demonstrated concerned intonation while asking the experimenter what was wrong while reaching for the box and then quickly changed to positive intonation while he asked if he could see.

Table 18

Number of Children who 'Formed an Opinion' in the Joy Condition as a Function of Diagnostic Group

\begin{tabular}{lccc}
\hline & Down Syndrome & & Williams Syndrome \\
\cline { 1 - 2 } Did Not Form an Opinion & 2 & 0 \\
Formed an Opinion & 9 & 11 \\
\hline
\end{tabular}


Table 19

Number of Children who 'Formed an Opinion' in the Fear Condition as a Function of Diagnostic Group

\begin{tabular}{lccc}
\hline & Down Syndrome & & \multicolumn{2}{c}{ Williams Syndrome } \\
\cline { 1 - 2 } Did Not Form an Opinion & 3 & & 5 \\
\hline
\end{tabular}

\section{Discussion}

In the present chapter, four research questions were addressed using a task similar to the Social Referencing task used in Chapter III but with one key difference: a reduction in the attentional demands on the child. The first research question addressed the likelihood that the two groups of children would acknowledge the adult's behavioral reaction and map it to the stimulus. Performance of children with DS and children with WS was once again comparable. When the experimenter demonstrated a joyful reaction toward the stimulus, the majority of children with DS and the majority of children with WS produced behaviors that demonstrated that they acknowledged the experimenter's reaction and mapped it to the stimulus. In contrast, when the experimenter evidenced a fearful reaction to the stimulus, few children in either group produced behaviors that demonstrated that they acknowledged the experimenter's reaction and mapped it to the stimulus.

The second research question addressed the likelihood that the two groups of children would imitate the experimenter's behavioral reaction. It was predicted that children with WS would be more likely to imitate the experimenter than would children 
with DS. However, no child in either diagnostic group imitated the experimenter's behavioral reaction.

The third research question addressed the likelihood that the two groups of children would approach the stimulus (the contents of the box) to which the experimenter directed a behavioral reaction. Results indicated that the approach behavior of children in the two diagnostic groups was comparable with the majority of children in each group reaching for the box both in response to the experimenter's expressions of joy and the experimenter's expressions of fear.

Finally, the fourth research question addressed the likelihood that the two groups of children would form an opinion of the stimulus. When the experimenter demonstrated a joyful reaction, the majority of children in both diagnostic groups formed an opinion of the stimulus in the Joy condition and all of the children who formed an opinion formed a positive one. When the experimenter demonstrated a fearful reaction, once again, the majority of children formed an opinion of the stimulus. However, despite the experimenter's fearful reaction, almost all of the children who formed an opinion of the stimulus formed a positive opinion; only one child in each diagnostic group formed a negative opinion. In addition, despite clearly seeing the experimenter's fearful reaction, most children in each group who formed a positive opinion reached for the stimulus without communicating disagreement with the experimenter or demonstrating behaviors suggesting they saw through the experimenter's fearful reaction.

Overall, the results of the present study suggest that both children with DS and children with WS have difficulty comprehending the significance of another person's fearful reaction. This finding is consistent with that of Porter (2008), who found that 
when controlling for MA, both individuals WS ( $n=9$; CA range: $6.0-43.67$ years) and individuals with DS ( $n=20$; CA range: $6.75-40.75$ years) demonstrated comparable difficulty with regard to recognizing expressions of fear as high mean proportions of errors for expressions of fear were observed for both groups, even when high intensity emotional stimuli were used (High Intensity Stimuli: WS $=.56, \mathrm{DS}=.56$; Low Intensity Stimuli: WS $=.66, \mathrm{DS}=.75$ ) 


\section{CHAPTER VII}

\section{GENERAL DISCUSSION}

From birth, children are immersed in a world that necessitates constant learning. One of the components important for psychological growth and effective functioning within the environment involves learning about what it means to be a person. Children develop an understanding of the world around them, who they are, who other people are, and how to negotiate interactions with other people and objects/events within the environment. In addition to being a source of comfort and support, people are a valuable source of information about the surrounding environment. Impairments in the ability to utilize other people's nonverbal communicative behaviors and in the ability to understand other people's actions in terms of their underlying mental states have severe repercussions, as can be seen in the case of ASDs (American Psychiatric Association, 2000).

The present project was the first to directly investigate the social referencing process (use of another person as a source of information regarding novel or ambiguous situations) in two neurodevelopmental disorders that have been well defined genetically and are characterized by differing patterns of socio-cognitive development: DS and WS. The social referencing process requires a child to coordinate multiple abilities. Thus, if a child does not utilize a person as a source of information about objects and events in the environment, it may be difficult to specify where the child is encountering difficulties solely by observing the social referencing process. For this reason, in addition 
to a Social Referencing task, the present project also included three studies that each examined one of the abilities fundamental to social referencing (initiation of joint attention, gaze following, and emotion recognition/emotional responsivity) to obtain clarifying information as to what difficulties are likely impeding the social referencing process. In this chapter, I summarize and discuss the implications of the findings across studies as well as provide suggestions for future directions for research.

\section{The Regulatory Function of Social Referencing}

The results of the Social Referencing study presented in Chapter III indicated differences in the behavioral responses of children with DS and children with WS both in situations in which the experimenter communicated a joyful message about an ambiguous stimulus and in situations in which the experimenter communicated a fearful message about an ambiguous stimulus. When the experimenter communicated a joyful message, results indicated that children with DS shifted their attention between the adult and the stimulus more than did children with WS. In addition, children with DS (75\%) were more likely than were children with WS (40\%) to produce behaviors that acknowledged the experimenter's joyful message and indicated that they mapped her message to the stimulus. Children with DS were also more likely (80\%) than were children with WS $(65 \%)$ to approach the stimulus. Comparisons of superficial imitation of the experimenter's facial expressions between the two groups did not reach criterion for a significant difference, with only a small proportion of each group ( $\sim 5 \%$ of children with DS and $20 \%$ of children with WS) imitating the experimenter's joyful reaction. In the end, when the experimenter communicated a joyful message about the stimulus, the majority of children with DS (80\%) and children with WS (65\%) formed an opinion of 
the stimulus and the vast majority of the opinions formed by children in each group were positive.

When the experimenter communicated a fearful message about an ambiguous stimulus, a partially different pattern of findings was observed across the two groups of children. Once again, children with DS were more likely than were children with WS both to shift their attention between the stimulus and the experimenter and to approach the stimulus. However, the longest look to the experimenter by the children with WS was longer than the longest look to the experimenter by children with DS. In addition, the children with WS were more likely to imitate the experimenter's fearful expression than were the children with DS (DS $=\sim 11 \%, \mathrm{WS}=40 \%$ ). Results also indicated that children with WS (35\%) were less likely than were children with DS (60\%) to form an opinion of the stimulus. In the end, $38 \%$ of the children with DS and $40 \%$ of the children with WS who formed an opinion of the fearful stimulus formed a negative opinion; the majority of children in each group who formed an opinion formed a positive one. Descriptive information obtained regarding the responses of the children who formed a positive opinion indicated that most of the children with DS and all of the children with WS, despite clearly seeing the experimenter's fearful expression, approached the stimulus without communicating disagreement with the experimenter or demonstrating behaviors suggesting they saw through her fearful reaction.

These results highlight an attentional component in the social referencing process (the child's regulation of his or her attention between the adult and the stimulus) as well as an informational component (comprehension of the communicative significance of the fearful reaction). However, it is difficult to tell from this study alone if difficulties with 
one or both of these components in the social referencing process are contributing to why children are not utilizing the experimenter as a source of information about the stimulus. To further complicate the situation, because the components that make up the social referencing process are so tightly intertwined within a naturalistic interaction, pinpointing the exact point in the process where a problem may have occurred is extremely difficult and tells us little regarding the children's strengths and weaknesses in the components whose use should have come after the identified problem occurred. However, despite these difficulties with interpretation, the results of the Social Referencing study have provided a direction in which to begin an exploration of the social referencing process.

When we consider the attentional component of the social referencing process, we are considering the necessity for the child to link the experimenter's reaction to the stimulus. There are two fundamental abilities that a child should use to link the experimenter's reaction to the stimulus: initiating joint attention and gaze following. First, the child must be able to coordinate his or her attention between the object and the experimenter in a social context. That is, the child must initiate joint attention. The ability to initiate joint attention is important to the social referencing process, as the child must shift his or her attention from the stimulus to the experimenter in order to gain access to the message (experimenter's reaction). Secondly, once the child notices the message, the child must be able to follow the experimenter's gaze to identify the focus of the her attention.

Once the child has linked the experimenter's reaction to the stimulus, the informational component of the social referencing process must be considered. In order for social referencing to occur, the child must interpret the communicative signal 
provided by the experimenter. When considered on an interpersonal level, emotions provide a tool with which a person can establish, maintain, or disrupt interactions within the environment (Walden \& Knieps, 1996). In the Social Referencing task used in Chapter III, the experimenter demonstrated either a joyful or a fearful reaction to the stimulus. In this context, for the social referencing process to occur, the child must comprehend the communicative significance of this emotionally valenced message. That is, the child must interpret the experimenter's reaction as an indication that either the stimulus is something enjoyable (when seeing the experimenter's joyful reaction) or that the stimulus is something to be feared (when seeing the experimenter's fearful reaction).

While TD children are able to coordinate these multiple abilities such that they can use another person's appraisal of a situation to guide their own behavior by around 12 months of age, this is not the case for children with syndromes associated with ID (e.g., Dickstein et al., 1984; Feinman \& Lewis, 1984; Klinnert et al., 1986; Walden \& Ogan, 1988). Children are not born with a complete understanding of what it means to be a person or with a complete understanding of how human beings differ from objects. Children learn this information from their interactions with the people and objects around them. In the case of children who have syndromes associated with ID, delays in the acquisition of knowledge and skills are observed. As such, the present project also assessed three abilities that are fundamental to the social referencing process individually in order to obtain clarifying information as to what difficulties could be contributing to why children are not using the experimenter as a source of information in Chapter III. In the next three sections, each of these abilities is discussed separately. 


\section{Initiating Eye Contact}

The study presented in Chapter IV considered children's ability to shift attention from an object to an adult in response to the adult's production of ambiguous and nonambiguous gestures. Results indicated that both children with DS and children with WS were more likely to look at the experimenter in response to her ambiguous gestures (blocking or teasing) than they were to look at her in response to her unambiguous gesture (giving). In addition, the two groups of children were not statistically different from one another in terms of their likelihood of looking at the experimenter in response to her blocking and teasing gestures; most children in both groups looked at the experimenter in these situations. These results demonstrate that both children with DS and children with WS are likely to look to the adult if she produces a gesture that prevents the child from gaining access to an object of interest. By preventing the child from accessing the object, the experimenter produced an action that created a dyadic interaction. As such, these findings are consistent with the existing literature, which demonstrates that both children with DS and children with WS use eye contact relatively well in dyadic interactions (Kasari et al., 1990; Laing et al., 2002).

The results presented in Chapter IV also demonstrated that children with DS were more likely to look to the experimenter in response to her giving gesture than were the children with WS. Since the experimenter's giving gesture did not attempt to draw the child's attention to her, this situation remained triadic in nature. As such, this finding provides further support for the growing body of literature demonstrating that children with DS evidence better joint attention skills than do children with WS of the same CA (Rowe et al., 2005). 
Framed within the context of the social referencing process, by not shifting their attention between the adult and the object of interest as much as children with DS do, children with WS are potentially getting access to less information about the situation at hand than are the children with DS. If this is the case, it is easy to see how breakdowns in interactions for the children with WS can occur. In addition, it is important to point out that not only does the child's lack of shifting attention limit his or her understanding of the social interaction, but it may also influence the understanding of the person interacting with the child. For example, both the research assistants who coded the videotapes for this study and the experimenters who interacted with the children frequently reported that it was easier to interpret the behavioral responses of the children with DS than those of the children with WS, as the children with DS gave the adult "more information." Interestingly, this impression was obtained even though the children with WS had considerably more advanced language skills than did the children with DS, many of whom were able to produce only a few single words or manual signs. In contrast, the coders and experimenters often said that the interactions with the children with WS were "weird" and that they were not entirely sure what was happening except that clearly "something had gone wrong."

\section{Gaze Following}

The study presented in Chapter V considered children's ability to shift attention from the experimenter to the object that was the focus of the experimenter's attention, that is, the child's ability to follow another person's gaze. Results indicated that both children with DS and children with WS were more likely to follow the experimenter's head turn when her eyes were open than when her eyes were closed. This finding indicates that 
both groups of children demonstrated sensitivity to the meaningfulness of a person's eyes. That being said, the findings also indicated that children with DS were more likely to follow another person's head turn paired with open eyes than were children with WS. The finding that children with WS were less likely than were children with DS to respond to joint attention acts adds more evidence to the growing body of literature demonstrating that children with WS evidence impairments in response to joint attention (John \& Mervis, 2010; Klein-Tasman et al., 2007; Laing et al., 2002; Lincoln et al., 2007; Rowe et al., 2005).

Framed within the context of the social referencing process, impairments in the child's ability to follow the adult's gaze may result in the child not being able to identify the source of the adult's emotional reaction. Without a source for the reaction, the experimenter's reaction may become an ambiguous situation in and of itself and cause increased confusion for the child. It is possible that this could be an explanation for why so many children did not form an opinion of the stimulus in the Fear condition of the Social Referencing Study (Chapter III). On the other hand, it is also possible that without a source for the reaction, the intent of the communication is lost. As pointed out by Meltzoff (1995), human beings would be difficult to predict and even harder to explain if we had to restrict our understanding of them to their physical behaviors and movements. It is possible then that not identifying the source of the experimenter's reaction could be a contributing reason behind the finding reported in Chapter III that children with WS were more likely to superficially imitate the experimenter's emotionally valenced reactions than were children with DS. This explanation could account for why no imitation was observed in the Surprise Box study presented in Chapter VI, when the source of the 
experimenter's reaction was much more obvious. Alternately, the lack of imitation in the Surprise Box study could be due to children being more interested in determining what was in the box than they were in what the experimenter was doing. The finding in Chapter VI that the majority of children in each group reached for the box in both the Joy and the Fear conditions is consistent with this possibility.

\section{Utilizing Emotional Reactions}

The study presented in Chapter VI considered children's ability to comprehend the communicative significance of another person's emotionally valenced behavioral reaction in a task with a reduced attentional demand on the child. In situations in which the experimenter communicated a joyful message about the ambiguous stimulus, results indicated that the reactions of children with DS and children with WS were comparable. The majority of children in both groups (DS $=73 \%$, WS $=64 \%$ ) produced behaviors acknowledging the experimenter's joyful message and demonstrating that they mapped that message to the stimulus. In addition, most children with DS (91\%) and all of the children with WS (100\%) attempted to approach the stimulus and most children in both groups formed a positive opinion of it (DS $=82 \%, \mathrm{WS}=100 \%$ ).

When the experimenter communicated a fearful message about the ambiguous stimulus, while the reactions of both children with DS and children with WS were comparable in response to the fearful communication, the pattern of findings was different from that observed in the Joy condition. Few children with DS (22\%) or children with WS (33\%) produced behaviors that demonstrated that they acknowledged the experimenter's fearful reaction and mapped it to the stimulus. At the same time, the majority of children in both groups reached for the stimulus (DS $=67 \%$, WS $=67 \%$ ). 
Finally, although the majority of children with DS (67\%) and children with WS (56\%) formed an opinion of the fearful stimulus, only one child in each group formed a negative opinion of it. In addition, it was found that, despite clearly seeing the experimenter's fearful expression, most of the children in each group who formed a positive opinion reached for the box without communicating disagreement with the experimenter or demonstrating behaviors suggesting they saw through the fearful reaction.

While one must be careful in interpreting the findings in Chapter VI due to the limited sample size, the reactions of children in the two groups were quite similar. When the adult communicated a joyful message about the ambiguous stimulus, the majority of the children with DS (75\%) and the majority of children with WS (55\%) formed positive opinions of the stimulus as well. However, when the adult communicated a fearful message about the stimulus, only one child with DS and only one child with WS formed a negative opinion of the fearful stimulus.

Given the existing body of literature demonstrating that both individuals with DS and individuals with WS evidence more difficulty interpreting fearful expressions than do their same age peers (Gagliardi et al., 2003; Kasari et al., 2001; Plesa-Skwerer et al., 2006; Porter, 2008; Williams et al., 2005), it is plausible that the findings from Chapter VI provide another indication that children with DS and children with WS have difficulty comprehending the communicative significance of another person's fearful reactions. When considered within the context of the social referencing process, this could explain why so many children with DS approached the stimulus in the Social Referencing task and formed a positive opinion of it despite being more likely than the children with WS 
to shift attention between the experimenter and the stimulus and more likely to acknowledge the experimenter's fearful response and map it to the stimulus.

\section{Future Directions}

Social referencing is a complex process because it involves the interaction of multiple abilities within a social context. However, despite this complexity, the results from the present project provide valuable information that may be used as a guide for future studies. In this section, I discuss possible directions for future research on children with DS and children with WS and suggest some factors that should be examined as potential contributors to social referencing ability.

It will be important to continue to examine the abilities that are fundamental to the social referencing process and determine their role in the later socio-cognitive and sociocommunicative challenges experienced by individuals with DS and individuals with WS. More specifically, it is important that future studies focus on the development of joint attention and examine the impact of early delays in joint attention on later development for both children with DS and children with WS. This will be a valuable line of research in WS in particular. By not shifting their attention between objects and people as much as other children do, it is likely that children with WS are getting access to less information about both people and objects within their environment than do other children of the same age and intellectual abilities. Much of how children learn about other people's underlying states comes from observing people's interactions with the surrounding world. As such, these early impairments may be contributing to the significant social cognitive impairments observed in older children and adults with WS. 
Furthermore, future studies should examine the development of gaze following and emotional responsivity/emotion recognition in children with DS and children with WS. In particular, more research is needed examining the role of gaze following in children's understanding of emotion. Early difficulties in efficiently linking people's actions/reactions/messages to their referents in the environment are likely to have significant effects on later language, social cognitive, and social emotional development. In addition, it is important that more research be conducted focusing on children's comprehension of the communicative significance of emotionally valenced messages. It is plausible that the results from the present project indicate that both children with DS and children with WS have difficulty interpreting the communicative significance of fearful reactions. However, it is vital that more research be conducted to determine when and in what situations these two groups of children are able to comprehend the communicative significance of emotionally-valenced messages, especially those that involve negative emotions such as fear. Research in these areas will not only provide a much more complete understanding of the behavioral phenotypes associated with these neurodevelopmental disorders and the development of these behavioral phenotypes but also may help shed light on the intricacies of the development of these processes in TD children.

It is also important that future studies consider the possible contributions of other factors to social referencing and to the abilities that are fundamental to this process. Preliminary evidence that two such factors (executive functioning and "wary" temperament) may influence social referencing is available in the literature. In a study examining the executive functioning abilities of children with autism $(n=18$; mean $C A=$ 
51.11 months) relative to a group of children with DD of mixed-etiology ( $n=17$; mean $C A=51.00$ months), Griffith and colleagues (1999) examined the relation between executive functioning abilities and joint attention abilities in an attempt to explore the hypothesis that deficits in executive functioning in autism may be the underlying cause of the significant impairments observed in joint attention. The authors found a significant negative correlation between the number of perseveration errors on the Spatial Reversal task (Kaufman, Leckman, \& Ort, 1989) and both Initiating Joint Attention and Responding to Joint Attention on the ESCS when both the autism group and the DD group were combined. The Spatial Reversal task builds up a prepotent response and then requires the child to inhibit that response once it is no longer successful. More recently, Sheinkopf, Mundy, Claussen, and Willoughby (2004) theorized, in interpreting their findings from a study comparing infant joint attention skill and preschool behavioral outcomes in children with a history of prenatal exposure to cocaine, that joint attention ability may reflect, at least in part, the child's ability to inhibit prepotent responses and initiate appropriate actions in social situations.

The results from the present project also are consistent with this body of research. Based on parental report on the BRIEF-Preschool, children with DS were found to have better inhibitory self-control (as well as better overall executive functioning abilities, shifting, and emotional control) than did the children with WS. These differences in inhibitory self-control and other executive functioning abilities favoring the children with DS, may explain why despite having lower overall intellectual ability and lower verbal ability, children with DS evidenced better initiation of joint attention and gaze following abilities than did children with WS. Given this body of evidence, further research on the 
potential role of executive functioning in the social referencing process, as well as in social cognitive development more generally is warranted.

Preliminary evidence also exists that temperament, particularly "wary" temperament, may affect the social referencing process. Hornik and Gunnar (1988) examined the social referencing responses of 12-month-old TD infants $(n=16)$ and 18month-old TD infants $(n=16)$ in their first encounter with a large black rabbit. The results of this study demonstrated that infants who were classified as demonstrating a 'wary' initial reaction to the rabbit were more likely than were infants classified as demonstrating a 'bold' initial reaction to the rabbit to reference their mothers when the rabbit was first encountered.

The differences found in the reactions of children with DS and children with WS in the present project may be in part due to differences in temperament. Klein and Mervis (2003), when attempting to develop a personality profile specific to WS, found that very low mean ratings on the Children's Behavior Questionnaire (CBQ; Rothbart, Ahadi, Hershey, \& Fisher, 2001) Shyness scale, a scale measuring slow or inhibited approach in novel or uncertain situations, together with high mean ratings on the CBQ Empathy scale characterized $96 \%$ of their WS sample but only $15 \%$ of their mixed etiology group (which included several children with DS). The findings of Hornik and Gunnar (1988) suggest that if as expected based on Klein-Tasman and Mervis's (2003) results, children with DS score higher than children with WS on the CBQ Shyness scale, children with DS would be more likely to evidence a 'wary' initial reaction and therefore be more likely to reference their mothers in ambiguous situations such as the social referencing task. Given this possibility, it is important that future studies examining the social referencing process 
in children with DS and children with WS consider whether or not 'shyness' is a factor contributing to the advantages shown by children with DS and the difficulties evidenced by children with WS. The possible contribution of other aspects of temperament also should be considered.

Finally, while the findings from the present study are important in that they have provided a direction in which to begin an exploration of the specific difficulties encountered within the social referencing process, the analyses in this project were focused on variables that were expected to differentiate children with DS from children with WS. These variables may not be the same as the ones that are most likely to provide insight into within-syndrome differences in social referencing or the fundamental abilities underlying social referencing. Furthermore, the variables most likely to evidence withinsyndrome differentiation may not be the same for children with DS and children with WS. Given the differing reactions evidenced by children with DS and children with WS, it will be important for future studies to include a within-subjects approach when examining the social referencing process and to begin examining the role of individual differences among children who have the same syndrome on the social referencing process. These studies will allow more specific information to be obtained which will potentially provide insight into how specific actions taken or not taken by a child in an ambiguous situation impact the process of social referencing as a whole.

\section{Conclusions}

In summary, the present project is the first to directly examine the process of using another person as a source of information regarding novel or ambiguous situations, referred to as social referencing, in children with DS and children with WS. The results 
of the Social Referencing study suggest that both groups of children are not using another person's expression of fear to regulate their own behavior in ambiguous situations. However, since the different abilities a child must utilize in order to use another person's appraisal of the situation as information to guide his or her behavior are so tightly intertwined in complex social interactions like the social referencing process, it is difficult to tell from this study alone exactly what kind of challenges children in these groups are encountering. In order to obtain clarifying information as to what kinds of difficulties children with DS and children with WS are encountering within the social referencing process, the present project also included follow-up studies which examined three abilities that are fundamental to social referencing: initiation of joint attention, gaze following, and emotional responsivity.

Taken together, the results of the follow-up studies suggest that, at the group level, there are both similarities and differences in the problems encountered by children with DS and children with WS within the social referencing process. Both children with DS and children with WS had difficulty interpreting the communicative significance of the experimenter's fearful reactions. However, children with DS were more successful than were children with WS both at coordinating attention between the object and the experimenter and at identifying the source of her interest. Furthermore, despite demonstrating poorer overall intellectual ability and more limited verbal ability, children with DS evidenced better executive functioning than did children with WS. This difference in executive functioning may contribute to some of the advantages shown by children with DS. 
It is important that future studies continue to examine the social referencing process in these two neurodevelopmental disorders and the impact of executive functioning abilities and temperament characteristics on social referencing. If these two groups of children are having difficulty using another person's fearful expression to guide their own behavior, they can inadvertently put themselves into dangerous situations. Increasing our understanding of the specific nature of the problems encountered during the social referencing process is an important step toward the development of interventions to address these difficulties as well as the more general social communication challenges experienced by children with DS and children with WS. 


\section{REFERENCES}

Adamson, L. B. (Ed.). (1995). Communication development during infancy. Madison, WI: Brown and Benchmark.

American Psychiatric Association. (2000). Diagnostic and statistical manual of mental disorders (4th ed., text revision ed.). Washington, DC: American Psychiatric Association.

American Psychological Association. (1996). Definition of mental retardation. In J. W. Jacobson \& J. D. Mulick (Eds.), Manual of diagnosis and professional practice in mental retardation (pp. 13-54). Washington, DC: American Psychological Association, Editorial Board of Division 33.

Bacon, A. L., Fein, D., Morris, R., Waterhouse, L., \& Allen, D. (1998). The responses of autistic children to the distress of others. Journal of Autism and Developmental Disorders, 28, 129-142. doi:10.1023/A:1026040615628

Bakeman, R., \& Adamson, L. B. (1984). Coordinating attention to people and objects in mother-infant and peer-infant interaction. Child Development, 55, 1278-1289. doi: $10.2307 / 1129997$

Baldwin, D. A. (Ed.). (1995). Understanding the link between joint attention and language. Hillsdale, NJ: Erlbaum.

Bandura, A. (1969). Social learning theory of identification processes. In D. A. Goslin (Ed.), Handbook of socialization theory and research (pp. 213-262). Chicago IL: Rand McNally.

Baron-Cohen, S. (1995). Mindblindness: An essay on autism and theory of mind. Cambridge, MA: MIT Press.

Benton, A. L., Hamsher, K. d. S., Varney, N. R., \& Spreen, O. (1983). Contributions to neuropsychological assessment. New York, NY: Oxford University Press.

Berger, J., \& Cunningham, C. (1981). The development of eye contact between mothers and normal versus Down's syndrome infants. Developmental Psychology, 17, 678-689. doi: $10.1037 / 0012-1649.17 .5 .678$ 
Berger, J., \& Cunningham, C. (1983). Development of early vocal behaviors and interactions in Down's syndrome and nonhandicapped infant-mother pairs. Developmental Psychology, 19, 322-331. doi: 10.1037/0012-1649.19.3.322

Boccia, M., \& Campos, J. J. (1989). Maternal emotional signals, social referencing, and infants' reactions to strangers. New Directions for Child Development, 44, 25-49. doi:10.1002/cd.23219894404

Bretherton, I. (Ed.). (1991). Intentional communication and the development of an understanding of mind. Hillsdale, NJ: Erlbaum.

Brooks, R., \& Meltzoff, A. N. (2002). The importance of the eyes: How infants interpret adult looking behavior. Developmental Psychology, 38, 958-966. doi: 10.1037/0012-1649.38.6.958

Campos, J. J., \& Stenberg, C. (1981). Perception, appraisal, and emotion: The onset of social referencing. In M. E. Lamb \& L. R. Sherrod (Eds.), Infant social cognition: Empirical and theoretical considerations (pp. 273-314). Hillsdale, NJ: Erlbaum.

Camras, L. A., \& Sachs, V. B. (1991). Social referencing and caretaker expressive behavior in a day care setting. Infant Behavior \& Development, 14, 27-36. doi:10.1016/0163-6383(91)90052-T

Carpenter, M., Nagell, K., \& Tomasello, M. (1998). Social cognition, joint attention, and communicative competence from 9 to 15 months of age. Monographs of the Society for Research in Child Development, 63, 1-176. doi: 10.2307/1166214

Carr, J. (1995). Down's syndrome: Children growing up. Cambridge, England: Cambridge University Press.

Carr, J. (2002). Down syndrome. In P. Howlin \& O. Udwin (Eds.), Outcomes in neurodevelopmental and genetic disorders (pp. 169-197). Cambridge, England: Cambridge University Press.

Centers for Disease Control and Prevention. (2006). Improved national prevalence estimates for 18 selected major birth defects - United States, 1999 - 2001. Morbidity and Mortality Weekly Report, 54, 1301-1305.

Chapman, R. S. (1999). Language development in children and adolescents with Down syndrome. In J. F. Miller, M. Leddy, \& L. A. Leavitt (Eds.), Improving the communication of people with Down syndrome (pp. 41-60). Baltimore, MD: Brookes.

Chapman, R. S. (2003). Language and commuication in individuals with Down syndrome. In L. Abbeduto (Ed.), Language and communication in mental retardation (pp. 1-34). San Diego, CA: Elsevier. 
Charman, T., Swettenham, J., Baron-Cohen, S., Cox, A., Baird, G., \& Drew, A. (1998). An experimental investigation of social-cognitive abilities in infants with autism: Clinical implications. Infant Mental Health Journal, 19, 260-275. doi:10.1002/(SICI)1097-0355(199822)19:2<260::AID-IMHJ12>3.0.CO;2-W

Cherniske, E. M., Carpenter, T. O., Klaiman, C., Young, E., Bregman, J., Insogna, K., et al. (2004). Multisystem study of 20 older adults with Williams syndrome. American Journal of Medical Genetics Part A, 131A, 255-264. doi:10.1002/ajmg.a.30400

Cohn, J. F., Campbell, S. B., Matias, R., \& Hopkins, J. (1990). Face-to-face interactions of postpartum depressed mother-infant pairs at 2 months. Developmental Psychology, 26, 15-23. doi: 10.1037/0012-1649.26.1.15

Corkum, V., \& Moore, C. (1995). Development of joint visual attention in infants. In C. Moore \& P. J. Dunham (Eds.), Joint attention: Its origins and role in development (pp. 61-83). Hillsdale, NJ: Erlbaum.

D'Entremont, B., Hains, S. M. J., \& Muir, D. W. (1997). A demonstration of gaze following in 3- to 6-month-olds. Infant Behavior \& Development, 20, 569-572.

Davies, M., Udwin, O., \& Howlin, P. (1998). Adults with Williams syndrome. Preliminary study of social, emotional and behavioural difficulties. The British Journal of Psychiatry, 172, 273-276. doi:10.1192/bjp.172.3.273

de Rosnay, M., Cooper, P. J., Tsigaras, N., \& Murray, L. (2006). Transmission of social anxiety from mother to infant: An experimental study using a social referencing paradigm. Behaviour Research and Therapy, 44, 1165-1175. doi:10.1016/j.brat.2005.09.003

Dickstein, S., Thompson, R. A., Estes, D., Malkin, C., \& Lamb, M. E. (1984). Social referencing and the security of attachment. Infant Behavior \& Development, 7 , 507-516. doi: 10.1016/S0163-6383(84)80009-0

Dilts, C. V., Morris, C. A., \& Leonard, C. O. (1990). Hypothesis for development of a behavioral phenotype in Williams syndrome. American Journal of Medical Genetics Supplement, 6, 126-131.

Dissanayake, C., \& Crossley, S. A. (1996). Proximity and sociable behaviours in autism: Evidence for attachment. Journal of Child Psychology and Psychiatry, 37, 149156. doi:10.1111/j.1469-7610.1996.tb01386.x

Dykens, E. M., \& Rosner, B. A. (1999). Refining behavioral phenotypes: Personalitymotivation in Williams and Prader-Willi syndromes. American Journal on Mental Retardation, 104, 158-169. doi:10.1352/08958017(1999)104<0158:RBPPIW >2.0.CO;2 
Ekman, P., \& Friesen, W. V. (1971). Constants across cultures in the face and emotion. Journal of Personality and Social Psychology, 17, 124- 129.

Ekman, P., \& Friesen, W. V. (2003). Unmasking the face. Cambridge, MA: Malor Books.

Ekman, P., Sorenson, E. R., \& Friesen, W. V. (1969). Pan-cultural elements in facial displays of emotion. Science, 164(3875), 86-88. doi:10.1126/science.164.3875.86

Elliott, C. D. (2007). Differential Ability Scales (2nd ed.). San Antonio, TX: Psychological Corporation.

Emde, R. N. (1992). Social referencing research: Uncertainty, self, and the search for meaning. In S. Feinman (Ed.), Social referencing and the social construction of reality in infancy (pp. 79-94). New York, NY: Plenum Press.

Ewart, A. K., Morris, C. A., Atkinson, D., Jin, W., Sternes, K., Spallone, P., et al. (1993). Hemizygosity at the elastin locus in a developmental disorder, Williams syndrome. Nature Genetics, 5, 11-16. doi:10.1038/ng0993-11

Feinman, S. (1982). Social referencing in infancy. Merrill-Palmer Quarterly, 28, 445470.

Feinman, S. (1991). Bringing babies back into the social world. In M. Lewis \& S. Feinman (Eds.), Social influences and socialization in infancy (pp. 281-325). New York, NY: Plenum Press.

Feinman, S. (1992a). An integrative look at social referencing. In S. Feinman (Ed.), Social referencing and the social construction of reality in infancy (pp. 3-13). New York, NY: Plenum Press.

Feinman, S. (1992b). Social referencing and the social construction of reality in infancy. New York, NY: Plenum Press.

Feinman, S., \& Lewis, M. (1983). Social referencing at ten months: A second-order effect on infants' responses to strangers. Child Development, 54, 878-887. doi: $10.2307 / 1129892$

Feinman, S., Roberts, D., Hsieh, K.-F., Sawyer, D., \& Swanson, D. (1992). A critical review of social referencing in infancy. In S. Feinman (Ed.), Social referencing and the social construction of reality in infancy (pp. 15-54). New York, NY: Plenum Press.

Feiring, C., Lewis, M., \& Starr, M. D. (1984). Indirect effects and infant's reaction to strangers. Developmental Psychology, 20, 485-491. doi: 10.1037/00121649.20.3.485 
Fidler, D. J. (2005). The emerging Down syndrome behavioral phenotype in early childhood: Implications for practice. Infants and Young Children, 18, 86-103. doi:10.1097/00001163-200504000-00003

Fidler, D. J., Barrett, K. C., \& Most, D. E. (2005). Age-related differences in smiling and personality in Down syndrome. Journal of Developmental and Physical Disabilities, 17, 263-280. doi: (10.1007/s10882-005-4384-x)

Fidler, D. J., Hepburn, S., Most, D., \& Philofsky, A. (2007). Emotional responsivity in young children with Williams syndrome. American Journal on Mental Retardation, 112, 194-206. doi:10.1352/08958017(2007)112[194:ERIYCW]2.0.CO;2

Fishler, K., \& Koch, R. (1991). Mental development in Down syndrome mosaicism. American Journal of Mental Deficiency, 96, 345-351.

Freeman, S. F. N., \& Kasari, C. (2002). Characteristics and qualities of the play dates of young children with Down syndrome: Emerging or true friendships? American Journal of Mental Retardation, 107, 16-31. doi: 10.1352/08958017(2002)107<0016:CAQOTP $>2.0 . \mathrm{CO} ; 2$

Fryns, J., Borghgraef, M., Volcke, P., \& van den Berge, H. (1991). Adults with Williams syndrome. American Journal of Medical Genetics, 40, 253. doi:10.1002/ajmg.1320400228

Gagliardi, C., Frigerio, E., Burt, D., Cazzaniga, I., Perrett, D., \& Borgatti, R. (2003). Facial expression recognition in Williams syndrome. Neuropsychologia, 41, 733738. doi: 10.1016/S0028-3932(02)00178-1

Gibbs, M. V., \& Thorpe, J. G. (1983). Personality stereotype of noninstitutionalized Down syndrome children. American Journal of Mental Deficiency, 87, 601-605.

Gioia, G. A., Espy, K. A., \& Isquith, P. K. (2003). Behavior Rating Inventory of Executive Function - Preschool version. Lutz, FL: Psychological Assessment Resources, Inc.

Gosch, A., \& Pankau, R. (1997). Personality characteristics and behaviour problems in individuals of different ages with Williams syndrome. Developmental Medicine \& Child Neurology, 39, 527-533. doi:10.1111/j.1469-8749.1997.tb07481.x

Griffith, E. M., Pennington, B. F., Wehner, E. A., \& Rogers, S. J. (1999). Executive functions in young children with autism. Child Development, 70, 817-832. doi: $10.1111 / 1467-8624.00059$

Gross, A. L., \& Ballif, B. (1991). Children's understanding of emotion from facial expressions and situations: A review. Developmental Review, 11, 368-398. doi: $10.1016 / 0273-2297(91) 90019-\mathrm{K}$ 
Gunnar, M. R., \& Stone, C. (1984). The effects of positive maternal affect on infant responses to pleasant, ambiguous, and fear-provoking toys. Child Development, 55, 1231-1236. doi: http://dx.doi.org/10.2307/1129992

Hala, S. (Ed.). (1997). The development of social cognition. Hove, England: Psychology Press.

Hiatt, S. W., Campos, J. J., \& Emde, R. N. (1979). Facial patterning and infant emotional expression: Happiness, surprise and fear. Child Development, 50, 1020-1035. doi: $10.2307 / 1129328$

Hirshberg, L. M., \& Svejda, M. (1990). When infants look to their parents: I. Infants' social referencing of mothers compared to fathers. Child Development, 61, 11751186. doi: $10.2307 / 1130885$

Hobson, R., Ouston, J., \& Lee, A. (1988). Naming emotion in faces and voices: Abilities and disabilities in autism and mental retardation. British Journal of Developmental Psychology, 7, 237-250.

Hodapp, R. M., \& Dykens, E. M. (2001). Strengthening behavioral research on genetic mental retardation syndromes. American Journal on Mental Retardation, 106, 415. doi: 10.1352/0895-8017(2001)106<0004:SBROGM>2.0.CO;2

Holodynski, M., \& Friedlmeier, W. (2005). The internalization model of emotional development. In M. Holodynski \& W. Friedlmeier (Eds.), Development of emotions and emotion regulation (pp. 43-88). New York, NY: Springer.

Hornik, R., \& Gunnar, M. R. (1988). A descriptive analysis of infant social referencing. Child Development, 59, 626-634. doi:10.2307/1130562

Hornik, R., Risenhoover, N., \& Gunnar, M. (1987). The effects of maternal positive, neutral, and negative affective communications on infant responses to new toys. Child Development, 58, 937-944. doi:10.2307/1130534

Howlin, P., \& Udwin, O. (2006). Outcome in adult life for people with Williams syndrome: Results from a survey of 239 families. Journal of Intellectual Disability Research, 50, 15-160. doi:10.1111/j.1365-2788.2006.00775.x

Izard, C. E. (1971). The face of emotion. New York, NY: Appleton-Century-Crofts.

Jahromi, L. B., Gulsrud, A., \& Kasari, C. (2008). Emotional competence in children with down syndrome: Negativity and regulation. American Journal on Mental Retardation, 113, 32-43. doi: 10.1352/08958017(2008)113[32:ECICWD]2.0.CO;2

Jarrold, C., Baddeley, A. D., \& Hewes, A. K. (1998). Verbal and nonverbal abilities in the Williams syndrome phenotype: Evidence for diverging developmental 
trajectories. The Journal of Child Psychology and Psychiatry and Allied Disciplines, 39, 511-523. doi:10.1017/S0021963098002443

Jarrold, C., Baddeley, A. D., \& Hewes, A. K. (2005). Genetically dissociated components of working memory: Evidence from Down's syndrome and Williams syndomre. Neuropsychologia, 37, 637-651. doi: 10.1016/S0028-3932(98)00128-6

John, A. E., \& Mervis, C. B. (2010). Comprehension of the communicative intent behind pointing and gazing gestures by young children with Williams syndrome or Down syndrome. Journal of Speech, Language, and Hearing Research, 53, 950-960. doi: 10.1044/1092-4388(2009/08-0234)

Jones, W., Bellugi, U., Lai, Z., Chiles, M., Reilly, J., Lincoln, A., et al. (2000). II. Hypersociability in Williams syndrome. Journal of Cognitive Neuroscience, 12, 30-46. doi:10.1162/089892900561968

Kasari, C., Freeman, S., Mundy, P., \& Sigman, M. D. (1995). Attention regulation by children with Down syndrome: Coordinated joint attention and social referencing looks. American Journal on Mental Retardation, 100, 128-136.

Kasari, C., Freeman, S. F., \& Hughes, M. A. (2001). Emotion recognition by children with Down syndrome. American Journal on Mental Retardation, 106, 59-72. doi: 10.1352/0895-8017(2001)106<0059:ERBCWD $>2.0 . \mathrm{CO} ; 2$

Kasari, C., \& Freeman, S. F. N. (2002). Task-related social behavior in children with Down syndrome. American Journal of Mental Retardation, 106, 253-264. doi: 10.1352/0895-8017(2001)106<0253:TRSBIC $>2.0 . \mathrm{CO} ; 2$

Kasari, C., Mundy, P., Yirmiya, N., \& Sigman, M. (1990). Affect and attention in children with Down syndrome. American Journal of Mental Retardation, 95, 5567.

Kaufman, P., Leckman, J., \& Ort, S. (1989). Delayed response performance in males with Fragile X. Journal of Clinical and Experimental Neuropsychology, 12, 69.

Klein-Tasman, B. P., \& Mervis, C. B. (2003). Distinctive personality characteristics of 8-, 9-, and 10-year-olds with Williams syndrome. Developmental Neuropsychology, 23, 269-290. doi:10.1207/S15326942DN231\&2_12

Klein-Tasman, B. P., Mervis, C. B., Lord, C., \& Phillips, K. (2007). Sociocommunicative deficits in young children with Williams syndrome: Performance on the Autism Diagnostic Observation Schedule. Child Neuropsychology, 13, 444-467. doi:10.1080/09297040601033680

Klein-Tasman, B. P., Phillips, K., Lord, C., Mervis, C. B., \& Gallo, F. J. (2009). Overlap with the autism spectrum in young children with Williams syndrome. Journal of Developmental and Behavioral Pediatrics, 30, 289-299. doi:10.1097/DBP.0b013e3181ad1f9a 
Klein, B. P., \& Mervis, C. B. (1999). Contrasting patterns of cognitive abilities of 9- and 10-year-olds with Williams syndrome or Down syndrome. Developmental Neuropsychology, 16, 177-196. doi: 10.1207/S15326942DN1602_3

Klinnert, M. D., Campos, J. J., Sorce, J. F., Emde, R. N., \& Svejda, M. (1983). Emotions as behavior regulators: Social referencing in infancy. In R. Plutchik \& $\mathrm{H}$.

Kellerman (Eds.), Emotion: Theory, research and experience (Vol. 2, pp. 57-86). New York, NY: Academic Press.

Klinnert, M. D., Emde, R. N., Butterfield, P., \& Campos, J. J. (1986). Social referencing: The infant's use of emotional signals from a friendly adult with mother present. Developmental Psychology, 22, 427-432. doi: 10.1037/0012-1649.22.4.427

Knieps, L., Walden, T. A., \& Baxter, A. (1994). Affective expressions of toddlers with and without Down syndrome in a social referencing context. American Journal of Mental Retardation, 99, 301-312.

Korenberg, J. R., Chen, X. N., Schipper, R., Sun, Z., Gonsky, R., Gersehr, S., et al. (1994). Down syndrome phenotypes: The consequences of chromosomal imbalances. Proceedings of the National Academy of Sciences, 91, 4997-5001. doi: 10.1073/pnas.91.11.4997

Laing, E., Butterworth, G., Ansari, D., Gsodl, M., Longhi, E., Panagiotaki, G., et al. (2002). Atypical development of language and social communication in toddlers with Williams syndrome. Developmental Science, 5, 233-246. doi:10.1111/14677687.00225

Leekam, S., Baron-Cohen, S., Perrett, D., Milders, M., \& Brown, S. (1997). Eyedirection detection: A dissociation between geometric and joint attention skills in autism. British Journal of Developmental Psychology, 15, 77-95.

Lewy, A. L., \& Dawson, G. (1992). Social stimulation and joint attention in young autistic children. Journal of Abnormal Child Psychology, 20, 555-566. doi:10.1007/BF00911240

Lincoln, A. J., Searcy, Y. M., Jones, W., \& Lord, C. (2007). Social interaction behaviors discriminate young children with autism and Williams syndrome. Journal of the American Academy of Child and Adolescent Psychiatry, 46, 323-331. doi:10.1097/chi.0b013e31802b9522

Lord, C., Rutter, M., DiLavore, P. C., \& Risi, S. (Eds.). (1999). Autism Diagnostic Observation Schedule - WPS Edition. Los Angeles, CA: Western Psychological Services.

Meltzoff, A. N. (1995). Understanding the intentions of others. Re-enactment of intended acts by 18-month-old children. Developmental Psychology, 31, 838-850. doi:10.1037/0012-1649.31.5.838 
Mervis, C. B., \& Becerra, A. M. (2007). Language and communication development in Williams syndrome. Mental Retardation and Developmental Disabilities Research Reviews, 13, 3-15. doi:10.1002/mrdd.20140

Mervis, C. B., \& Bertrand, J. (1993). Acquisition of early object labels: The roles of operating principles and input. In A. P. Kaiser \& D. B. Gray (Eds.), Enhancing children's communication: Research foundations for intervention. (pp. pp. 287316). Baltimore, MD: Brookes.

Mervis, C. B., \& Bertrand, J. (1997). Developmental relations between cognition and language: Evidence from Williams syndrome. In L. B. Adamson \& M. A. Romski (Eds.), Research on communication and language disorders: Contributions to theories of language development (pp. 75-106). Baltimore, MD: Brookes.

Mervis, C. B., \& John, A. E. (2008). Vocabulary profiles in Williams syndrome: Strengths, weaknesses, and relation to nonverbal cognition. Journal of Speech, Language, and Hearing Research, 51, 967-982. doi: 10.1044/10924388(2008/071)

Mervis, C. B., \& John, A. E. (2010). Cognitive and behavioral characteristics of Williams syndrome. American Journal of Medical Genetics Part C Seminars in Medical Genetics, 154C, 266-276. doi:10.1002/ajmg.c.30263

Mervis, C. B., \& John, A. E. (in press). Precursors to language and early language development in Williams syndrome. In E. K. Farran \& A. Karmiloff-Smith (Eds.), Neuroconstructivism: The multidisciplinary study of genetic syndromes from infancy to adulthood. Oxford, England: Oxford University Press.

Mervis, C. B., \& Klein-Tasman, B. P. (2000). Williams syndrome: Cognition, personality, and adaptive behavior. Mental Retardation and Developmental Disabilities Research Reviews, 6, 148-158. doi:10.1002/10982779(2000)6:2<148::AID-MRDD10>3.0.CO;2-T

Mervis, C. B., \& Morris, C. A. (2007). Williams syndrome. In M. M. M. Mazzocco \& J. L. Ross (Eds.), Neurogenetic developmental disorders: Variation of manifestation in childhood (pp. 199-262). Cambridge, MA: MIT Press.

Mervis, C. B., Morris, C. A., Klein-Tasman, B. P., Bertrand, J., Kwitny, S., Appelbaum, L. G., et al. (2003). Attentional characteristics of infants and toddlers with Williams syndrome during triadic interactions. Developmental Neuropsychology, 23, 243-268. doi:10.1207/S15326942DN231\&2_11

Mervis, C. B., Robinson, B. F., Bertrand, J., Morris, C. A., Klein-Tasman, B. P., \& Armstrong, S. C. (2000). The Williams syndrome cognitive profile. Brain and Cognition, 44, 602-628. doi:10.1006/brcg.2000.1232

Miller, J. F., \& Leddy, M. (1999). Verbal fluency, speech intelligibility, and communicative effectiveness. In J. F. Miller, M. Leddy \& L. A. Leavitt (Eds.), 
Improving the communication of people with Down syndrome (pp. 81-91).

Baltimore, MD: Brookes.

Moore, C. (1999). Gaze following and the control of attention. In P. Rochat (Ed.), Early social cognition: Understanding others in the first months of life (pp. 241-256). Mahwah, NJ: Erlbaum.

Moore, C., \& Corkum, V. (1994). Social understanding at the end of the first year of life. Developmental Review, 14, 349-372. doi:10.1006/drev.1994.1014

Morris, C. A. (2006). The dysmorphology, genetics, and natural history of WilliamsBeuren syndrome. In C. A. Morris, H. M. Lenhoff \& P. P. Wang (Eds.), WilliamsBeuren syndrome: Research, evaluation and treatment (pp. 3-17). Baltimore, MD: The Johns Hopkins University Press.

Moses, L. J., Baldwin, D. A., Rosicky, J. G., \& Tidball, G. (2001). Evidence for referential understanding in the emotions domain at twelve and eighteen months. Child Development, 72, 718-735. doi:10.1111/1467-8624.00311

Mullen, E. M. (1995). Mullen Scales of Early Learning. Circle Pines, MN: American Guidance Service.

Mumme, D. L., Fernald, A., \& Herrera, C. (1996). Infants' responses to facial and vocal emotional signals in a social referencing paradigm. Child Development, 67, 32193237. doi: $10.2307 / 1131775$

Mundy, P. (1995). Joint attention and social-emotional approach behavior in children with autism. Development and Psychopathology, 7, 63-82. doi:

$10.1017 / \mathrm{S} 0954579400006349$

Mundy, P., Block, J., Delgato, C., Pomares, Y., Vaughn Van Hecke, A., \& Venezia Parlade, M. (2007). Individual differences and the development of joint attention in infancy. Child Development, 78, 938-954. doi: doi:10.1111/j.14678624.2007.01042.x

Mundy, P., \& Hogan, A. (1996). A preliminary manual for the abridged Early Social Communication Scales (ESCS). Available through the University of Miami Psychology Department: Coral Gables, FL:

http://www.psy.miami.edu/faculty/pmundy/ESCS.pdf.

Mundy, P., \& Neal, A. (2001). Neural plasticity, joint attention, and a transactional social-orienting model of autism. International Review of Research in Mental Retardation, 12, 139-168.

Mundy, P., Sigman, M., \& Kasari, C. (1993). The theory of mind and joint-attention deficits in autism. In S. Baron-Cohen, H. Tager-Flusberg \& D. Cohen (Eds.), Understanding other minds: Perspectives from autism (pp. 181-203). New York, NY: Oxford University Press. 
Mundy, P., Sigman, M., Kasari, C., \& Yirmiya, N. (1988). Nonverbal communication skills in Down syndrome children. Child Development, 59, 235-249. doi:

$10.2307 / 1130406$

Mutton, D., Alberman, E., \& Hook, E. B. (1996). Cytogenetic and epidemiological findings in Down syndrome, England and Wales 1989 to 1993. Journal of Medical Genetics, 33, 387-394. doi: 10.1136/jmg.33.5.387

Noldus. (2010). The Observer XT. Wageningen, The Netherlands: Noldus Information Technology b.v.

Nowicki, S., Jr., \& Duke, M. P. (1994). Individual differences in the nonverbal communication of affect: The Diagnostic Analysis of Nonverbal Accuracy Scale. Journal of Nonverbal Behavior, 18, 9-35.

Phillips, W., Baron-Coben, S., \& Rutter, M. (1992). The role of eye contact in goal detection: Evidence from normal infants and children with and without autism or mental handicap. Development and Psychopathology, 4, 375-383. doi: $10.1017 / \mathrm{S} 0954579400000845$

Pitcairn, T., \& Wishart, J. (1994). Reactions of young children with Down's syndrome to an impossible task. British Journal of Developmental Psychology, 12, 485-489.

Plesa-Skwerer, D., Faja, S., Schofield, C., Verbalis, A., \& Tager-Flusberg, H. (2006). Perceiving facial and vocal expressions of emotion in individuals with Williams syndrome. American Journal on Mental Retardation, 111, 15-26. doi: 10.1352/0895-8017(2006)111[15:PFAVEO]2.0.CO;2

Porter, M. A. (2008). Cognitive and social skills in neurodevelopmental disorders: An examination of Williams syndrome, Down syndrome, and Autism. Saarbrücken, Germany: VDM Verlag Dr. Müller Aktiengesellschaft \& Co. .

Porter, M. A., Coltheart, M., \& Langdon, R. (2007). The neuropsychological basis of hypersociability in Williams and Down syndrome. Neuropsychologia, 45, 28392849. doi:10.1016/j.neuropsychologia.2007.05.006

Pueschel, S. M., Bernier, J. C., \& Pezzullo, J. C. (1991). Behavioural observations in children with Down's syndrome. Journal of Intellectual Disability Research, 35, 502-511. doi: 10.1111/j.1365-2788.1991.tb00447.x

Repacholi, B. (1998). Infant's use of attentional cues to identify the referent of another person's emotional expression. Developmental Psychology, 34, 1017-1025. doi:10.1037/0012-1649.34.5.1017

Robins, D. L., Fein, D., Barton, M. L., \& Green, J. A. (2001). The Modified Checklist for Autism in Toddlers: An initial study investigating the early detection of autism and pervasive developmental disordesr. Journal of Autism and Developmental Disorders, 31, 131-144. doi: doi:10.1023/A:1010738829569 
Rodgers, C. (1987). Maternal support for the Down's syndrome stereotype: The effect of direct experience of the condition. Journal of Mental Deficiency Research, 85, 318-321.

Rosen, W. D., Adamson, L. B., \& Bakeman, R. (1992). An experimental investigation of infant social referencing: Mothers' messages and gender differences. Developmental Psychology, 28, 1172-1178.

Rothbart, M. K., Ahadi, S. A., Hershey, K. L., \& Fisher, P. (2001). Investigations of temperament at three to seven years: the Children's Behavior Questionnaire. Child Development, 72, 1394-1408. doi:10.1111/1467-8624.00355

Rowe, M. L. (2007). Mastery motivation in young children with Williams syndrome or Down syndrome (Doctoral Dissertation). Available from ProQuest Dissertations and Theses database (UMI No. 3267110)

Rowe, M. L., Peregrine, E., \& Mervis, C. B. (2005, April). Communicative development in toddlers with Williams syndrome. Poster presented at the Society for Research in Child Development. Atlanta, GA.

Saarni, C., Campos, J. J., Camras, L. A., \& Witherington, D. (2006). Emotional development: Action, communication, and understanding. In N. Eisenberg, W. Damon, \& R. M. Lerner (Eds.), Handbook of child psychology (Vol. 3, pp. 226299). Hoboken, NJ: Wiley.

Saxon, T. F., Frick, J. E., \& Colombo, J. (1997). A longitudinal study of maternal interactional styles and infant visual attention. Merrill-Palmer Quarterly, 43, 4866.

Scambler, D. J., Hepburn, S., Rutherford, M. D., Wehner, E. A., \& Rogers, S. J. (2007). Emotional responsivity in children with autism, children with other developmental disabilities, and children with typical development. Journal of Autism and Developmental Disorders, 37, 553-563. doi:10.1007/s10803-0060186-y

Sheinkopf, S. J., Mundy, P., Claussen, A. H., \& Willoughby, J. (2004). Infant joint attention skill and preschool behavioral outcomes in at-risk children, Development and Psychopathology, 16, 273-291. doi:10.1017/S0954579404044517

Sigman, M., Arbelle, S., \& Dissanayake, C. (1995). Current research findings on childhood autism. Canadian Journal of Psychiatry, 40, 289-294.

Sigman, M., Kasari, C., Kwon, J.-h., \& Yirmiya, N. (1992). Responses to the negative emotions of others by autistic, mentally retarded, and normal children. Child Development, 63, 796-807. doi: 10.2307/1131234 
Sigman, M., \& Ruskin, E. (1999). Continuity and change in the social competence of children with autism, Down syndrome, and developmental delays. Monographs of the Society for Research in Child Development, 64, v-114.

Sorce, J., Emde, R., Campos, J., \& Klinnert, M. (1985). Maternal emotional signaling: Its effect on the visual cliff behavior of 1-year-olds. Developmental Psychology, 21, 195-200. doi: 10.1037/0012-1649.21.1.195

Stenberg, G. (2003). Effects of maternal inattentiveness on infant social referencing. Infant and Child Development, 12, 399-419. doi:10.1002/icd.321

Stinton, C., Elison, S., \& Howlin, P. (2010). Mental health problems in adults with Williams syndrome. American Journal of Intellectual and Developmental Disabilities, 115, 3-18. doi:10.1352/1944-7558-115.1.3

Strømme, P., Bjørnstad, P. G., \& Ramstad, K. (2002). Prevalence estimation of Williams syndrome. Journal of Child Neuropsychology, 17, 269-271.

Sullivan, K., Winner, E., \& Tager-Flusberg, H. (2003). Can adolescents with Williams syndrome tell the difference between lies and jokes? Developmental Neuropsychology, 23, 85-104. doi:10.1207/S15326942DN231\&2_5

Tager-Flusberg, H., \& Plesa Skwerer, D. (2006). Social engagement in Williams syndrome. In P. J. Marshall \& N. Fox (Eds.), The development of social engagement: Neurobiological perspectives (pp. 331-354). Oxford, England: Oxford University Press.

Tager-Flusberg, H., \& Sullivan, K. (2000). A componential view of theory of mind: Evidence from Williams syndrome. Cognition, 76, 59-89. doi: 10.1016/S00100277(00)00069-X

Termine, N. T., \& Izard, C. E. (1988). Infants' responses to their mothers' expressions of joy and sadness. Developmental Psychology, 24, 223-229. doi: 10.1037/00121649.24 .2 .223

Thompson, R. A. (2006). The development of the person: Social understanding, relationships, conscience, and self. In N. Eisenberg, W. Damon \& R. M. Lermer (Eds.), Handbook of child psychology (Vol. 3, pp. 24-98). Hoboken, NJ: Wiley.

Thorndike, R. L., Hagen, E. P., \& Sattler, J. M. (1986). Stanford-Binet Intelligence Scale (4th ed.). Chicago, IL: Riverside.

Tomasello, M. (Ed.). (1995). Joint attention as social cognition. Hillsdale, NJ: Erlbaum.

Tomasello, M., Carpenter, M., Call, J., Behne, T., \& Moll, H. (2005). Understanding and sharing intentions: The origins of cultural cognition. Behavioral and Brain Sciences, 28, 675-735. doi:10.1017/S0140525X05000129 
Trevarthen, C., \& Aitken, K. J. (2001). Infant intersubjectivity: Research, theory, and clinical applications. Journal of Child Psychology and Psychiatry, 42, 3-48. doi: 10.1111/1469-7610.00701

Trevarthen, C., \& Hubley, P. (1978). Secondary intersubjectivity: Confidence, confiding and acts of meaning in the first year. In A. Lock (Ed.), Action, gesture and symbol: The emergence of language (pp. 183-229). New York, NY: Academic Press.

Udwin, O., \& Yule, W. (1991). A cognitive and behavioural phenotype in Williams syndrome. Journal of Clinical and Experimental Neuropsychology, 13, 232-244. doi:10.1080/01688639108401040

Vaish, A., \& Striano, T. (2004). Is visual reference necessary? Contributions of facial versus vocal cues in 12-month-olds' social referencing behavior. Developmental Science, 7, 261-269. doi:10.1111/j.1467-7687.2004.00344.x

Walden, T. A., Knieps, L., \& Baxter, A. (1991). Contingent provision of social referential information by parents of chidlrenw ith and without developmental disabilities. American Journal of Mental Retardation, 96, 177-187.

Walden, T. A., \& Baxter, A. (1989). The effect of context and age on social referencing. Child Development, 60, 1511-1518. doi:10.2307/1130939

Walden, T. A., \& Kim, G. (2005). Infants' social looking toward mothers and strangers. International Journal of Behavioral Development, 29, 356-360.

Walden, T. A., \& Ogan, T. A. (1988). The development of social referencing. Child Development, 59, 1230-1240. doi:10.2307/1130486

Warreyn, P., Roeyers, H., \& De Groote, I. (2005). Early social communicative behaviours of preschoolers with autism spectrum disorder during interaction with their mothers. Autism, 9, 342-361. doi:10.1177/1362361305056076

Wetherby, A. M., \& Prizant, B. M. (1993). Communication and Symbolic Behavior Scales Developmental Profile - First Normed Edition. Balitmore, MD: Brookes.

Wetherby, A. M., \& Prizant, B. M. (2002). Communication and Symbolic Behavior Scales - Developmental Profile Behavior Sample. Baltimore, MD: Brookes.

Wetherby, A. M., Watt, N., Morgan, L., \& Shumway, S. (2007). Social communication profiles of children with autism spectrum disorders late in the second year of life. Journal of Autism and Developmental Disorders, 37, 960-975. doi:10.1007/s10803-006-0237-4

Williams, K. R., Wishart, J. G., Pitcairn, T. K., \& Willis, D. S. (2005). Emotion recognition by children with Down syndrome: Investigation of specific 
impairments and error patterns. American Journal on Mental Retardation, 110, 378-392. doi:10.1352/0895-8017(2005)1 10[378:ERBCWD]2.0.CO;2

Wishart, J., \& Johnston, F. H. (1990). The effects of experience on attribution of a stereotyped personality to children with Down's syndrome. Journal of Mental Deficiency Research, 34, 409-420.

World Health Organization. (1996). Multiaxial classification of child and adolescent psychiatric disorders: The ICD-10 classification of mental and behavioral disorders in children and adolescents. Cambridge, England: Cambridge University Press.

Zarbatany, L., \& Lamb, M. E. (1985). Social referencing as a function of information source: Mothers versus strangers. Infant Behavior \& Development, 8, 25-33. doi:10.1016/S0163-6383(85)80014-X

Zigler, E. (1971). The retarded child as a whole person. In H. E. Adams \& W. K. Boardman (Eds.), Advances in experimental clinical psychology (pp. 47-121). New York, NY: Pergamon. 


\section{CURRICULUM VITAE}

\section{ANGELA E. JOHN}

\section{Contact Information:}
Work Address:
Department of Psychological and Brain Sciences University of Louisville
Louisville, KY 40292
Phone:
(502) 852-4638 (voice)
(502) 852-8271 (fax)
E-Mail:
aejohn11@louisville.edu

\section{Education:}

\section{University of Louisville}

Louisville, KY

Ph.D., Experimental Psychology:

Cognitive and Developmental Sciences

University of Louisville

Louisville, KY

M.A., Experimental Psychology:

Cognitive and Developmental Sciences

\section{University of Colorado at Denver}

Denver, CO

B.A., Psychology

\section{Honors, Awards, and Fellowships:}

August 2011 - July 2013 Post-doctoral Fellowship

Medical Investigation of Neurodevelopmental Disorders (MIND) Institute

University of California - Davis

March 2011 Trainee

NIH-funded Interdisciplinary Training Conference in Developmental Disabilities San Antonio, TX 
June - July 2005 Trainee

Summer Institute in Cognitive Neuroscience

Dartmouth University, Hanover, $\mathrm{NH}$

Professional History:

$\begin{array}{lcc}\text { Research Coordinator } & (2010 \text { - present }) & \begin{array}{c}\text { University of Louisville, } \\ \text { Neurodevelopmental } \\ \text { Sciences Laboratory }\end{array} \\ \text { Graduate Research Assistant } & \text { (2004- 2010) } & \begin{array}{c}\text { University of Louisville, } \\ \text { Neurodevelopmental } \\ \text { Sciences Laboratory }\end{array} \\ & & \\ \text { Project Coordinator } & (2003-2004) & \text { University of Colorado } \\ & & \text { Health Sciences Center, } \\ & & \text { Early Emergence of the } \\ & \text { Williams Syndrome } \\ & \text { Behavioral Phenotype } \\ \text { Professional Research Assistant }(2000-2004) & \text { University of Colorado } \\ & \text { Health Sciences Center, } \\ & \text { Autism Research Studies }\end{array}$

\section{Teaching Experience:}

March 2011 Guest lecturer for Spalding University, Louisville, KY

Course: Graduate Course ABA 609, Developmental Disabilities

Topic: Williams syndrome

October 2009 Guest lecturer for University of Louisville, Louisville, KY

Course: Graduate Topical Seminar PSYC 609, Social Communication

Topic: Intersubjectivity: Joint Attention, Intentionality, and Social Referencing

August 2009 Guest lecturer University of Louisville, Louisville, KY

Course: Graduate Topical Seminar PSYC 609, Social Communication

Topic: Primate Social Cognition

Fall 2007 Teaching practicum for University of Louisville, Louisville, KY

Course: Graduate Topical Seminar PSYC 609, Developmental Assessment

October 2005 Grand Rounds Instructor for University of Nevada School of Medicine

Topic: Autism for Practitioners 


\section{Publications:}

Mervis, C. B. \& John, A. E. (in press). Precursors to language and early language development in Williams syndrome. In E. Farran \& A. Karmiloff-Smith (Eds.), Neuroconstructivism: The multidisciplinary study of genetic syndromes from infancy to adulthood. Oxford, UK: Oxford University Press.

John, A. E. \& Mervis, C. B. (2010). Comprehension of the communicative intent behind pointing and gazing gestures by young children with Williams syndrome or Down syndrome. Journal of Speech, Language, and Hearing Research, 53, 950 - 960.

Mervis, C. B., \& John, A. E. (2010). Cognitive and behavioral characteristics of children with Williams syndrome: Implications for intervention approaches. American Journal of Medical Genetics Part C Seminars in Medical Genetics, 154C, $229-248$.

John, A. E. \& Mervis, C. E. (2010). Sensory modulation impairments in children with Williams syndrome. American Journal of Medical Genetics Part C Seminars in Medical Genetics, $154 C, 266-276$.

Mervis, C. B., \& John, A. E. (2010). Intellectual disability syndromes. In K. O. Yeates, M. D. Ris, H. G. Taylor, \& B. F. Pennington (Eds.), Pediatric neuropsychology: Research, theory and practice, 2 nd ed. (pp. $447-470$ ). New York: Guilford Press.

Mervis, C. B. \& John, A. E. (2009). Williams syndrome: Psychological characteristics. In B. K. Shapiro \& P. J. Accardo (Eds.), Neurogenetic syndromes: Behavioral issues and their treatment (pp. 81 -99). Baltimore: Brookes Publishing.

John, A. E., Rowe, M. L., \& Mervis, C. B. (2009). Referential communication skills of children with Williams syndrome: Understanding when messages are not adequate. American Journal on Intellectual and Developmental Disabilities, 114, 85 - 99.

Mervis, C. B., \& John, A. E. (2008). Vocabulary abilities of children with Williams syndrome: Strengths, weaknesses, and relation to visuospatial construction ability. Journal of Speech, Language, and Hearing Disorders, 51, 967 - 982.

Hepburn, S., Philofsky, A., John, A. E., \& Fidler, D. (2005). A case study of early development in Williams syndrome: Implications for early intervention. Infants and Young Children, 18, $234-244$

\section{Conference Presentations:}

John, A. E. \& Mervis, C. B. (2011, March). The regulatory function of social referencing in preschoolers with Down syndrome or Williams syndrome. Poster presented at Gatlinburg Conference on Research and Theory in Intellectual and Developmental Disabilities, San Antonio, TX.

John, A. E., Thomas, L. E., Dobson, L. A., \& Mervis, C. B. (2010, June). Preschool pragmatic abilities predict school-age pragmatic abilities of children with Williams syndrome. Poster presented at the Symposium on Research in Child Language Disorders, Madison, WI. 
Henderson, D. R., Becerra, A. M., John, A. E., \& Mervis, C. B. (2010, June). Language abilities in toddlers with Williams syndrome: Performance on the CDI-III. Poster presented at the Symposium on Research in Child Language Disorders, Madison, WI.

Becerra, A. M., Henderson, D. R., John, Angela E., \& Mervis, C. B. (2010, June). Relations between early linguistic milestones and intellectual abilities at age 4 years for children with Williams syndrome. Poster presented at the Symposium on Research in Child Language Disorders, Madison, WI.

Henderson, D. R., John, A. E., \& Mervis, C. B. (2010, March). Problem behaviors in preschoolers with Williams syndrome or Down syndrome. Poster presented at the Kentucky Psychological Association Academic Conference, Louisville, KY.

Harmon, A. A., John, A. E., \& Mervis, C. B. (2010, June). Literacy skills of 9 -17-year-olds with Williams syndrome: Impact of reading method. Poster presented at the Symposium on Research in Child Language Disorders, Madison, WI.

Harmon, A. A., John, A. E., \& Mervis, C. B. (2009, June). Pragmatic language ability in children with Williams syndrome. Poster presented at the Symposium on Research in Child Language Disorders, Madison, WI.

John, A. E., \& Mervis, C. B. (2009, June). The relation between theory of mind and language in children with Williams syndrome. Poster presented at the Society for Research in Child Language Disorders. Madison, WI.

John, A. E., \& Mervis, C. B. (2009, April). Sensory modulation problems in children with Williams syndrome. Poster presented at the Society for Research in Child Development, Denver, CO.

Mervis, C. B., Kistler, D. J., Peregrine, E., \& John, A. E. (2008, July). Longitudinal assessment of receptive vocabulary in children and adolescents with Williams syndrome: A multilevel modeling analysis. Poster presented at the International Williams Syndrome Association Professional Conference, Anaheim, CA.

John, A. E., Becerra, A. M., Peregrine, E., \& Mervis, C. B. (2008, July). Variability of language abilities of young 4-year-olds who have Williams syndrome. Poster presented at the International Williams Syndrome Association Professional Conference, Anaheim, CA.

John, A. E. \& Mervis, C. B. (2008, July). Sensory modulation in children with Williams syndrome. Poster presented at the International Williams Syndrome Association Professional Conference, Anaheim, CA.

Crawford, N. A., John, A. E., Woodruff-Borden, J., Mervis, C. B. (2008, July). Sensory processing difficulties predict internalizing symptoms, ADHD symptoms, and repetitive behaviors in 4-10 year old children with Williams syndrome. Poster presented at the International Williams Syndrome Association Professional Conference, Anaheim, CA.

Cashon, C., John, A. E., \& Mervis, C. B. (2008, July). Self recognition by toddlers with Williams syndrome. Poster presented at the International Williams Syndrome Association Professional Conference, Anaheim, CA. 
Becerra, A. M., John, A. E., Peregrine, E., \& Mervis, C. B. (2008, July). Reading abilities of 9 17-year-olds with Williams syndrome: Impact of reading method. Poster presented at the International Williams Syndrome Association Professional Conference, Anaheim, CA.

Mervis, C. B., Velleman, S. L., John, A. E., Currier, A., Peregrine, E., Becerra, A. M., \& Morris, C. A. (2008, July). Intellectual and behavioral characteristics of individuals with Williams syndrome or duplication of the Williams syndrome region. Platform presentation at the International Williams Syndrome Association Professional Conference, Anaheim, CA.

Morris, C. A., Velleman, S. L., Mervis, C. B., John, A. E., Currier, A., Peregrine, E., Rios, C., Kimberley, K., Hobart, H., Gowan, G., \& Gulbronson, M. (2008, July). Copy number variation in the Williams syndrome region: Detection of 7 q11.23 duplication by microarray allows phenotypic comparison. Platform presentation at the International Williams Syndrome Association Professional Conference, Anaheim, CA.

John, A. E., \& Mervis, C. B. (2008, July). Comprehension of communicative intent behind pointing and gazing gestures by young children with Williams syndrome or Down syndrome. Platform presentation at the International Williams Syndrome Association Professional Conference, Anaheim, CA.

Becerra, A. M., John, A. E., Peregrine, E., \& Mervis, C. B. (2008. June). Reading abilities of 9 12-year-olds with Williams syndrome: Impact of reading method. Poster presented at the Symposium on Research in Child Language Disorders, Madison, WI.

John, A. E., \& Mervis, C. B. (2008, June). Early pragmatic abilities in Williams syndrome and Duplication 7q11.23 syndrome: A case comparison. Poster presented at the Symposium on Research in Child Language Disorders, Madison, WI.

John, A. E., Becerra, A. M., Peregrine, E., \& Mervis, C. B. (2008, June). Variability of language abilities of young 4-year-olds who have Williams syndrome. Poster presented at the Symposium on Research in Child Language Disorders, Madison, WI.

Morris, C. A., Velleman, S., Mervis, C. B., John, A. E., Currier, A., Peregrine, E. Rios, C. Hobart, H., Gowans, G. (2008, March). Duplication 7ql1.23 phenotype. Poster presented at the American College of Medical Genetics, Phoenix, AZ.

Morris, C. A., Pani, A. M., John, A. E., Rios, C. M., Kimberley, K. W., Hobart, H. H., Gregg, R. G., \& Mervis, C. B. (2007, August). Mechanism of facial dysmorphogenesis in Williams syndrome: Combination of haploinsufficiency of ELN and GTF2IRD1 genes plus the epigenetic effects of age and hypotonia. Platform presentation at the David W. Smith Malformations and Morphogenesis meeting, Williamsburg, VA.

John, A. E., \& Mervis, C. B. (2007, June). Comprehension of the communicative intent behind pointing and gazing gestures by young children with Williams syndrome or Down syndrome. Poster presented at the Symposium on Research in Child Language Disorders, Madison, WI.

John, A. E., Rowe, M. L., \& Mervis, C. B. (2007, March). Comprehension of the communicative intent behind pointing and gazing gestures by young children with Williams syndrome. Poster presented at the Society for Research in Child Development, Boston, MA. 
Cashon, C. H., John, A. E., \& Mervis, C. B. (2007, March). Self-Recognition by toddlers with Williams syndrome. Poster presented at the Society for Research in Child Development, Boston, MA.

McNally, R. H., Klein-Tasman, B. P., John, A. E., Risi, S., \& Mervis, C. B. (2006, July). Relations between socio-communicative performance and intellectual, language, and adaptive behavior abilities in children with Williams syndrome. Poster presented at the International Williams Syndrome Association Professional Conference, Richmond, VA.

Mervis, C. B., Kistler, D. J., Peregrine, E., Rowe, M. L., \& John, A. E. (2006, July). Longitudinal assessment of intelligence in children and adolescents with Williams syndrome: A multilevel modeling analysis. Poster presented at the International Williams Syndrome Association Professional Conference, Richmond, VA.

John, A. E., Douglas, S. K., Hutchins, S. G., \& Mervis, C. B. (2006, July). The impact of parental input frequency and phonological characteristics of early vocabulary by children with Williams syndrome and typically developing children. Poster presented at the International Williams Syndrome Association Professional Conference, Richmond, VA.

John, A. E., Rowe, M. L., Peregrine, E., \& Mervis, C. B. (2006, July). Verbalizations of message inadequacy in children with Williams syndrome. Poster presented at the International Williams Syndrome Association Professional Conference, Richmond, VA.

John, A. E., Peregrine, E., Rowe, M. L., \& Mervis, C. B. (2006, July). Comparison of performance on the Kaufman Brief Intelligence Test (KBIT) and the Kaufman Brief Intelligence Test, second edition (KBIT-2) by children and adolescents who have Williams syndrome. Poster presented at the International Williams Syndrome Association Professional Conference, Richmond, VA.

John, A. E., Douglas, S. K., Hutchins, S., \& Mervis, C. B. (2006, June). Factors affecting the age of acquisition of early vocabulary in children with Williams syndrome and typically developing children. Poster presented at the Symposium on Research in Child Language Disorders, Madison, WI.

McNally, R. H., Klein-Tasman, B. P., John, A. E., Risi, S., Phillips, K. D., \& Mervis, C. B. (2006, June). Investigating the relation between socio-communicative deficits and intellectual and language abilities in children with Williams syndrome using the Autism Diagnostic Observation Schedule (ADOS). Poster presented at the International Meeting for Autism Research (IMFAR), Montreal, Canada.

McNally, R. H., Klein-Tasman, B. P., John, A. E., Risi, S., Phillips, K. D., \& Mervis, C. B. (2006, April). Relation between social communication and cognitive ability in children with Williams syndrome. Paper presented at the Conference on Human Development (CHD), Louisville, KY.

John, A. E., Rowe, M. L., Peregrine, E., \& Mervis, C. B. (2006, April). Referential communication ability of school age children with Williams syndrome: Verbalizing message inadequacy. Paper presented at the Conference on Human Development (CHD), Louisville, $\mathrm{KY}$. 
Rowe, M. L., Peregrine, E., John, A. E., Baugher, M. H., \& Mervis, C. B. (2006, April). Language and cognitive abilities of young 4-year-olds with Williams syndrome. Poster presented at the Conference on Human Development (CHD), Louisville, KY.

Morris, C. A., Mervis, C. B., Peregrine, E., Rowe, M. L., John, A. E., Hobart, H. H., Fricke, J. S., Somerville, M. J., Bamforth, S., Perez-Jurado, L., Scherer, S. W., Osborne, L. R. (2005, August). Duplication of the Williams syndrome region: Genotype/phenotype correlations. Platform presentation at the David W. Smith Malformations and Morphogenesis meeting, Iowa City, Iowa.

John, A. E., Rowe, M. L., Rollins, I., \& Mervis, C. B. (2005, June). Referential communication abilities in children with Williams syndrome: Understanding when messages are not adequate. Poster presented at the Symposium on Research in Child Language Disorders, Madison, WI.

Mervis, C. B., Peregrine, E., Rowe, M. L. John, A. E., Somerville, M. J., Bamforth, J. S., PerezJurado, L., Scherer, S. W., Osborne, L. R., \& Morris, C. A. (2005, June). Genotype/phenotype correlations in language and cognitive development: Contrasting effects of deletion and duplication of the Williams syndrome region. Poster presented at the Symposium on Research in Child Language Disorders, Madison, WI.

John, A. E., Fidler, D., Philofsky, A., \& Hepburn, S. (2004, June). Early emergence of the Williams syndrome behavioral phenotype: An analysis of pilot data. Poster presented at the Linking Research to Practice Conference, Denver, CO.

Scambler D. J., Rogers S. J., Rutherford M. D., Hepburn S., Hayes, A., John, A. E., Hagerman, R. (2003, June). Children's reactions to adults' displays of emotion: Differences among reactions of typical children and children with autism and other developmental disorders. Poster presented at the International Society for Research in Child and Adolescent Psychopathology (ISRCAP), Sydney, Australia.

Hepburn, S., Rogers, S., John, A. E., \& Philofsky, A. (2002, October) Sensitivity and specificity of the Autism Diagnostic Observation Schedule (ADOS) in young children with Autism and other developmental disorders. Poster presented at the International Meeting for Autism Research (IMFAR), Orlando, FL.

John, A. E., Hepburn, S., Philofsky, A., \& Rogers, S. (2002, May) Diagnostic validity of the Autism Diagnostic Observation Schedule (ADOS) in young children with Autism and other developmental disabilities. Poster presented at the annual meeting of the Developmental Psychobiology Research Group (DPRG), Estes Park, CO.

\section{Editorial Responsibilities: Journals}

Ad Hoc Reviewer: American Journal on Intellectual and Developmental Disabilities Journal of Neurolinguistics

Journal of Speech, Language, and Hearing Research 


\section{Membership in Professional Organizations:}

American Association on Intellectual and Developmental Disabilities (AAIDD) Autism Society of America (ASA) American Psychological Association (APA)

Williams Syndrome Association (WSA) 